ARTHUR BARBOSA DE ALMEIDA CAMPOS

PROJETO DE UM SIMULADOR RESPIRATÓRIO PARA APLICAÇÕES NEONATAIS

São Paulo 


\section{ARTHUR BARBOSA DE ALMEIDA CAMPOS}

\section{PROJETO DE UM SIMULADOR RESPIRATÓRIO PARA APLICAÇÕES}

NEONATAIS

Dissertação apresentada à Escola

Politécnica da Universidade de São Paulo para a obtenção do título de Mestre em Ciências

São Paulo 


\title{
PROJETO DE UM SIMULADOR RESPIRATÓRIO PARA APLICAÇÕES NEONATAIS
}

\author{
Versão Corrigida
}

Dissertação apresentada à Escola

Politécnica da Universidade de São Paulo para a obtenção do título de Mestre em Ciências

Área de Concentração: Engenharia de Controle de Automação

Orientador: Prof. Dr. Agenor de Toledo Fleury

São Paulo 
Autorizo a reprodução e divulgação total ou parcial deste trabalho, por qualquer meio convencional ou eletrônico, para fins de estudo e pesquisa, desde que citada a fonte.

Este exemplar foi revisado e corrigido em relação à versão original, sob responsabilidade única do autor e com a anuência de seu orientador.

São Paulo, de de

Assinatura do Autor:

Assinatura do Orientador:

\section{Catalogação-na-publicação}

Campos,Arthur

Projeto de um Simulador Respiratório para Aplicações Neonatais / A. Campos - São Paulo, 2020.

$152 \mathrm{p}$.

Dissertação (Mestrado) - Escola Politécnica da Universidade de São Paulo. Departamento de Engenharia Mecânica.

1.Sistemas de Controle 2.Modelo respiratório 3.Simulações 4.Neonatal I.Universidade de São Paulo. Escola Politécnica. Departamento de Engenharia Mecânica II.t. 
“É precisamente na fronteira do conhecimento que a imaginação tem seu papel mais importante; o que ontem foi apenas um sonho, amanhã poderá se tornar realidade."

(Gleiser, Marcelo) 


\section{AGRADECIMENTOS}

À Escola Politécnica da USP e a CAPES pela estrutura e suporte no qual foi essencial para a realização do trabalho.

Ao prof. Dr. Agenor de Toledo Fleury por toda a orientação e aprendizado. É difícil expressar quão importantes e valiosas foram nossas conversas, onde esteve sempre disposto a passar um pouco das experiências e conhecimentos sobre engenharia e a vida.

Ao Prof. MSc. Milton Harumi Miyoshi, Dr. Jorge Bonassa e Ana Paula Cruz de Castro Leão por me inspirarem, motivarem e proverem suporte durante a realização deste trabalho.

Aos meus pais, José Carlos de Almeida Campos e Vera Cristina Barbosa que me foram o alicerce no qual obtive todo suporte e apoio para realizar o presente trabalho.

Ao meu irmão Ricardo Barbosa de Almeida Campos por todo apoio e suporte sempre quando necessário.

À Lívia Silvestre Andrade por todo o suporte e apoio nos momentos mais difíceis.

Aos meus amigos que me acompanharam durante toda a construção e desenvolvimento do trabalho. 


\section{RESUMO}

O presente trabalho aborda o desenvolvimento de um simulador respiratório para aplicações neonatais que seja capaz reproduzir 2 tipos fundamentais de ventilação: espontâneo e controlado por pressão. Para cumprir tal objetivo foram desenvolvidos 2 modelos, o primeiro relativo ao sistema respiratório neonatal e o último associado à construção física do simulador, ou seja, a planta de simulação.

No aspecto biológico, um modelo RC de 5 compartimentos, incluindo uma resistência central e uma complacência relativa à caixa torácica foi desenvolvido com o intuito de reproduzir volumes, fluxos e pressões pulmonares que são os sinais de referência que alimentam a malha de controle. A utilização de 5 compartimentos, além de emular a anatomia humana, permite a simulação da respiração heterogênea. O esforço diafragmático foi modelado por uma função quarto de seno que permite iniciar o processo de inspiração e exalação quando espontâneo.

Por outro lado, um equipamento baseado em uma bomba de seringa foi escolhido como a planta de simulação. Duas equações foram utilizadas, a primeira foi obtida através da lei de conservação de massa e relaciona a velocidade angular do motor com o fluxo e volume de saída da seringa. O segundo modelo foi alcançado através das relações de escoamento em orifícios, nesse caso foi possível associar a pressão dentro da seringa com a pressão de uma bomba externa.

Na ventilação espontânea não há sistema de controle, a planta de simulação emite uma quantidade de volume e fluxo para o reservatório de ar de acordo com as variáveis de referência do modelo respiratório. Por outro lado, na ventilação controlada há sistema de controle de tal forma que a pressão dentro da seringa de ar seja semelhante à pressão pulmonar do modelo. Observa-se que nesse modo, o modelo respiratório emula a interação do neonato com um ventilador mecânico.

De maneira geral, os resultados foram satisfatórios. As variáveis de controle acompanharam o sinal de referência com menos de $5 \%$ de erro em todos os cenários críticos escolhidos.

Palavras-chave: modelo respiratório, neonatal, simulação, sistemas de controle 


\begin{abstract}
The present work addresses the development of a respiratory simulator for neonatal applications that is able to reproduce the 2 main types of ventilation: spontaneous, controlled by pressure. In order to abide such requirements 2 mathematical models were developed, the first one is relative to the neonatal's respiratory system and the latter is associated to the simulation plant, which is the equipment that emulates the respiratory patterns from the model.

From the biological perspective, a 5 compartments $\mathrm{RC}$ model with a central resistance and a compliance that emulates the rib cage was developed in order to replicate pulmonary volumes, flows and pressure which are sent to the control block as a reference signal. The utilization of a multicompartmental model allows the emulation of heterogeneous respiration. In addition, it respects the human anatomy. The diaphragmatic efforts, which initiate inspiration or exhalation, were modeled by a quarter of sine function.

On the other hand, an equipment based on a syringe pump was chosen as the simulation plant. Two equations were applied, one was obtained through the law of mass conservation and it relates the DC motor angular velocity with the outlet flow and volume. The second equation was achieved through the orifice flow mathematical models. In this case it was possible to associate the pressure inside the syringe pressure to an external pump pressure.

In the spontaneous ventilation there is no control system, the simulation plant's objective is to provide the amount of volume and flow to the air reservoir as determined through the respiratory model. Contrarily, in the controlled type there is a control system designed to control the syringe pressure in order to track the pulmonary pressure from the respiratory model. It is relevant to point that in this type ventilation the respiratory model emulates the interaction between a newborn and a mechanical ventilator.

In general, the results were satisfactory. The control variables were able to track the reference signal within a $5 \%$ error margin for every critical scenario.
\end{abstract}

Key words: respiratory model, neonatal, simulation, control systems. 


\section{LISTA DE FIGURAS}

Figura 1.1 - Distribuição por causas de mortes neonatais em recém-nascidos. Adaptado de (UNICEF, 2019) .......................................................................

Figura 1.2 - Simbaby da Laerdal Medical (Laerdal Medical $\left.{ }^{\circledR}\right)$...........................4

Figura 2.1 - Piloto em um treinador Link em 1942. (Charles C. Ebbets and Ebbets Photo Graphics LLC, 2019)

Figura 2.2 - Imagem do produto Adult\&Infant Test Lung Simulator (Michigan Instruments, 2019)

Figura 2.3 - Imagem do simulador de respiração ASL 500 da Ingar Medical ${ }^{\circledR}$. (IngMar Medical , 2019) 14

Figura 2.4 - Vista frontal dos principais órgãos do sistema respiratório. (Tortora \& Derrickson, 2017) 15

Figura 2.5 - Representação esquemática dos pulmões e suas divisões. (Marieb, Wilheim, \& Mallat, 2014) 17

Figura 2.6 - Visão a partir de um corte transversal dos pulmões. (Marieb, Wilheim, \& Mallat, 2014) 18

Figura 2.7 - Representação esquemática mais detalhista da pleura e cavidade pleural. (Gozzi, 2019) 18

Figura 2.8 - Representação esquemática da movimentação do sistema respiratório durante a inspiração. (Marieb, Wilheim, \& Mallat, 2014). 20

Figura 2.9 - Representação esquemática da movimentação do sistema respiratório durante a expiração. (Marieb, Wilheim, \& Mallat, 2014) .22

Figura 2.10 - Espirograma ilustrativo de uma paciente homem adulto. (Tortora \& Derrickson, 2017). 23

Figura 2.11 - Gráfico ilustrativo das mudanças de pressão ao longo do ciclo respiratório. (Hall, 2017) 26

Figura 2.12 - Diagrama de complacência de uma pessoa adulta saudável. (Hall, 2017) 31 
Figura 2.13 - Volume (Percentual) x Pressão, onde o coeficiente angular é a complacência. Neste caso, o gráfico é referente à pacientes adultos. (Kliegman, et al., 2019)

Figura 2.14 - Volume (Percentual) x Pressão, onde o coeficiente angular é a complacência. Neste caso, o gráfico é referente à pacientes infantos. (Kliegman, et al., 2019)

Figura 2.15 - Retrata um episódio de apneia, bradicardia ou desaturação. Note nessa figura que as pausas respiratórias podem ter durações distintas, no caso, 20 e 10 segundos. O pneumograma acima retrata a frequência cardíaca, a oxigenação e as impedâncias da caixa torácica, onde se pode notar o padrão respiratório randômico característico de um neonato pré-termo. (Fairchild, et al., 2016) 36

Figura 2.16 - Esquema ilustrativo de um sistema de ventilação mecânica. (Carvalho, Bonassa, Carvalho, Amaral, Beppu, \& Auler, 1997) 37

Figura 2.17 - Figura ilustrativa dos vários tipos e modos de ventilação mecânica, de acordo com o sinal de pressão. Importante salientar que uma seta representa o esforço inspiratório do paciente e duas setas representam os ciclos respiratórios com auxílio de um ventilador mecânico. A-C $\rightarrow$ Ventilação assistidacontrolada; VMI $\rightarrow$ Ventilação mandatória intermitente; VMIS $\rightarrow$ Ventilação mandatória intermitente sincronizada; VSP $\rightarrow$ Ventilação com suporte de pressão; CPAP $\rightarrow$ Pressão positiva contínua em vias aérea. (Carvalho W. B., 1998).

Figura 2.18 - Representação ilustrativa de um circuito elétrico condensado em um único componente de impedância $Z$.

Figura 2.19 - Representação llustrativa de um modelo multicompartimental genérico. (Autor)

Figura 2.20 - Representação do modelo proposto por Otis em 1956. (Ghafarian, Jamaati, \& Mohammadreza, 2016)

Figura 2.21 - Modelo de um sistema respiratório com 2 compartimentos. (Otis, et al., 1956) 50

Figura 2.22 - Representação Ilustrativa do modelo RIC. (Schmidt, Foitzik, Hochmuth, \& Schmalisch, 2003) 
Figura 2.23 - Representação ilustrativa do modelo estendido RIC. Onde, R $\rightarrow$ resistência central; I $\rightarrow$ Indutor central; $\mathrm{R}_{p} \rightarrow$ resistência periférica; $\mathrm{C} \rightarrow$ capacitância pulmonar (Diong, Nazeran, Nava, \& Goldman, 2007) 52

Figura 2.24 - Representação ilustrativa do modelo de Mead. Onde, $\mathrm{R}_{\mathrm{c}}$ $\rightarrow$ resistência central; I $\rightarrow$ Indutor central; $\mathrm{R}_{p} \rightarrow$ resistência periférica; $C_{l} \rightarrow$ capacitância pulmonar; $C_{b} \rightarrow$ complacência dos brônquios; $C_{w} \rightarrow$ complacência da caixa torácica; $C_{l}$ $\rightarrow$ complacência extratorácica. (Diong, Nazeran, Nava, \& Goldman, 2007) .53

Figura 2.25 - Representação Ilustrativa do modelo de Dubois. Onde, $\mathrm{R}_{\mathrm{aw}} \rightarrow$ resistência das vias aéreas centrais; $I_{a w} \rightarrow$ indutor relativo às vias aéreas centrais; $R_{t} \rightarrow$ resistência dos tecidos pulmonares; $I_{t} \rightarrow$ Indutor relativo aos tecidos pulmonares; $C_{t} \rightarrow$ complacência dos tecidos; $\mathrm{C}_{\mathrm{g}} \rightarrow$ complacência alveolar. (Diong, Nazeran, Nava, \& Goldman, 2007). 54

Figura 2.26 - Representação Ilustrativa do modelo viscolástico de Lutchen. Onde, $\quad \mathrm{R}_{\mathrm{aw}} \rightarrow$ resistência da vias aéreas centrais; $\mathrm{C}_{\mathrm{s}} \rightarrow$ Complacência estática; $\mathrm{R}_{\mathrm{ve}} \rightarrow$ resistência viscoelática dos tecidos; $\mathrm{C}_{\mathrm{ve}} \rightarrow$ complacência viscoelástica dos tecidos. (Diong, Nazeran, Nava, \& Goldman, 2007) 54

Figura 2.27 - Representação ilustrativas das diversas técnicas de aplicação da FOT. a) Mede-se a impedância de entrada na boca no recém-nascido, ou seja a caixa de som está vibrando o ar para dentro da boca do R.N (b). Mede-se a impedância de entrada, porém, a caixa de som está na região da boca do paciente c). Por último, mede-se a impedância de transferência, onde a caixa de some está na região torácica do RN. (Schmidt, Foitzik, Hochmuth, \& Schmalisch, 2003). 56

Figura 2.28 - Modelo de Lonardoni e Iwata. De forma resumida, o lado direito do modelo é referente ao sistema respiratório humano e o restante do circuito referente ao ventilador mecânico. (Lonardoni, Iwata, \& Fleury, 2003) .58

Figura 2.29 - alguns resultados obtidos por Lonardoni e Iwata para o modo de volume controlado, Dados os parâmetros acima mostrados. (Lonardoni, Iwata, \& Fleury, 2003) 
Figura 2.30 - Modelo viscolástico com elastância E, e o corpo de maxwell representado pela resistência, Rm e elastância, Em. (Schmidt, Foitzik, Hochmuth, \& Schmalisch, 2003)

Figura 2.31 - Diagrama de bloco referente ao modelo descrito por Mesic. Note que é possível identificar 2 regiões distintas, uma relativa à complacência dinâmica e outra referente a resistência não linear. (Schmidt, Foitzik, Hochmuth, \& Schmalisch, 2003)

Figura 2.32 - Diagrama esquemático do simulador respiratório de Mesic. (Mesic, Babuska, Hoogsteden, \&Verbraak, 2003) 64

Figura 2.33 - a) Representação llustrativa do modelo respiratório de 5 compartimentos. b) Circuito equivalente com 2 impedâncias em paralelo. (Baldoli, et al., 2015) 65

Figura 2.34 - GUI do simulador MERESSINA. (Baldoli, et al., 2015) 68

Figura 2.35 - Diagrama Ilustrativo do simulador respiratório neonatal (Baldoli, et al., 2015) 68

Figura 2.36 - Imagem do protótipo construído pelo trabalho. (Baldoli, et al., 2015) 69

Figura 2.37 - Esquema llustrativo do simulador respiratório de Stankiewicz. (Stankiewicz, Palko, Darowski, Zielisnki, \& Kozarski, 2017)

Figura 2.38 - Simulação de pressão e fluxos para os casos de R.N pré-termos: a) Sem sintomas de broncodisplasia pulmonar e b) Com sintomas broncodisplasia pulmonar .(Stankiewicz, Palko, Darowski, Zielisnki, \& Kozarski, 2017). 74

Figura 2.39 - Setup do simulador respirador neonatal. (Stankiewicz, Palko, Darowski, Zielisnki, \&Kozarski, 2017) 75

Figura 3.1- - Modelo respiratório proposto desenvolvido por analogia com sistemas elétricos. 3.1a - Modelo do sistema respiratório neonatal com 5 compartimentos. 3.1b - Modelo do sistema respiratório neonatal com 2 compartimentos.

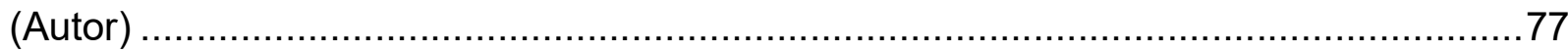

Figura 3.2 - Mecanismo bomba de infusão. (Pagatini, 2017) ...........................80

Figura 3.3 - Representação ilustrativa do conjunto simulador respiratório no tipo de ventilação controlada por pressão. O simulador é composto por 1 ou vários pistões 
contendo molas com dureza, Ks, um sistema de acionamento e controle do motor e uma fonte de pressão externa, que pode ou não ser um ventilador mecânica. (Autor) 81

Figura 3.4 - Representação ilustrativa do conjunto simulador respiratório no tipo de ventilação espontânea, onde agora, a fonte de pressão é substituída por um reservatório de ar a fim de tornar a simulação mais visual para os seus usuários. (Autor)

Figura 3.5 - Representação llustrativa de um capacitor de fluido. Adaptado de Kulakoswski, 2007. 84

Figura 3.6 - Diagrama de blocos relativo ao projeto de controle via variáveis de estado. (Autor).

Figura 3.7 - Representação Ilustrativa da planta de simulação com 5 seringas sendo controladas através do sistema de acionamento dos motores. (Autor). 90

Figura 3.8 - Representação llustrativa da planta de simulação com 5 seringas sendo controladas através do sistema de acionamento dos motores no tipo de ventilação controlada por pressão constate. Observa-se que as seringas estão conectadas a uma fonte de pressão simulando um ventilador mecânico. (Autor) 93

Figura 3.9 - Sensor de medição de vazão mássica de ar OEM Mass Flow Sensor 840205 da TSI. (TSI Incorporated, 2020). .95

Figura 3.10 - Sensor térmico e de vazão mássica FS5 da IST. (IST - Innovative Sensor Technology, 2020) 96

Figura 3.11 - a) Sensor de temperatura e pressão Bosch BMP180. b) Sensor de gradiente de pressão AMS5915-0100-D da NCD® 96

Figura 4.1 - Gráfico de pressão muscular espontânea. 99

Figura 4.2 - Variáveis do modelo respiratório para recém-nascidos a termo saudável para o modo espontâneo de respiração. (Autor). 101

Figura 4.3 - Variáveis da planta de simulação referentes a um recém-nascido a termo saudável para o modo espontâneo de respiração. (Autor). 102

Figura 4.4 - Gráfico referente ao deslocamento e aos fluxos de ar gerados pelas 5 seringas da planta de simulação. (Autor). 103

Figura 4.5 - Representação ilustrativa do funcionamento do simulador respiratório em modo espontâneo com 5 compartimentos. A figura apresenta uma 
fotografia do instante relativo ao final da inspiração e o volume de cada compartimento é ilustrado com o volume final do reservatório de ar em cada um dos compartimentos. Além disso, a linha azul em cada seringa representa a posição inicial do pistão. (Autor) 104

Figura 4.6 - Variáveis do modelo respiratório referente a um recém-nascidos com extremo baixo peso sem sintomas para o modo espontâneo de respiração. (Autor)

Figura 4.7 - Variáveis da planta de simulação referente a um recém-nascido de extremo baixo peso sem sintomas para o modo espontâneo de respiração. (Autor) ...105

Figura 4.8 - Gráfico referente ao deslocamento e aos fluxos de ar gerados pelas 5 seringas da planta de simulação. 106

Figura 4.9 - Representação ilustrativa do funcionamento do simulador respiratório em modo espontâneo com 5 compartimentos. A figura apresenta uma fotografia do instante relativo ao final da inspiração e o volume de cada compartimento é ilustrado com o volume final do reservatório de ar em cada um dos compartimentos. Além disso, a linha azul em cada seringa representa a posição inicial do pistão. (Autor) 107

Figura 4.10 - Pressão exercida pelo ventilador mecânico no modo controlado em pressão constante. (Autor) 108

Figura 4.11 - Variáveis respiratórioas para recém-nascidos à termo saudável para o modo controlado de respiração. (Autor) 111

Figura 4.12 - Variáveis de controle para recém-nascidos à termo saudável para o modo controlado de respiração. (Autor)

Figura 4.13 - Variáveis respiratórios referente a um recém-nascidos com extremo baixo peso sem sintomas para o modo controlado de respiração. (Autor).....112

Figura 4.14 - Variáveis de controle referente a um recém-nascido com extremo baixo peso sem sintomas para o modo controlado de respiração. (Autor). 112

Figura 8.1 - Modelo de simulação em diagrama de blocos. (Autor) 128 


\section{LISTA DE TABELAS}

Tabela 1 - Parâmetros respiratórios de acordo com a idade do paciente (Insoft \& Todres, 2018).

Tabela 2 - Tabela de analogia entre parâmetros respiratórios com parâmetros elétricos

Tabela 3 - Dados usados na simulação. Os cenários são segmentados em 2 grandes grupos, a termo e pré-termo. AT $\rightarrow$ a termo; ATp1 $\rightarrow$ a termo com maiores resistências e menores complacências; MBP ext $\rightarrow$ baixo peso com extubação realizada com sucesso; MBP F ext $\rightarrow$ baixo peso com falhas na extubação; EBP s/ DBP $\rightarrow$ extremo baixo peso sem broncodisplasia pulmonar; EBP c/ BDP $\rightarrow$ extremo baixo peso com broncodisplasia pulmonar. (Stankiewicz, Palko, Darowski, Zielisnki, \&

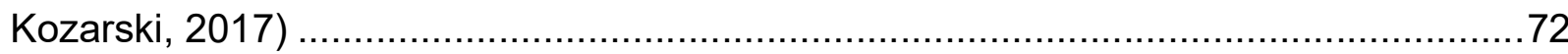

Tabela 4 - Parâmetros do sistema respiratório utilizados na simulação. Note que os cenários abaixo são os mesmos da tabela 3, acima. (Stankiewicz, Palko, Darowski, Zielisnki, \& Kozarski, 2017) .73

Tabela 5 - Parâmetros da planta para as simulações. (Autor). 98

Tabela 6 - Parâmetros do modelo respiratório para o cenário de R.N saudável. (Stankiewicz, Palko, Darowski, Zielisnki, \& Kozarski, 2017) 101

Tabela 7 - Parâmetros do modelo respiratório. (Stankiewicz, Palko, Darowski, Zielisnki, \& Kozarski, 2017) 104

Tabela 8 - Propriedades físicas, geométricas e de escoamento da planta de simulação. (Autor) 109 


\title{
LISTA DE ABREVIATUARAS E SIGLAS
}

\author{
ONU Organizações das Nações Unidas \\ UNICEF Fundo das Nações Unidas para a Infância \\ UTI Unidade de Terapia Intensiva \\ UNIFESP Universidade Federal de São Paulo \\ CRM Gerenciamento de Recursos no Cockpit \\ NASA National Aeronautics and Space Adminstration \\ RN Recém-Nascido \\ MERESSINA Mechatronic Respiratory System Simulator for Neonatal Aplications \\ RC Resistivo-capacitivo \\ VAC Volume de ar corrente \\ VRI Volume Reserva Inspiratório \\ VRE Volume Reserva Expiratório \\ VR Volume Residual \\ Cl Capacidade Inspiratória \\ CRF Capacidade Residual Funcional \\ CV Capacidade Vital \\ CPT Capacidade Pulmonar Total \\ VM Ventilação-Minuto \\ ECG Eletrocardiograma \\ RLC Circuito Ressonante (resistor + indutor + capacitor)
}




$\begin{array}{cl}\text { FOT } & \text { Técnica da Oscilação Forçada } \\ \text { GUI } & \text { Interface Gráfica do Usuário } \\ \text { PIP } & \text { Pressão Inspiratória } \\ \text { PEEP } & \text { Pressão Expiratória Final } \\ \text { SDR } & \text { Síndrome do Desconforto Respiratório } \\ \text { DBP } & \text { Displasia Bronco Pulmonar } \\ \text { AT } & \text { À Termo } \\ \text { MBP } & \text { Muito baixo peso } \\ \text { EBP } & \text { Extremo baixo peso } \\ \text { CPM } & \text { Ciclos por minuto } \\ \text { LQR } & \text { Regulador Quadrático Linear } \\ \text { PT } & \text { Pré-termo }\end{array}$




\section{LISTA DE SÍMBOLOS}

\begin{tabular}{cl}
$R$ & Resistência ao fluxo \\
$\Delta P$ & Pressão entre duas localidades \\
$\dot{V}$ & Fluxo de ar entre os dois pontos determinados \\
$L$ & Comprimento da tubulação ou via \\
$\eta$ & Viscosidade do Fluido em movimento \\
$r$ & Raio da tubulação por onde o fluido é escoado \\
$K_{v}$ & Constante de resistência associada ao volume \\
$K_{f}$ & Constante de resistência associada ao fluxo \\
$\Delta V$ & Variação de volume \\
$C$ & Complacência \\
$C_{T}$ & Complacência da caixa torácica \\
$C_{p u l}$ & Complacência pulmonar \\
$K_{e l}$ & Razão da variação de pressão em relação a variação de volume \\
$K_{1}, K_{2}$ & Constantes relativas propriedade de pressão-volume \\
$\tau$ & Constante de tempo \\
$I$ & Indutância \\
$Z_{r s}$ & Impedância do sistema respiratório \\
$\omega$ & Velocidade angular associada à frequência respiratória \\
$f$ & Frequência respiratória \\
$R_{a w}$ & Unidade imaginária \\
\hline & Resistência das vias aéreas \\
\hline &
\end{tabular}




$$
\begin{array}{cl}
P_{e s p}(t) & \text { Pressão espontânea muscular } \\
R_{i n s} & \text { Resistência do ramo inspiratório do circuito do paciente } \\
R_{p s} & \text { Resistência Intrínseca do Ventilador } \\
R_{e t} & \text { Resistência do tubo endotraqueal } \\
\mathrm{R}_{\text {exp }} & \text { Resistência do ramo expiratório do circuito do paciente } \\
P S(t) & \text { Pressão Suporte } \\
P_{a w} & \text { Pressão na via aérea } \\
\dot{V}_{a w} & \text { Fluxo na via aérea } \\
\dot{V}_{1}, \dot{V}_{e} & \text { Fluxo no Pulmão esquerdo } \\
\dot{V}_{2}, \dot{V}_{d} & \text { Fluxo no Pulmão direito } \\
P_{a} & \text { Pressão Alveolar } \\
V_{p u l} & \text { Volume pulmonar } \\
\text { Re } & \text { Parte real da impedância do sistema respiratório } \\
\text { Im, } X & \text { Parte imaginária da impedância do sistema respiratório } \\
R_{c} & \text { Resistência associadas as vias aéreas centrais } \\
K_{c o n v} & \text { Constante de conversão } \\
Z_{s i m} & \text { Impedância do simulador } \\
Z_{x} & \text { Impedância de entrada do capacitor pneumático } \\
C_{1}, C_{e} & \text { Complacência do pulmão esquerdo } \\
C_{2}, C_{d} & \text { Complacência do pulmão direito } \\
P_{P l e u r a l} & \\
\hline & \\
& \text { Pressão intrapleural } \\
&
\end{array}
$$




\begin{tabular}{cl}
$\dot{q}_{\text {seringa }}$ & Fluxo de ar na saída da seringa \\
$A_{\text {seringa }}$ & Área da seringa \\
$T$ & Passo do fuso de acionamento do êmbolo \\
$\omega_{\text {fuso }}$ & Velocidade angular do fuso \\
$\dot{x}_{\text {pistão }}$ & Velocidade linear do pistão \\
$\delta$ & Coeficiente de escoamento laminar \\
$D_{h}$ & Diâmetro hidráulico \\
$A_{o}$ & Área referente ao orifício \\
$P_{\text {seringa }}$ & Pressão interna da seringa \\
$P_{o}$ & Pressão da fonte externa, bomba \\
$\mu$ & Viscosidade dinâmica do ar \\
$C_{d}$ & Coeficiente de descarga \\
$\rho$ & Densidade do ar \\
$C_{f}$ & Capacitância do compartimento \\
$x(t)$ & Detor de estados \\
\hline &
\end{tabular}

$\mathrm{A}, \mathrm{B}$ e $\mathrm{C} \quad$ Matrizes de parâmetros conhecidos sobre a dinâmica do sistema $u(t) \quad$ Vetor de variável de entrada do sistema $y(t) \quad$ Vetor de observação

$N_{u}, N_{x} \quad$ Coeficientes de realimentação da malha de controle 
$K_{c t r} \quad$ Ganho de controle

referência Vetor das variáveis de referência

$\operatorname{erro}(t) \quad$ Vetor de erros 


\section{SUMÁRIO}

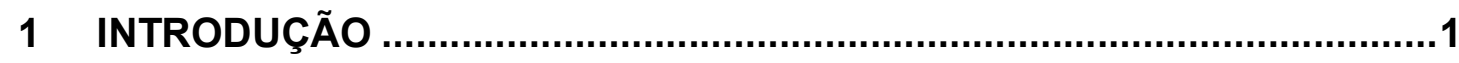

1.1 Contexto para o desenvolvimento do projeto 1

1.2 Objetivos 5

1.3 Metodologia 6

1.4 Contribuição da dissertação $\quad 7$

$\begin{array}{lll}1.5 & \text { Organização do texto } & 7\end{array}$

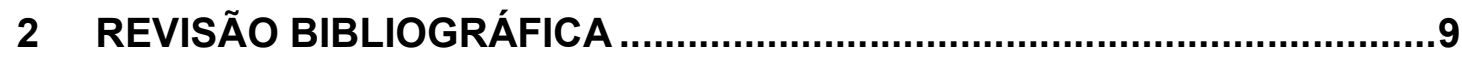

$\begin{array}{lll}2.1 & \text { Aprendizado via simulação } & 9\end{array}$

2.1.1 Breve história da aprendizagem via simulação 9

$\begin{array}{ll}2.1 .2 \text { Neonatologia e simulação } & 11\end{array}$

2.1.3 Simuladores respiratórios na neonatologia 12

$\begin{array}{lll}2.2 & \text { O Sistema Respiratório } & 14\end{array}$

2.2.1 Anatomia básica do sistema respiratório 15

$\begin{array}{ll}\text { 2.2.2 Mecanismo da ventilação Pulmonar } & 19\end{array}$

2.2.3 Pressões e volumes característicos do sistema respiratório 22

$\begin{array}{lll}2.2 .4 & \text { Propriedades resistivas } & 27\end{array}$

2.2.5 Propriedades Elásticas do Sistema respiratório 30

2.2.6 Particularidades do sistema respiratório neonatal 33

2.3 Ventilação mecânica 36

2.4 Modelos dos sistemas respiratórios $\quad 41$

2.4.1 Modelos por analogia $\quad 42$

$\begin{array}{lll}\text { 2.4.2 } & \text { Modelos compartimentais } & 46\end{array}$ 
2.5 Modelos e especificações técnicas de simuladores respiratórios atuais 57

2.5.1 Simulador respiratório didático multicompartimental

2.5.2 Simulador Mecânico respiratório de ventilação artificial

2.5.3 MERESSINA 64

2.5.4 Simulador respiratório Híbrido de Infantos

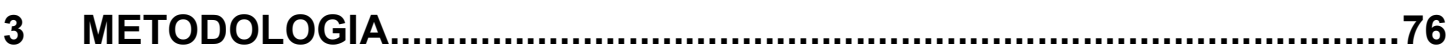

$\begin{array}{lll}3.1 & \text { Modelo do sistema respiratório } & 76\end{array}$

$\begin{array}{lll}3.2 & \text { Definição e modelagem da planta } & 79\end{array}$

3.3 Projeto do sistema de controle 86

$\begin{array}{lll}\text { 3.3.1 Modo espontâneo } & 89\end{array}$

$\begin{array}{ll}\text { 3.3.2 Modo controlado } & 91\end{array}$

$\begin{array}{lll}3.4 & \text { Sensoriamento } & 94\end{array}$

3.4.1 Medição do fluxo de ar 95

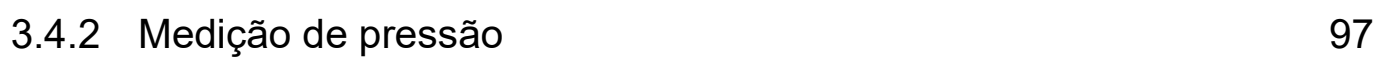

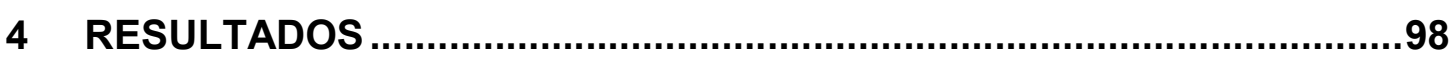

$\begin{array}{lll}4.1 & \text { Modo espontâneo } & 99\end{array}$

4.1.1 Recém-nascido a termo saudável (AT) 100

4.1.2 Pré-termo de extremo baixo peso (MBP Ext.) 104

4.2 Modo controlado - Pressão controlada 107

4.2.1 Recém-nascidos a termo saudável (AT) 111

4.2.2 Pré-termo de extremo baixo peso (MBP Ext.) 112 
5 DISCUSSÃO DOS RESULTADOS …....................................................113

$\begin{array}{lll}5.1 & \text { Modelo Respiratório Neonatal } & 113\end{array}$

$\begin{array}{lll}5.2 & \text { Planta e sistema de controle } & 115\end{array}$

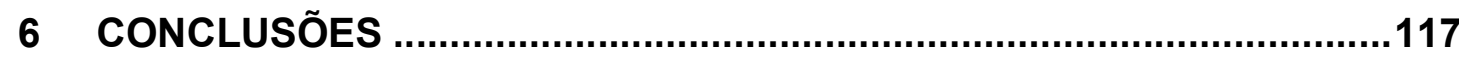

7 PROPOSTAS DE MELHORIA ........................................................119

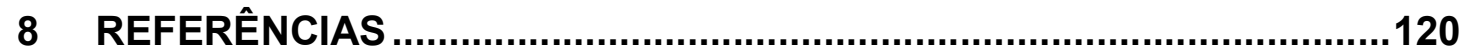

Apêndice A - Patologias Relacionadas ao Sistema Respiratório Neonatal 127

Apêndice B - Modelo de simulação Simulink 


\section{INTRODUÇÃO}

\subsection{Contexto para o desenvolvimento do projeto}

De acordo com a Organizações das Nações Unidas (ONU), estima-se que no mundo, entre 2015 e 2020, nascerão por volta de 700 milhões de bebês, 15 milhões somente no Brasil, em uma média de 3 milhões de bebês por ano. (United Nations, Department of Economic and Social Affairs, Population Division, 2017). Infelizmente nem todos esses bebês irão sobreviver. Conforme o último relatório da UNICEF em 2019, estima-se que a taxa de mortalidade infantil, abaixo de 5 anos de idade, é de 39 mortes para cada 1000 nascimentos. Nesse contexto é importante notar que aproximadamente $47 \%$ da taxa de mortalidade decorre dentro do período neonatal, caracterizado pelos 27 dias pós-parto. Portanto, nota-se que a criticidade das primeiras semanas de vida de um bebê. (UNICEF, 2019)

A Figura 1.1 revela, em um espectro global, as principais causas de mortes neonatais. Verifica-se que $34 \%$ das mortes são oriundas de complicações neonatais, isto é, relacionadas às complicações pós-nascimento e $23 \%$ são eventos relacionados ao parto, definidos como sendo as intervenções médicas na sala de parto.

Também é relevante salientar que aproximadamente 1/3 dos recém-nascidos morrem no mesmo dia de seus nascimentos. Esse dado corrobora com a relevância das primeiras semanas de vida para o recém-nascido. Consequentemente, nota-se a importância da capacidade técnica e da infraestrutura que a equipe médica deve possuir para o sucesso das intervenções e sobrevivência dos recém-nascidos. 


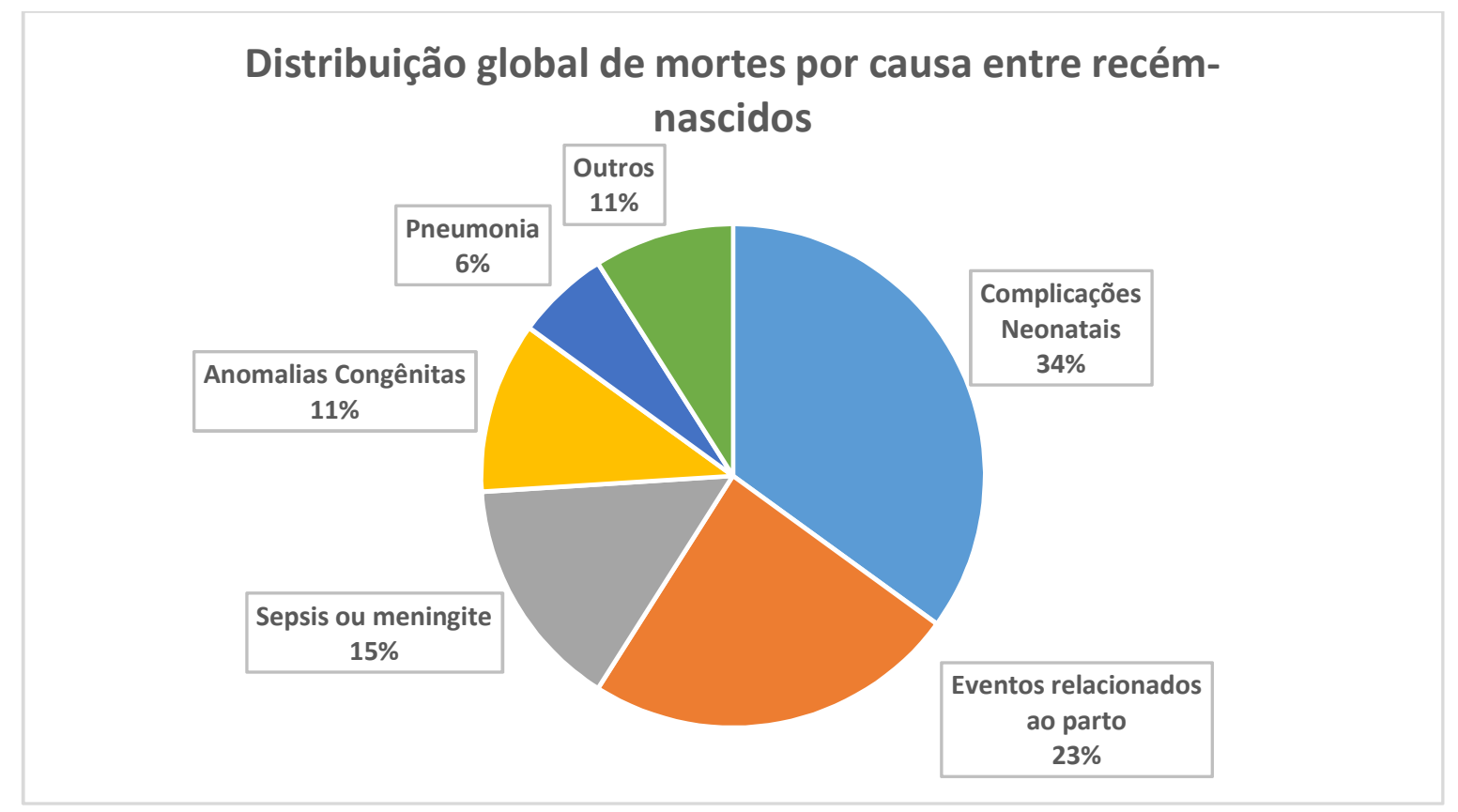

Figura 1.1 - Distribuição por causas de mortes neonatais em recém-nascidos. Adaptado de (UNICEF, 2019)

No âmbito nacional, a situação é um pouco melhor. De acordo com os trabalhos mais recentes sobre o assunto, as mortes neonatais, no Brasil, são equivalentes a 11,1 mortes para cada 1000 nascimentos. A taxa é abaixo da média mundial, porém acima quando comparado a países europeus, asiáticos e alguns latino americanos. Vale salientar a distribuição dessa taxa nas classes socioeconômicas mais baixas e nas regiões norte, nordeste, onde o índice de mortalidade é mais alto. (Lansky, et al., 2014)

Um aspecto não usual apontado na literatura é que apesar de $98,4 \%$ dos partos ocorrerem predominantemente em hospitais e $88,7 \%$ dos partos serem assistidos por médicos, os resultados de mortalidade no Brasil não são satisfatórios quando comparados a países com essa mesma proporção. Esse cenário é denominado por alguns de "paradoxo perinatal brasileiro". Não há estudos assertivos sobre tal tema, mas possivelmente há relação com o nível de qualidade da assistência e da utilização de práticas menos modernas. (Lansky, et al., 2014) 
Adicionalmente, trabalhos sugerem que quanto mais rápidas e assertivas forem as intervenções, maiores serão as chances de sobrevivência de um recém-nascido. Além disso, assinalam também que a mortalidade neonatal pode diminuir aproximadamente $71 \%$ caso as intervenções sejam dessa maneira (Lehtonen, Gimeno, Parra-Llorca, \& Vento, 2017). Novamente é válido enfatizar que a formação técnica do profissional envolvido em uma UTI Neonatal seja a melhor possível, com treinamentos específicos, eficazes e de boa qualidade.

Especificamente em recém-nascidos, o sistema respiratório é uma estrutura sensivel e de suma importância para sua sobrevivência. Estudos evidenciam que a faixa etária mais atingida pela mortalidade infantil é a neonatal precoce (0-6 dias pósparto), na qual as principais causas são: prematuridade, má formação congênita e asfixia intraparto. Pesquisas de autópsia revelam que entre $32 \%$ e $52 \%$ de todos os óbitos perinatais (período relativo a $28^{\circ}$ semana de gestação até a primeira semana de vida) estão relacionados às patologias respiratórias. (Komatsu, 2007)

Ventilação mecânica e terapias com surfactantes são procedimentos padrão para o tratamento de muitas patologias respiratórias em recém-nascidos, todavia a assistência respiratória não é algo trivial. Devido à alta variabilidade fisiológica de um paciente neonatal para o outro, parâmetros do sistema respiratório como resistências, complacências, constante de tempo entre outros também podem variar significativamente. Além do aspecto físico, desafios adicionais buscam estudar com maiores detalhes o sincronismo entre os ventiladores mecânicos e a respiração dos neonatos. (Cuttano, Boldrini, Arianna, Laschi, Sigali, \& Cecchi, 2013)

Como descrito no parágrafo anterior há alta variabilidade física entre pacientes. Esse fator implica diretamente os profissionais que atendem os recém-nascidos. Médicos e enfermeiras devem ser capacitados para poder identificar rapidamente a situação, os sintomas e os sinais vitais, e assim intervir assertivamente. 
Diante do contexto descrito acima, torna-se pertinente refletir se os métodos de aprendizagem utilizados hoje em dia são os mais eficientes para o treinamento dos profissionais da área da saúde. Com esse intuito, a metodologia de aprendizagem via simulação de alta fidelidade tem se mostrado a mais eficaz para a formação do profissional na área médica. (Murphy \& Halamek, 2005).Todavia sua implementação depende de grandes recursos financeiros, além de poder deparar-se em barreiras culturais. (Edler, Chen, Honkanen, Hackel, \& Golianu, 2010). Para ilustrar a barreira financeira existente, os dois principais modelos de simuladores neonatais no mercado são apresentados: a SuperTory da GaurmardScientific®e o Simbaby ${ }^{\mathrm{TM}}$ da Laerdal Medical que custam aproximadamente $U \$ 40.000,00$ e $U \$ 30.000,00$, respectivamente. Este último está na Figura 1.2, abaixo.

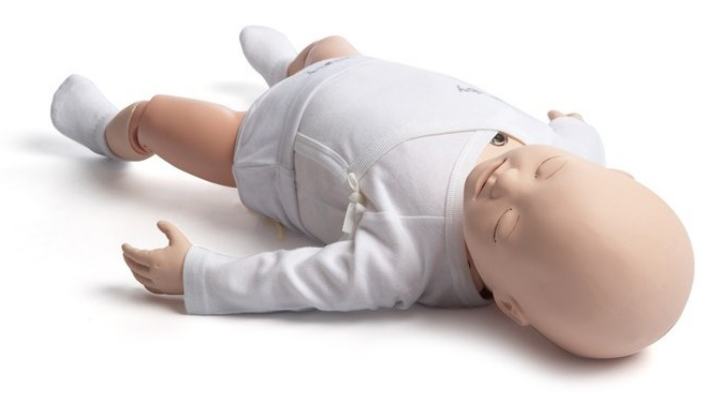

Figura 1.2 - Simbaby da Laerdal Medical (Laerdal Medical $®)$

Com isso em mente, este trabalho visa o desenvolvimento de um projeto de um simulador respiratório para aplicações neonatais, com capacidade de reproduzir respiração espontânea do neonato, além de emular patologias e condições críticas que possam ocorrer durante o período neonatal. Busca-se que o simulador reproduza respiração de recém-nascidos que estão sob auxílio de ventiladores mecânicos, ou seja, que emule a respiração neonatal quando auxiliada por ventiladores nos 2 principais modos de ciclos respiratórios: ciclo espontâneo e ciclo controlado. 
Visto que os robôs simuladores disponíveis no mercado têm custo proibitivo devido à sua vasta gama de funções e recursos, o foco no sistema respiratório é um fator restritivo capaz de diminuir as funções, patologias e respostas do simulador, consequentemente, diminuindo o custo do mesmo. Além disso, a utilização de materiais e equipamentos mais acessíveis, sem a perda de qualidade e precisão do equipamento, têm como resultado um produto com preço final mais baixo para o consumidor e habilitado para o ensino. A questão financeira do equipamento é relevante, pois o intuito do mesmo é levar a metodologia de aprendizado ao maior número possível de clínicas, hospitais e universidades, e assim capacitar, com melhor qualidade, profissionais para atender os recém-nascidos.

\subsection{Objetivos}

O objetivo da dissertação é desenvolver um simulador respiratório neonatal capacitado a emular o sistema respiratório neonatal e as suas características de volume e pressão, além de reproduzir algumas patologias críticas. Adicionalmente, o equipamento deverá atuar nos 2 tipos fundamentais de ciclos de ventilação:

- Ciclos espontâneos;

- Ciclos controlados;

O escopo do projeto aborda somente os ciclos ventilatórios controlados por pressão constante. Além disso, vale salientar que o presente trabalho não busca a construção física de um protótipo, mas sim, a simulação de operação tal como o desenvolvimento de um sistema de controle com o intuito de que a planta se comporte de forma similar ao modelo respiratório neonatal. 


\subsection{Metodologia}

As maiores preocupações para a progressão do projeto foram relacionadas ao desenvolvimento de um simulador que atenda às necessidades médicas atuais e que possa ser utilizado para a formação de futuros médicos, evidentemente, focado no sistema respiratório de um recém-nascido.

A fim de alcançar esses objetivos, o trabalho foi desenvolvido em parceria com o Laboratório Neonatal da Universidade Federal de São Paulo (UNIFESP) liderado pelo Dr. Milton Harumi Miyoshi e sua equipe, onde através de seus conhecimentos foi possível determinar características importantes que o modelo e a planta necessitavam possuir para atender de forma satisfatória os interesses médicos juntamente com a perspectiva da aprendizagem.

Primeiramente, o equacionamento matemático do sistema respiratório foi desenvolvido baseando-se nos diversos modelos disponíveis na literatura, além de ter sido pesquisado na academia parâmetros e constantes necessários para uma simulação fidedigna da respiração espontânea de um recém-nascido.

Posteriormente, definiu-se a planta de simulação, de onde foram obtidas as equações de movimento para tal mecanismo. Nota-se que foi procurado um equipamento de simples funcionamento e de baixo custo financeiro.

Finalmente, desenvolveu-se um sistema de controle capaz de integrar o modelo do sistema respiratório com a planta de simulação, no qual o equipamento deva se comportar de forma a emular o sistema respiratório de acordo com alguns parâmetros como resistência, complacência, frequência respiratória entre outros. Vale enfatizar que as simulações do sistema de controle foram realizadas em ambiente Matlab/Simulink com o intuito de verificar se o modelo respiratório satisfaz os dados da literatura e se é possível projetar um sistema de controle para reproduzir tal sistema de maneira a minimizar erros da planta com o modelo respiratório. 


\subsection{Contribuição da dissertação}

Essa dissertação disponibiliza um projeto de um simulador respiratório para aplicações neonatais. O produto de simulação, diferentemente de alguns modelos disponíveis atualmente no mercado, possui um foco evidente no sistema respiratório neonatal, dessa forma, reduzindo custos adicionais, consequentemente tende a ser mais acessível financeiramente à maioria das instituições de saúde e de formação de futuros profissionais. Entretanto, não perde relevância técnica, uma vez que se pode emular a integração de um ventilador mecânico a um neonato e, assim, torna-se adequado a capacitar o médico em situações reais de atendimento. Em adição, a construção do modelo multicompartimental auxilia na emulação de doenças e patologias que geram heterogeneidade respiratória, além de poder simular secreção nas vias aéreas, entre outros cenários.

Espera-se que ao atender diversas regiões com baixo e/ou alto nível de desenvolvimento socioeconômico, um maior número de profissionais da área médica estejam melhores capacitados a atuarem em uma situação de emergência respiratória, especialmente em um neonato.

\subsection{Organização do texto}

Evidentemente como já notado pelo leitor, o primeiro capítulo trata de uma introdução para a dissertação, ou seja, aqui está presente o contexto pelo qual o projeto floresceu, seus objetivos, as metodologias aplicadas a fim de alcançar os objetivos e as contribuições da dissertação para a academia e para a sociedade.

O capítulo 2 descreve a revisão bibliográfica, onde se retrata de maneira mais detalhada os conceitos e conhecimentos necessários para que leitor consiga absorver da melhor forma os conteúdos técnicos desta dissertação. Essa secção será subdividida em três grandes vertentes: a metodologia de aprendizado via simulação de 
alta fidelidade, a anatomia do sistema respiratório humano com foco posterior em neonatos, os modelos de sistemas respiratórios e alguns simuladores respiratórios atuais na literatura.

Por sua vez, o capítulo 3 trata das características gerais e construtivas do projeto. Nesse capítulo serão apresentados os modelos matemáticos relativos ao sistema respiratório e a planta de simulação. Além disso, será exibido o desenvolvimento do sistema de controle para os 2 principais tipos de ciclos ventilatórios, de tal forma que a planta de simulação consiga acompanhar o sinal de referência emitida pelo modelo respiratório.

O capítulo 4 apresenta os resultados, além de algumas análises preliminares.

Imediatamente após a apresentação dos resultados, o capítulo 5 exibe com detalhes as discussões dos resultados, dividindo-as nos aspectos biológicos e físicos e/ou de controle.

Por fim, no capítulo 6 a dissertação é encerrada com a conclusão do projeto, onde também são apresentadas sugestões para o trabalho que podem ser acrescidas e/ou melhoradas para uma eventual continuidade do projeto. 


\section{REVISÃO BIBLIOGRÁFICA}

\subsection{Aprendizado via simulação}

O treinamento ou aprendizado via simulação pode ser entendido como um método de aprendizado, no qual a pessoa a ser submetida ao treinamento é imersa em um cenário de simulação (roteiro próximo da realidade), dentro de um simulador, (espaço físico) que tenta emular o ambiente com fidelidade para a melhor eficácia do treinamento. Tal metodologia vem sendo considerada como procedimento padrão para a preparação de profissionais em áreas que envolvem alto nível técnico, alta complexidade e em ambientes que apresentam alto risco à vida humana. (Murphy \& Halamek, 2005)

\subsubsection{Breve história da aprendizagem via simulação}

Por muitos é apontado que as primeiras simulações a terem sucesso para fins de treinamento foram desenvolvidas na indústria da aviação. Criado por Edward Link, por volta dos anos de 1920, o "treinador Link", como era chamada a plataforma de treinamento, consistia basicamente de uma miniatura de um avião na qual as asas e a fuselagem eram montadas em cima de uma junta universal, conforme pode ser visto na Figura 2.1. A partir dos comandos de controle do piloto, roll e pitch, a plataforma se movimentava angularmente, consequentemente o piloto se preparava de uma forma mais segura e menos custosa que um voo real. (Aebersold, 2016)

Com o sucesso dessa plataforma de simulação houve inúmeras melhorias, incluído a emulação de outras aeronaves, de pequeno, médio e grande porte. Essa metodologia é utilizada até hoje, para isso incorporando diversos recursos técnicos como realidade aumentada, sistemas de controle e etc. 


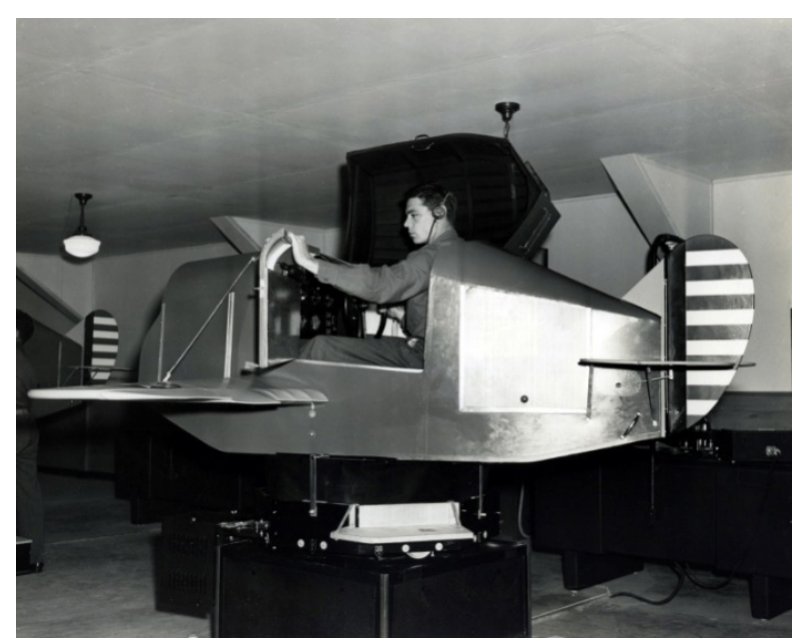

Figura 2.1 - Piloto em um treinador Link em 1942. (Charles C. Ebbets and Ebbets Photo Graphics LLC, 2019)

Seguindo a sucessão histórica, os simuladores tiveram suas aplicações expandidas. Além do treinamento de movimentos e técnicas específicas, os simuladores também foram empregados com o intuito de ajudar na comunicação entre membros de uma equipe, tornando-as mais assertivas e objetivas possíveis. Um exemplo de tal evolução pode ser observado no CRM (Cockpit Resource Management), desenvolvido pela NASA, em 1979, no qual a finalidade era praticar as comunicações e interações de toda uma tripulação de voo, incluindo a equipe de atendimento, de maneira a evitar erros de comunicação e de interação, caso necessário um esforço conjunto. (Aebersold, 2016)

Com os princípios de simulação do CRM, a área da saúde se interessou por tais metodologias de aprendizagem, primeiramente, com o desenvolvimento de um simulador capaz de melhorar a capacidade e habilidade dos anestesiologistas de atuarem durante uma crise e/ou situação de alto estresse. Exemplos de tais simuladores são o Sim One, desenvolvido em 1960 por Sierra Engineering Company e o MedSim Eagle Simulation através de uma parceria CAE-Link Corporation por volta de 1990. (Cuttano, et al., 2012) 
Com o avanço da tecnologia, a metodologia de aprendizado via simulação assume diversas formas, como jogos de vídeo games e cenários em realidade virtual. Vale ressaltar que tais plataformas vêm sendo utilizadas principalmente no setor militar e no treinamento de soldados para combates. Simuladores de última geração buscam integrar a alta fidelidade com metodologias de interações e comunicação entre membros de equipes. Tais equipamentos estão sendo utilizados em outras áreas, como a simulação de pacientes em UTI e UTI neonatal. (Aebersold, 2016)

\subsubsection{Neonatologia e simulação}

A neonatologia pode ser definida como uma especialidade médica no quais esforços são focados à assistência aos recém-nascidos, consequentemente é uma especialidade multidisciplinar que faz interface com conhecimentos de pediatria, anestesiologia, cirurgias minimamente invasivas, entre outras. Essa diversidade de conhecimentos também pode ser observada, de forma geral, na formação técnica e no tamanho das equipes em um trabalho de parto.

Ao se agregar o que foi dito anteriormente com a necessidade de agir de maneira rápida e assertiva após a ocorrência de eventos inesperados, nota-se que a metodologia de aprendizado via simulação é compatível com o perfil da neonatologia. Assim como em equipes e tripulações na aviação, erros devem ser previstos anteriormente para que as estratégias de ação possam ser feitas da melhor maneira possível, e sem que o médico tenha que passar por uma situação nova para ele.

Há diversos simuladores neonatais, entre eles, manequins que emulam características gerais do paciente, e simuladores mais específicos que possuem um objetivo de simular determinado sistema ou processo do corpo humano de um recémnascido. O presente trabalho busca enfatizar simuladores respiratórios como apresentado na próxima seção. 


\subsubsection{Simuladores respiratórios na neonatologia}

O gerenciamento das doenças respiratórias, durante o período neonatal, exige grandes esforços e conhecimento, pois há alta variabilidade de parâmetros entre um paciente e outro, como já dito anteriormente. Além disso, o profissional da saúde precisa ser capaz de reconhecer rapidamente sintomas e sinais para identificar o estado de saúde do paciente, além de possíveis intervenções, como por exemplo, efetuar modificações nos parâmetros de respiradores, caso esteja sendo utilizado. Com essa ideia, os simuladores de alta fidelidade buscam reproduzir esse ambiente agregando características de interação e didática, e assim, otimizar o aprendizado. (Baldoli, et al., 2015)

Autores sugerem que o mercado de simuladores respiratórios na neonatologia é dividido em 3 segmentos distintos: manequins de simulação, simuladores passivos e simuladores ativos. (Stankiewicz, et al., 2017)

Manequins de simulação: é o segmento mais realista do mercado, no aspecto construtivo. Podem emular respiração ativa e mudanças de frequência respiratória, entretanto de forma superficial. Por sua vez, eles não possuem a capacidade de simular as resistências e complacências presentes no sistema respiratório humano, consequentemente, são incapazes de reproduzir diferentes patologias pulmonares. São exemplos: SimNewB $®$ da Laerdal Medical, onde somente o manequim custa em torno de $\cup \$ 16.000,00$ e, caso considerada a instalação dos equipamentos,o preço pode se aproximar de U $\$ 25.000,00$, e Newborn Hall $\$ 3010$ da Gaumard®.

Simuladores passivos: em geral são simuladores menores que permitem a alteração de resistência e complacência para a simulação, ou seja, reproduz diferentes patologias. Todavia não reproduzem respiração ativa/espontânea e não permitem a dinâmica de interação com ventiladores mecânicos. São exemplos: Adult \& Infant Test Lung Simulators da Michigan Instruments (vide Figura 2.2) e a SmartLung Infant Test Lung da Rigel $\circledast$. 


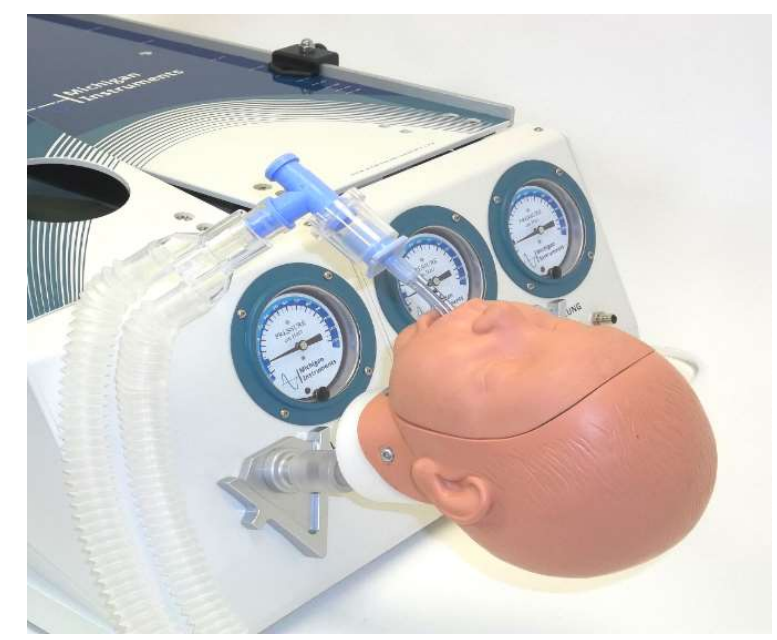

Figura 2.2 - Imagem do produto Adult\&Infant Test Lung Simulator (Michigan Instruments, 2019)

Simuladores ativos: evidentemente, esse tipo de simulador é capaz simular diferentes patologias, emular respiração ativa e permitir a interação entre simulador e ventilador mecânico.

A primeira geração de simuladores desse segmento pode ser representada pelo ASL 5000 Adult/Neonatal Simulator da IngMar Medical® que é capaz de replicar pulmões saudáveis ou com patologias que não ocasionam em heterogeneidade da respiração. Na seguinte geração, 2 simuladores destacam-se, o de Checchinni et al (2010), onde os autores desenvolveram o primeiro simulador eletromecânico com malha de controle aberta para a simulação de respiração ativa. Tal abordagem foi possível em virtude de o modelo ter incorporado a compressibilidade do ar. $O$ segundo simulador a ganhar notoriedade foi o MERESSINA, onde através de um modelo de 5 compartimentos pulmonares em RC (composto por um elemento resistivo e um capacitivo) conseguiu-se fazer com que o emulador interagisse com ventiladores mecânicos, além de possuir uma interface amigável para o aprendizado via simulação. 


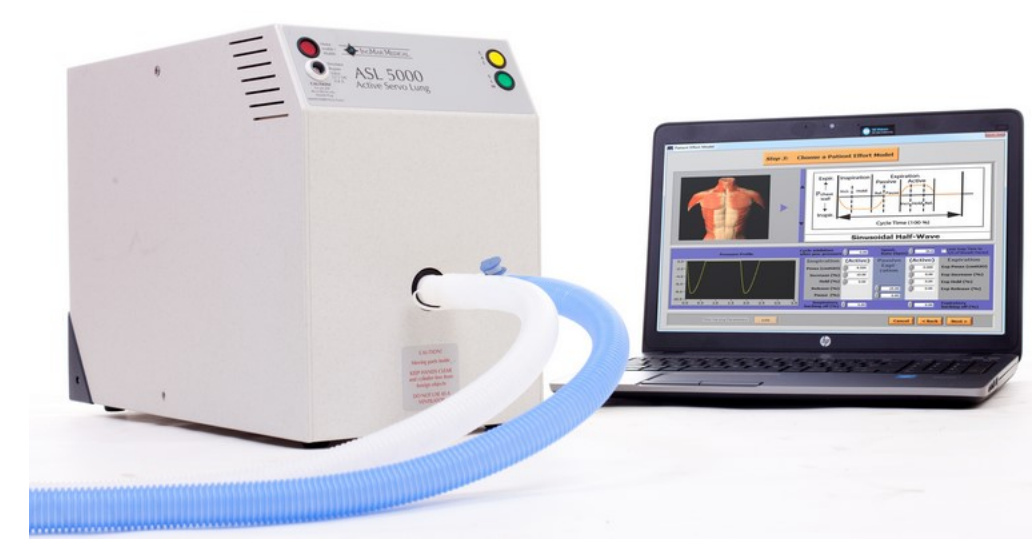

Figura 2.3 - Imagem do simulador de respiração ASL 500 da Ingar Medical®. (IngMar Medical , 2019)

A fim de apresentar os modelos matemáticos do sistema respiratório utilizados na literatura e em alguns dos simuladores acima é necessário introduzir alguns conceitos e definições fundamentais, entre eles, o sistema respiratório e sua anatomia, propriedades resistivas e capacitivas e métodos para obtenção das equações de movimento do sistema respiratório.

\subsection{O Sistema Respiratório}

O sistema respiratório tem as funções de assegurar as trocas gasosas, captar oxigênio $\left(\mathrm{O}_{2}\right)$ e eliminar gás carbônico $\left(\mathrm{CO}_{2}\right)$ em um processo denominado respiração. (Tortora \& Derrickson, 2017)

A respiração pode ser dividida em 3 etapas:

- Ventilação pulmonar;

- Respiração externa;

- Respiração interna.

Como o presente trabalho não enfoca as trocas gasosas em si, somente o componente de ventilação pulmonar e os seus mecanismos de funcionamento serão detalhados. 
Para uma melhor compreensão do leitor esse capítulo será composto por 4 subseções:

- Anatomia básica do sistema respiratório;

- O mecanismo respiratório;

- Pressões e volumes característicos do sistema respiratório;

- Particularidades do sistema respiratório de um neonato.

\subsubsection{Anatomia básica do sistema respiratório}

Os principais órgãos do sistema respiratório são: nariz, faringe, laringe, brônquios, traqueia, brônquios e Pulmões, conforme pode ser observada na Figura 2.4.

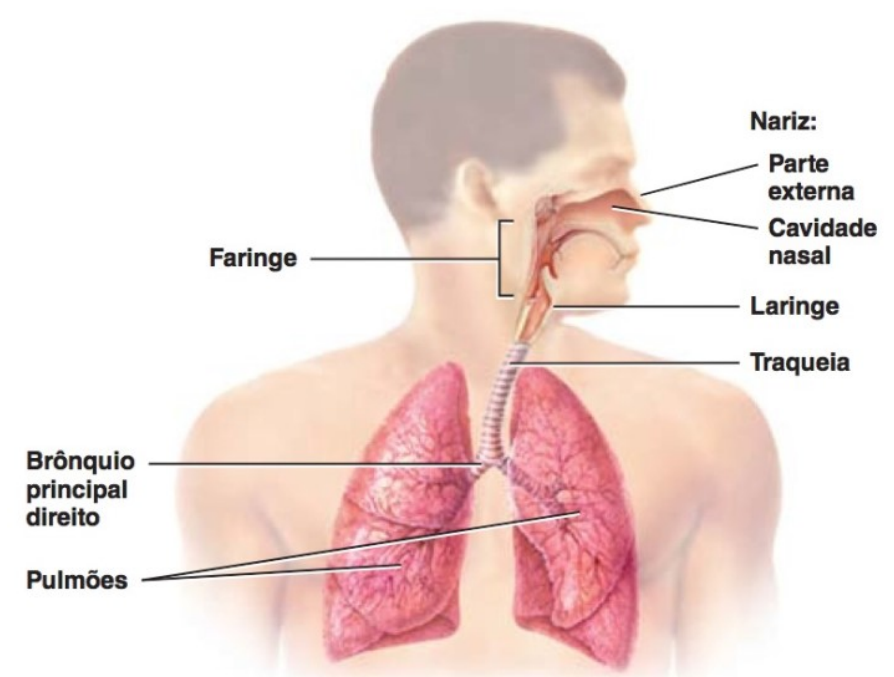

Figura 2.4 - Vista frontal dos principais órgãos do sistema respiratório. (Tortora \& Derrickson, 2017)

Em diversas referências é observado que sistema respiratório pode ser segmentado de acordo com a sua estrutura, denominadas parte superior e parte 
inferior. E também segmentado de acordo com a sua funcionalidade, designado como parte condutora e parte respiratória.

Dada a ultima configuração de classificação do sistema respiratório, a parte respiratória trata dos tecidos responsáveis pelos processos de trocas gasosas. Logo, não serão tratados no presente trabalho. Por outro lado, a parte condutora é composta pelos órgãos, tubos interligados e uma série de cavidades que levam o fluxo de ar aos bronquíolos terminais, onde ocorre a respiração. Portanto, percebe-se que a parte condutora é um ponto chave do projeto.

\subsubsection{Pulmões}

Os pulmões estão localizados dentro da caixa torácica, são compostos por 2 órgãos nos quais são separados pelo coração e outras estruturas do mediastino. Sua extensão é definida iniciando no diafragma (base do pulmão) até uma região localizada abaixo da clavícula.

Importante para o contexto citar que há várias fissuras encontradas nos dois pulmões, e assim os fragmentam em lobos. O pulmão esquerdo possui 2 lobos, denominados, lobo inferior e lobo superior,por outro lado, o pulmão direito possui 3 lobos chamados, lobo inferior, lobo superior e lobo médio. Esses detalhes podem sem observados na Figura 2.5 abaixo.

Invólucro a cada pulmão há uma membrana chamada pleura. A camada interna da pleura, em contato com os pulmões, é denominada de pleura visceral. Há também, uma membrana que envolve internamente a caixa torácica, chamada pleura parietal, que por sua vez, acaba cobrindo a superfície superior do diafragma e as superfícies laterais do mediastino. 

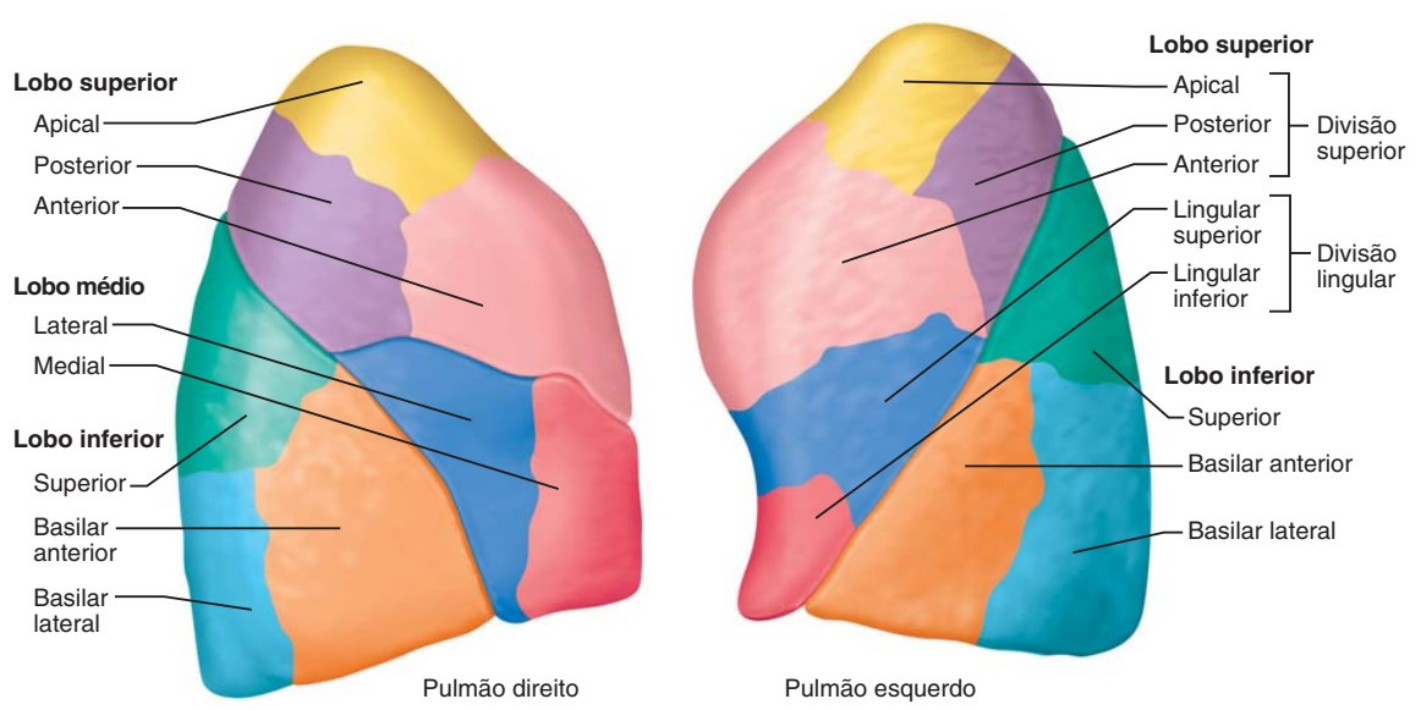

Figura 2.5 - Representação esquemática dos pulmões e suas divisões. (Marieb, Wilheim, \& Mallat, 2014)

Importante observar que entre as duas pleuras existe um espaço denominado cavidade pleural na qual é preenchida com uma fina película de fluido pleural. O fluido executa uma função de manter as pleuras visceral e parietal "unidas", de tal maneira a diminuir o atrito entre a caixa torácica e os pulmões, fator de suma importância devido à movimentação dos pulmões no processo de ventilação. Além disso, o fluido faz com que os pulmões e a caixa torácica expandem e retraem juntas em todo o processo de respiração. A anatomia descrita acima pode ser melhor observada nas Figura 2.6Figura 2.7. 


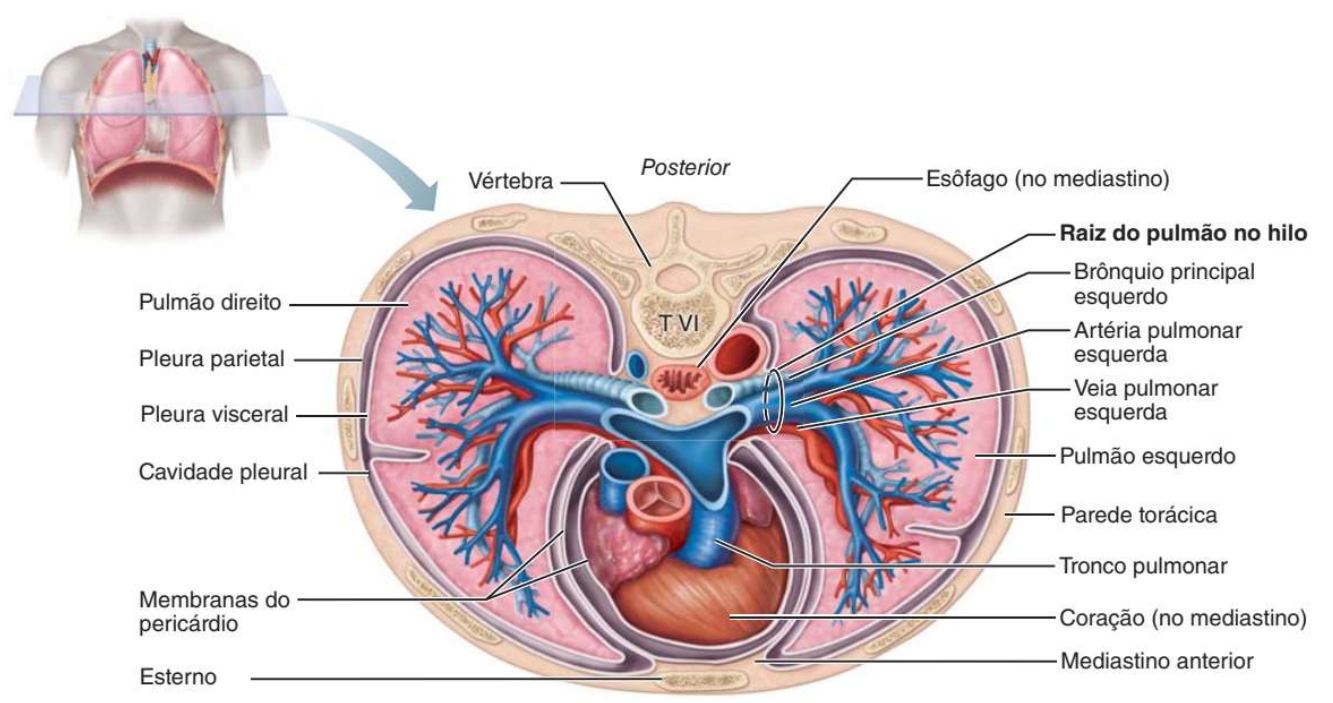

Figura 2.6 - Visão a partir de um corte transversal dos pulmões. (Marieb, Wilheim, \& Mallat, 2014)

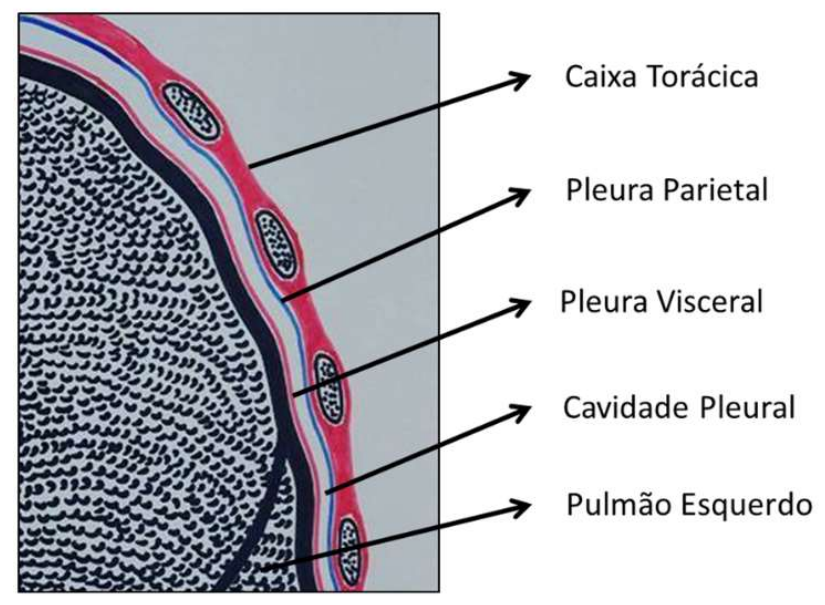

Figura 2.7 - Representação esquemática mais detalhista da pleura e cavidade pleural. (Gozzi, 2019)

Nota-se que a Figura 2.7 exibe objetivamente a anatomia existente entre as pleuras, cavidade pleural e caixa torácica. 


\subsubsection{Mecanismo da ventilação Pulmonar}

A ventilação pulmonar ocorre em 2 processos distintos: a inspiração e a expiração. Em ambas as situações o fluxo de ar escoa entre o ar atmosférico e os pulmões, devido à diferença de pressão entre esses dois pontos. Inspiramos quando a pressão no pulmão é menor que a pressão atmosférica e expiramos quando a pressão alveolar é maior que a pressão atmosférica. De maneira geral, as mudanças de pressão são causadas pelo relaxamento ou contração dos músculos Intercostais.

\subsubsection{Inspiração}

Para o entendimento mais claro, pode-se imaginar os pulmões como um único recipiente expansível no qual as ações musculares fazem com que ocorra um aumento dos volumes dos pulmões e da caixa torácica, consequentemente a pressão diminui a ponto que fique menor que a pressão atmosférica. Gera-se, então, um fluxo de ar da atmosfera até os pulmões. (Marieb, Wilheim, \& Mallat, 2014)

Vale enfatizar que as ações musculares responsáveis por esse processo são:

\section{Ação do diafragma:}

O diafragma se contrai, movendo a base dos pulmões para baixo, e assim aumenta-se o volume dos pulmões e da caixa torácica.

\section{Ação dos músculos intercostais:}

Os músculos intercostais internos e externos se contraem o que leva a uma elevação das costelas e a um enrijecimento da parede torácica, dessa forma aumentando o volume sem ter mudanças de formas do conjunto pulmão e caixa torácica. 
De maneira sucinta, pode-se resumir o processo de inspiração nos seguintes passos:

a) Músculos inspiratórios se contraem, logo provoca o diafragma a descer e a caixa torácica a subir;

b) Cavidade torácica e cavidade pleural aumentam de volume;

c) Pulmões se alongam e o volume pulmonar aumenta;

d) Pressão alveolar diminui, e assim escoa-se ar para os pulmões.

O processo de inspiração descrito acima pode ser observado na Figura 2.8

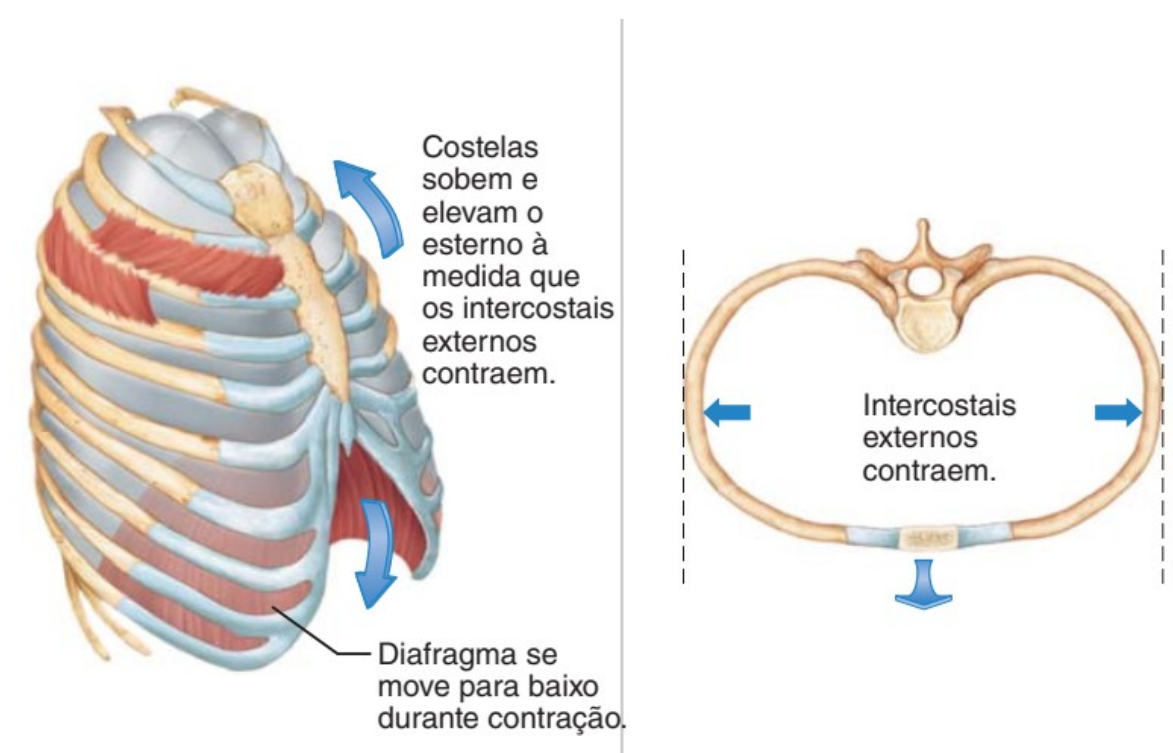

Figura 2.8 - Representação esquemática da movimentação do sistema respiratório durante a inspiração. (Marieb, Wilheim, \& Mallat, 2014)

É valido destacar que a inspiração profunda ou forçada é uma contração exacerbada dos músculos intercostais e do diafragma. Dessa forma, o volume pulmonar é aumentado além de sua condição padrão, consequentemente diminui-se a pressão pulmonar, aumenta-se o fluxo pulmonar e, por conseguinte, o volume pulmonar total também é aumentado. 


\subsubsection{Expiração}

Também denominado de exalação, é um processo antagônico à inspiração. Inicia-se a partir do momento em que os músculos intercostais e o diafragma relaxam. A principal diferença entre os dois processos é o modo e origem com o qual ocorre a movimentação dos órgãos do sistema respiratório. Em uma expiração não forçada os músculos relaxam, todavia, as propriedades elásticas dos pulmões e das vias aéreas os fazem retornar ao volume inicial, ou seja, é um processo passivo.

É importante salientar que a presença de surfactantes presentes no líquido alveolar reduz o recuo elástico, o que diminui a chance de colapso alveolar.

Sucintamente, o processo de exalação, assim como na inspiração, pode ser resumido nos seguintes passos:

a) Músculos inspiratórios relaxam (diafragma sobe, caixa torácica desce devido ao recuo elástico das cartilagens costais);

b) Cavidade torácica e cavidade pleural diminuem de volume;

c) Pulmões retraem passivamente e volume pulmonar diminui;

d) A pressão pulmonar aumenta, e assim acarreta-se um fluxo de ar pulmões para a atmosfera.

Tal processo pode ser observado com mais detalhes na Figura 2.9. 


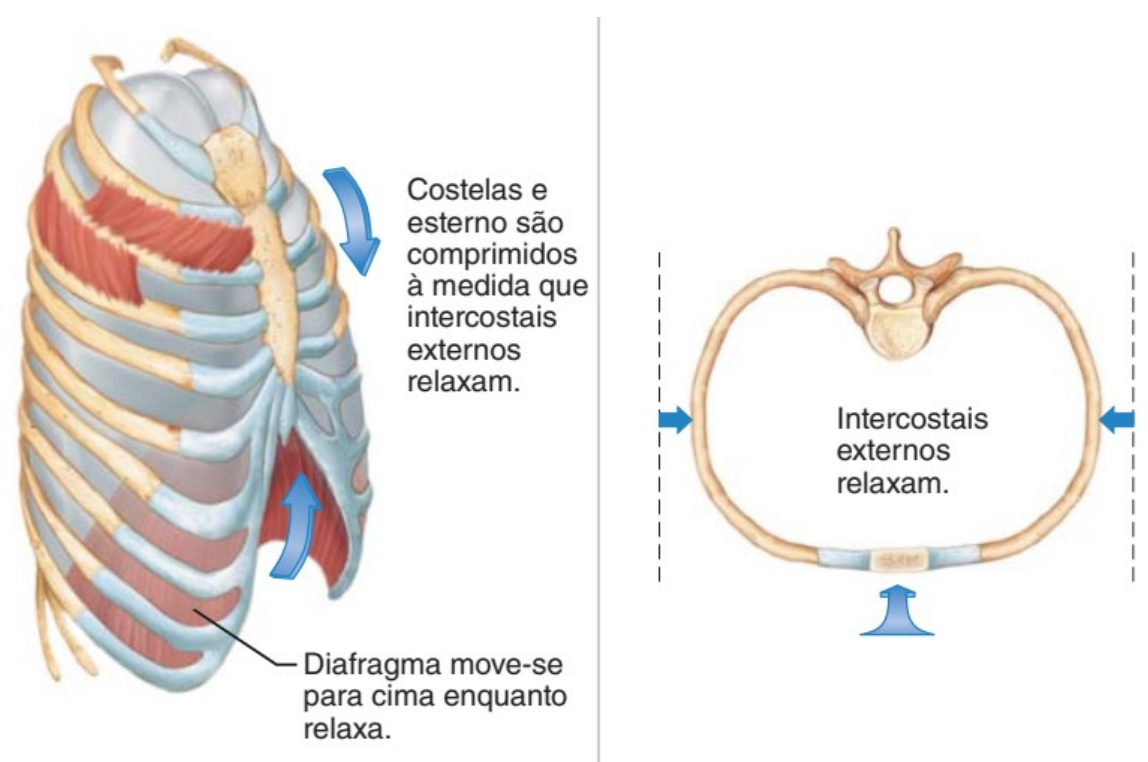

Figura 2.9 - Representação esquemática da movimentação do sistema respiratório durante a expiração. (Marieb, Wilheim, \& Mallat, 2014)

Por outro lado, a exalação forçada é um processo ativo no qual além do recuo elástico dos órgãos e vias aéreas, os músculos intercostais e diafragma trabalham para diminuir o volume desses órgãos, o que ocasiona um maior fluxo de ar escoado para a atmosfera.

\subsubsection{Pressões e volumes característicos do sistema respiratório}

O principal procedimento, para a análise quantitativa e qualitativa da respiração de um paciente, é um exame clínico, chamado de espirometria, onde é analisada a respiração do paciente via um instrumento denominado espirômetro. O aparelho faz a aquisição dos dados de fluxo da respiração e a partir dos mesmos gera-se um registro no formato de gráfico, o espirograma, que pode ser visto na Figura 2.10. 


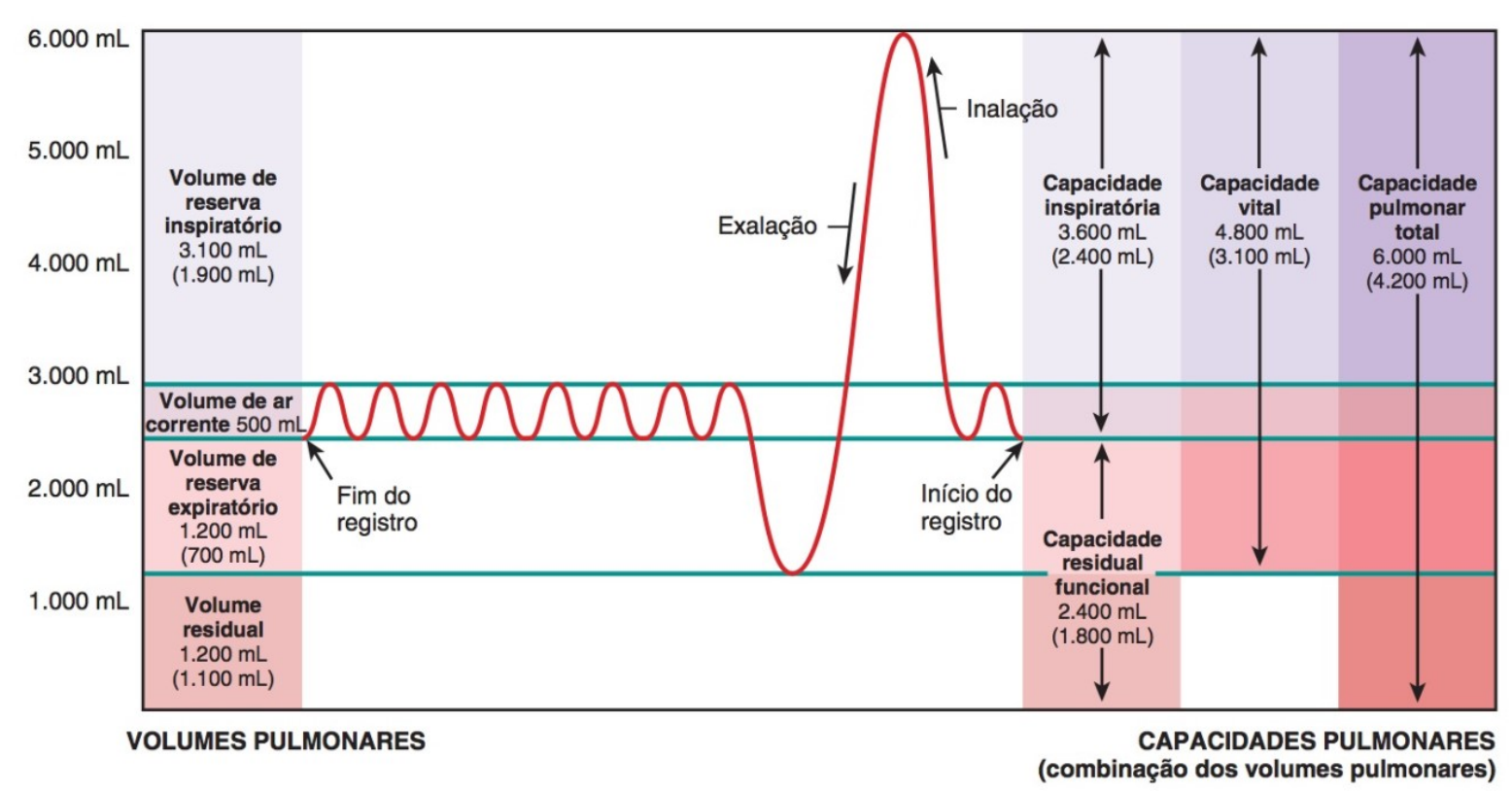

Figura 2.10 - Espirograma ilustrativo de uma paciente homem adulto. (Tortora \& Derrickson, 2017)

Para uma análise e comparação de paciente para paciente é necessário definir alguns parâmetros pertinentes com respeito aos volumes pulmonares.

\section{Volume de ar corrente (VAC):}

É o volume total decorrente de uma inspiração ou expiração não-forçada. Em um adulto saudável, em repouso, o volume médio é de $500 \mathrm{~mL}$.

\section{Volume reserva inspiratório (VRI):}

Caracterizado pelo volume de ar inalado complementar ao volume de ar corrente, ou seja, é o quanto de ar a mais do usual está entrando no sistema respiratório do paciente.

\section{Volume reserva expiratório (VRE):}

De maneira análoga ao VRI, o volume reserva expiratório pode ser descrito como o volume de ar exalado complementar ao volume de ar corrente. Nesse caso, o paciente expira uma quantidade acima do usual para um ser humano em repouso. 


\section{Volume residual (VR):}

Nota-se que após a expiração forçada, o VRE é consumido, entretanto, existe uma reserva de ar sobressalente, e assim impede-se um colapso do sistema respiratório. Essa crucial reserva de ar é denominada volume residual.

Importante salientar que somente $70 \%$, aproximadamente, do volume de ar corrente chegam aos bronquíolos respiratórios e aos sacos alveolares, dessa forma faz parte da troca gasosa. Isso quer dizer que próximo de $30 \%$ do ar fica retida nas vias aéreas e nos órgãos do sistema respiratório. $O$ volume não aproveitado para a troca gasosa é chamada de Espaço morto anatômico.

Com os parâmetros fundamentais apresentados acima é possível ter um entendimento mais claro da Figura 2.10. Ainda assim, há parâmetros adicionais relevantes para a continuação da dissertação, como por exemplo, as capacidades pulmonares que são na verdade uma combinação dos volumes fundamentais descritos anteriormente. Abaixo seguem alguns parâmetros complementares.

\section{Capacidade inspiratória (Cl):}

Define-se como a soma do volume de ar corrente (VC) com o volume reserva inspiratório (VRI). Percebe-se através da Figura 2.10 que a capacidade inspiratória se trata do volume total que uma pessoa consegue inspirar até o preenchimento total dos pulmões e vias aéreas. Em um homem adulto saudável essa propriedade é de aproximadamente $3600 \mathrm{~mL}$ ou $3,6 \mathrm{~L}$.

\section{Capacidade residual funcional (CRF):}

É a soma do volume residual (VR) com o volume reserva expiratório (VRE). Pode ser entendida como sendo o volume remanescente dentro do sistema respiratório após uma exalação não forçada. 


\section{Capacidade vital (CV):}

É definida como a soma do volume reserva inspiratório (VRI) com o volume de ar corrente (VAC) e o volume reserva expiratório (VRE). Pode ser interpretado como o volume máximo deslocado após uma inspiração e exalação forçadas.

\section{Capacidade pulmonar total (CPT):}

É a soma da capacidade vital (CV) com o volume residual (VR), ou seja, tratase do volume de ar total que um ser humano pode ter dentro do sistema respiratório.

Um parâmetro amplamente utilizado, porém, não apresentado de forma direta no espirograma é a chamada ventilação-minuto (VM), que se trata do volume de ar inalado e exalado por minuto. É calculado a partir da multiplicação da frequência respiratória com o volume de ar corrente (VAC).

Dentro do ciclo de respiração há variação do volume pulmonar em relação ao tempo, e consequentemente a etapa do ciclo respiratório. Com isso, é evidente que mudanças de volume ocasionam em mudanças de pressão, por isso, torna-se válido descrever alguns parâmetros de pressão e a sua relevância dentro do ciclo de respiração.

\section{Pressão alveolar:}

Pode ser definida como a pressão dentro dos pulmões, ou seja, a pressão dentro dos alvéolos. Como já descrito acima, para haver inspiração a pressão alveolar tem de ser menor que a pressão atmosférica. Por outro lado, para que haver expiração, a pressão alveolar tem de ser maior que pressão atmosférica.

\section{Pressão intrapleural:}

É a pressão do fluido pleural, ou seja, dentro da cavidade pleural. Em geral, é menor que a pressão alveolar, com isso a tendência é que as pleuras estejam sempre muito próximas umas das outras, expandindo e retraindo de maneira conjunta. 


\section{Pressão transpulmonar:}

É a diferença entre a pressão alveolar e a pressão intrapleural, ou seja, pode ser entendida como sendo a diferença de pressão entre o interior dos alvéolos e a superfície do pulmão. Portanto, quanto maior for a pressão transpulmonar maior será o fluxo de ar que escoa para dentro ou para fora dos pulmões.

Graficamente, os parâmetros de pressão acima descritos podem ser visualizados na Figura 2.11 abaixo.

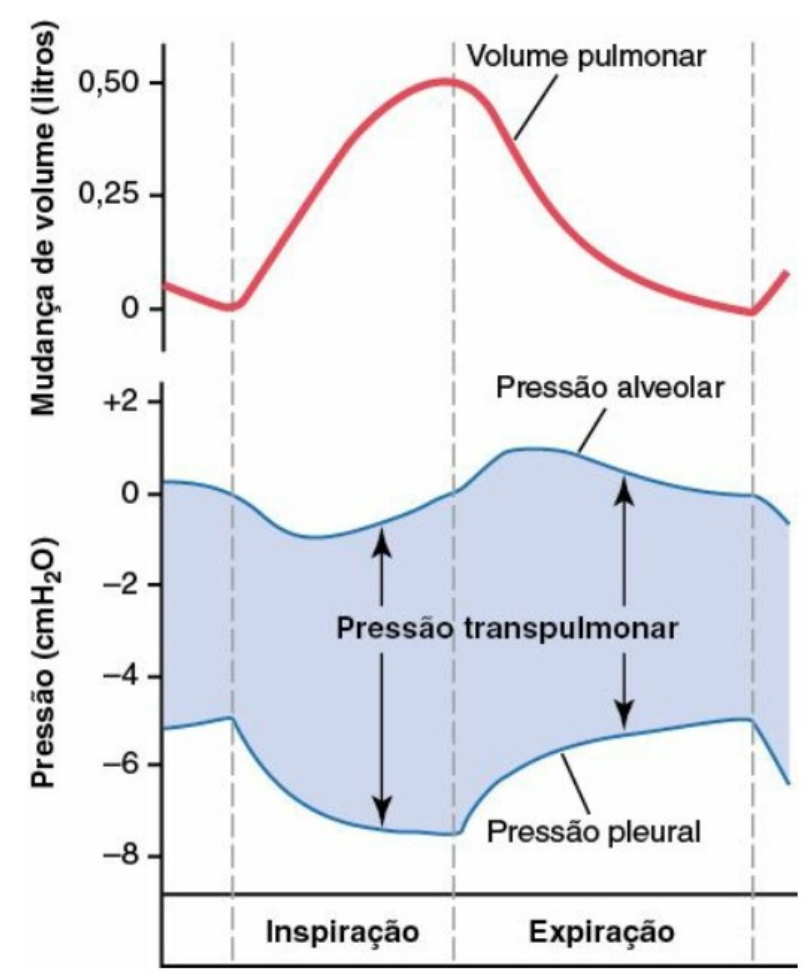

Figura 2.11 - Gráfico ilustrativo das mudanças de pressão ao longo do ciclo respiratório. (Hall, 2017) 


\subsubsection{Propriedades resistivas}

Evidentemente há deslocamento de ar durante o ciclo respiratório, o ar escoa para dentro dos pulmões durante a inspiração e para fora dos pulmões durante a expiração, o que gera atrito entre as moléculas de ar, as paredes das vias aéreas e outros órgãos. A dificuldade de movimentação do fluido imposta pelo sistema respiratório é chamada de resistência. Matematicamente pode ser expressa na Equação (1). (Ochs \& O'brodovich, 2019)

$$
R=\frac{\Delta P}{\dot{V}}
$$

Onde:

$\mathrm{P} \rightarrow$ Pressão medida entre dois pontos determinados, medido em $\mathrm{CmH} 2 \mathrm{O}$;

$\dot{V} \rightarrow$ Fluxo de ar entre os dois pontos determinados, medido em L/s;

$\mathrm{R} \rightarrow$ Resistência do sistema respiratório, medido em $\mathrm{CmH} 2 \mathrm{O} / \mathrm{L} / \mathrm{s}$

Evidentemente, como em mecânica dos fluidos, a resistência pode ser interpretada pela perda de energia (carga) do ar ao longo do sistema respiratório.

Nota-se a partir da Equação (1) que a resistência é função da vazão de ar, portanto a secção transversal no qual o fluido escoa é relevante para determinar a resistência dessa região na via aérea. Um exemplo prático pode ser ilustrado com o amadurecimento físico. À medida que infantos amadurecem, a resistência relativa à via aérea principal diminui motivada pelo aumento do diâmetro das vias aéreas, e assim, há queda na magnitude da resistência. Em geral, a resistência do sistema respiratório de um adulto saudável é de aproximadamente entre 19 a $28 \mathrm{cmH} 2 \mathrm{O} / \mathrm{L} / \mathrm{s}$. Por sua vez, em recém-nascidos estima-se que tal valor é próximo de $2 \mathrm{cmH} 2 \mathrm{O} / \mathrm{L} / \mathrm{s}$. 
É valido apontar que um adulto saudável possui por volta de $80 \%$ da resistência ao ar relativo às vias aéreas maiores que $2 \mathrm{~mm}$ de diâmetro, portanto, $20 \%$ está associado à resistência das vias aéreas menores. Entretanto quando se trata de infantos e recém-nascidos a proporção se iguala, ou seja, $50 \%$ da resistência é oriunda das vias aéreas maiores e $50 \%$ relativo às vias menores. Vale ressaltar que esses dados corroboram com o fato de que bebes e recém-nascidos são mais afetados por doenças que atingem as vias aéreas menores, sendo um exemplo a bronquiolite. (Ochs \& O'brodovich, 2019)

É conhecido que a perda de pressão (carga) devido ao atrito varia em função do padrão de escoamento. Em geral, escoamentos laminares geram baixo nível de resistências, por outro lado escoamentos turbulentos associam-se a altos níveis de resistência.

Importante salientar que esses 2 tipos de regimes de escoamento estão presentes no sistema respiratório humano. Escoamentos turbulentos estão mais presentes nas vias aéreas centrais, todavia, escoamentos laminares se desenvolvem nas vias aéreas menores, periféricas. (Ochs \& O'brodovich, 2019)

A equação de Poiseuille pode ser usada para calcular o gradiente de pressão necessário para manter o escoamento laminar. A formulação matemática é apresentada abaixo.

$$
P=\dot{V}\left(\frac{8 L \eta}{\pi r^{4}}\right)
$$

Onde:

$\dot{V} \rightarrow$ Fluxo de ar entre os dois pontos determinados, medido em L/s;

$\mathrm{L} \rightarrow$ Comprimento da tubulação, medido em metros;

$\eta \rightarrow$ Viscosidade do fluido em movimento; 
$r \rightarrow$ Raio da tubulação por onde o fluido é escoado, medido em metros.

No caso do escoamento turbulento, a pressão capaz de manter o mesmo regime é influenciada pelo diâmetro da via aérea, pela densidade do gás e pelo quadrado do fluxo do fluido. Não há unanimidade acadêmica sobre a equação a ser utilizada para essa situação e em alguns casos utilizam-se componentes empíricos nessas relações.

A Equação (1) apresenta uma dependência entre a resistência e o fluxo que pode não condizer com a realidade. De fato, acredita-se que a resistência possui uma relação de dependência também com o volume e, dessa maneira, autores, como Otis, et al., 1956 e Mead, 1961, utilizam a Equação (3), abaixo.

$$
R=R_{0}+K_{v} V+K_{f}|\dot{V}|
$$

Onde:

$R_{0} \rightarrow$ Resistência ao fluxo em regime laminar;

$K_{V} \rightarrow$ Constante de resistência associada ao volume;

$K_{F} \rightarrow$ Constante de resistência associada ao fluxo

O conceito de resistência aqui apresentado pode também ser estendido a tecidos e estruturas do sistema respiratório, uma vez que tecidos oferecerem resistência à mudança de volumes e/ou deslocamentos a partir da variação da pressão. Dessa forma, observa-se que resistência total do sistema respiratório é uma combinação das resistências das vias aéreas, resistências dos tecidos e das estruturas do sistema respiratório. 


\subsubsection{Propriedades Elásticas do Sistema respiratório}

Autores utilizam 2 componentes principais para descrever as propriedades elásticas do sistema respiratório: a complacência e a elastância (retorno elástico). $\mathrm{A}$ complacência diz respeito à capacidade do corpo de se distender na presença de uma diferença de pressão. Por sua vez, a elastância possui relação com a capacidade do corpo de se contrair, e assim voltar a sua forma inicial. (Insoft \& Todres, 2018)

A complacência pode ser descrita matematicamente conforme a Equação (4), abaixo:

$$
C=\frac{\Delta V}{\Delta P}
$$

Onde:

$\Delta V \rightarrow$ Variação de volume, medido em L;

$\Delta P \rightarrow$ Variação de pressão, medido em $\mathrm{cmH} 2 \mathrm{O}$.

Graficamente, pode ser interpretada como o coeficiente angular da reta no gráfico de pressão x volume, como nota-se na Figura 2.12. Percebe-se, observando o gráfico que a complacência não é constante ao longo do ciclo respiratório. 


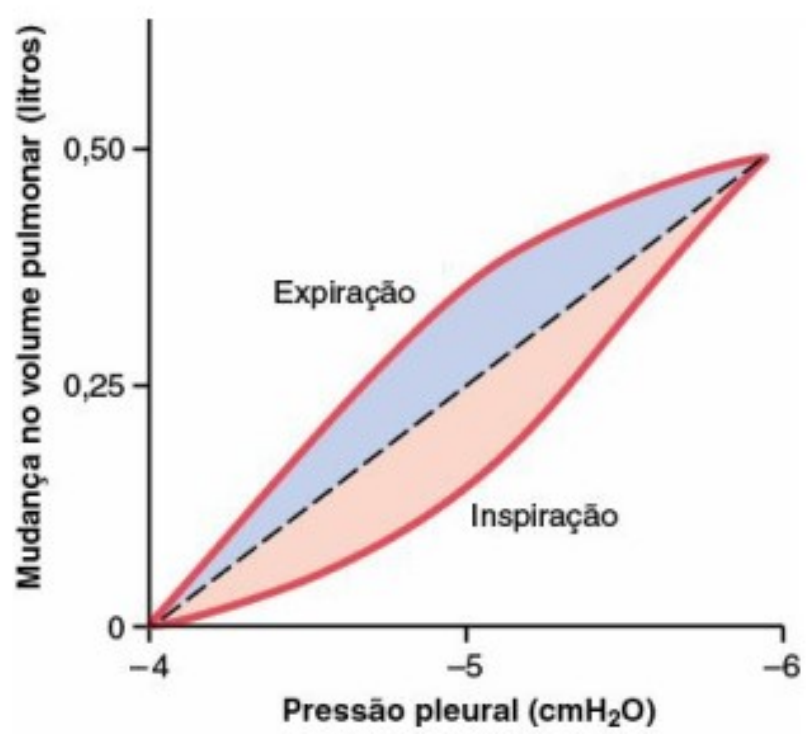

Figura 2.12 - Diagrama de complacência de uma pessoa adulta saudável. (Hall, 2017)

O diagrama de complacência acima denota uma curva de histerese. De forma geral, há 2 fatores principais que afetam a complacência pulmonar:

- Retorno elástico do tecido pulmonar (Fibras e colágeno);

- Tensão superficial dos líquidos que revestem as paredes internas dos alvéolos e outros espaços do sistema respiratório.

Recentemente, autores adicionaram 2 fatores que afetam a complacência total do sistema respiratório, o volume pulmonar e a interação do pulmão com a caixa torácica. (Ochs \& O'brodovich, 2019)

A influência do volume pulmonar também pode ser observada na Figura 2.12. Nota-se que o coeficiente angular do gráfico durante a fase inspiratória diminui na medida em que os pulmões inflam, ou seja, no princípio da inspiração a complacência é elevada, os pulmões estão longe de seu limite elástico. Entretanto uma vez que o tecido é distendido sua complacência diminui ao ponto de alcançar o limite elástico, caso o volume de ar inspirado seja muito alto. 
Quando infantos apresentam alguma patologia, a complacência da caixa torácica diminui e, com isso, é necessário um esforço inspiratório maior. Consequentemente, a pressão pleural diminui, ocasionando uma contração da caixa torácica. Logo, a eficiência das trocas de gases diminui o que implica um aumento do trabalho respiratório.

A fim de estimar a complacência total do sistema respiratório, pode-se fazer uma associação em paralelo das 2 complacências, conforme pode ser observado na Equação (5). (Lonardoni, Iwata, \& Fleury, 2003)

$$
C_{R S}=\frac{C_{C T} C_{P u l}}{C_{C T}+C_{P u l}}
$$

Estudos apontam que a complacência dos pulmões de adultos saudáveis é mantida em uma faixa de $125 \mathrm{ml} / \mathrm{cmH} 2 \mathrm{O}$ a $190 \mathrm{ml} / \mathrm{cmH} 2 \mathrm{O}$. Por outro lado, nota-se em infantos que esse valor diminui na ordem de 40 vezes, a aproximadamente 6,0 $\mathrm{ml} / \mathrm{cmH} 2 \mathrm{O}$. A complacência em prematuros é ainda menor, entre 1,9 e 2,0 ml/cm 20 . É pertinente acrescentar que a complacência da caixa torácica varia em função da idade. Um paciente neonatal que possui complacência relativamente baixa, ao longo de seu envelhecimento a complacência aumenta devido à calcificação dos ossos da caixa torácica e ao desenvolvimento dos tecidos. (Ochs \& O'brodovich, 2019).

As Figura 2.13-2.14 ilustram a diferença de complacência pulmonar, da caixa torácica e entre adultos e infantos. 


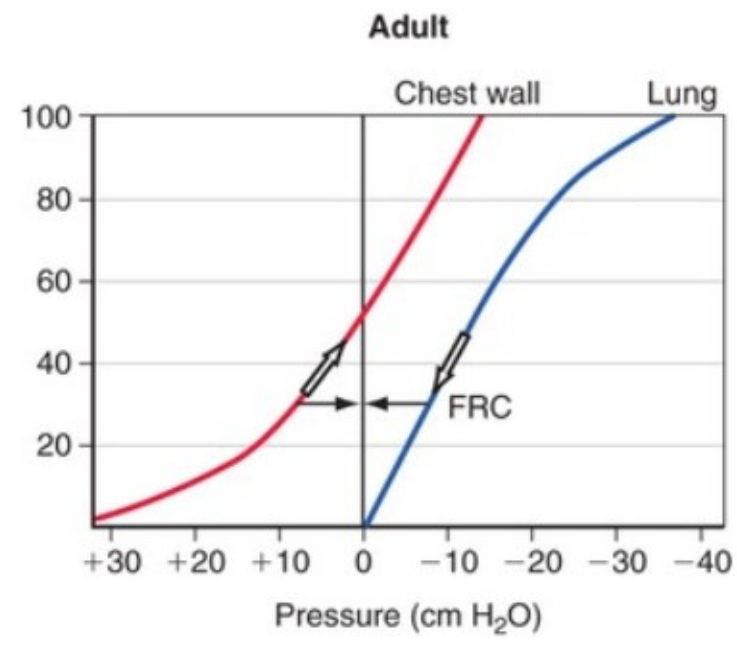

Figura 2.13 - Volume (Percentual) x Pressão, onde o coeficiente angular é a complacência. Neste caso, o gráfico é referente à pacientes adultos. (Kliegman, et al., 2019)

Infant

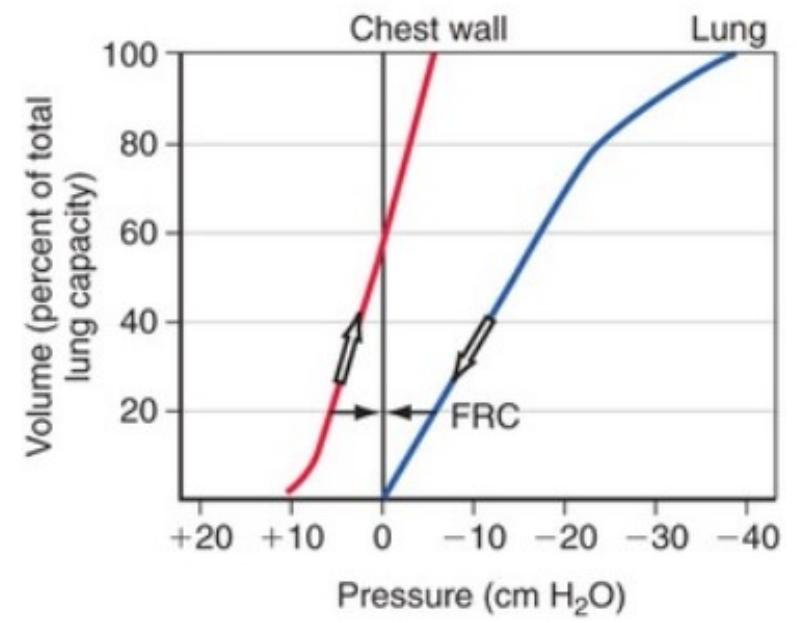

Figura 2.14 - Volume (Percentual) x Pressão, onde o coeficiente angular é a complacência. Neste caso, o gráfico é referente à pacientes infantos. (Kliegman, et al., 2019)

\subsubsection{Particularidades do sistema respiratório neonatal}

O sistema respiratório e o mecanismo de ventilação em um neonato possuem algumas particularidades decorrentes, principalmente, da anatomia ainda pouco desenvolvida do corpo humano durante essa fase da vida. 
Estudos evidenciam que o mecanismo de ventilação de um neonato apresenta uma maior dependência do diafragma. Primeiramente, os músculos intercostais são menos efetivos devido a uma configuração anatômica não favorável. Além disso, a caixa torácica é mais maleável, em razão da alta presença de cartilagem quando comparada a um adulto e, dessa maneira, a caixa torácica perde a sua forma. Consequentemente, não há uma mudança significativa de volume. Logo, conclui-se que o ciclo respiratório depende quase que exclusivamente do diafragma. (Insoft \& Todres, 2018)

Como dito anteriormente, a rigidez da caixa torácica aumenta proporcionalmente com a idade do infanto e, portanto, quanto mais velho, menor será a carga de trabalho no diafragma, pois a caixa torácica consegue manter sua forma.

As capacidades pulmonares apresentam algumas observações pertinentes quando relativas a neonatos. Estudos apontam que a CPT em recém-nascidos é menor que em um adulto ou um adolescente. Uma razão para isso é o fato dos músculos intercostais pouco desenvolvidos. Em decorrência, o VAC diminui o que implica em menores fluxos, volumes e pressão.

A Tabela 1 apresenta de maneira sintética a variação de alguns parâmetros respiratórios, citados anteriormente, como as capacidades pulmonares, frequência respiratória entre outros. 
Tabela 1 - Parâmetros respiratórios de acordo com a idade do paciente (Insoft \& Todres, 2018)

\begin{tabular}{|c|c|c|c|c|c|c|c|c|}
\hline & $\begin{array}{c}\text { Recém- } \\
\text { Nascido }\end{array}$ & $\mathbf{6}$ Meses & $\mathbf{1 2}$ Meses & 3 Anos & $\mathbf{5}$ Anos & $\mathbf{1 2}$ Anos & Adultos & Unidade \\
\hline \multirow{2}{*}{ F } & $50 \pm 1$ & $30 \pm 5$ & $24 \pm 6$ & $24 \pm 6$ & $23 \pm 5$ & $18 \pm 5$ & $12 \pm 3$ & $\begin{array}{c}\text { Respirações } \\
\text { por minuto }\end{array}$ \\
\hline \multirow{2}{*}{ VAC } & 21 & 45 & 78 & 112 & 270 & 480 & 575 & $\mathrm{~mL}$ \\
\cline { 2 - 9 } & $06-008$ & & & & & & $06-007$ & $\mathrm{~mL} / \mathrm{Kg}$ \\
\hline \multirow{2}{*}{ VM } & 1050 & 1350 & 1780 & 2460 & 5500 & 6200 & 6400 & $\mathrm{~mL} / \mathrm{min}$ \\
\cline { 2 - 9 } & $200-260$ & & & & & & 90 & $\mathrm{~mL} / \mathrm{kg} / \mathrm{min}$ \\
\hline \multirow{2}{*}{ VA } & 665 & & 1245 & 1760 & 1800 & 3000 & 3100 & $\mathrm{~mL} / \mathrm{min}$ \\
\cline { 2 - 9 } & $100-150$ & & & & & & 60 & $\mathrm{~mL} / \mathrm{kg} / \mathrm{min}$ \\
\hline \multirow{2}{*}{ CV } & 120 & & & 870 & 1160 & 3100 & 4000 & $\mathrm{~mL}$ \\
\hline \multirow{2}{*}{ CRF } & 80 & & & 490 & 680 & 1970 & 3000 & $\mathrm{~mL}$ \\
\cline { 2 - 9 } & 30 & & & & & & 30 & $\mathrm{~mL} / \mathrm{Kg}$ \\
\hline \multirow{2}{*}{ CPT } & 160 & & & 1100 & 1500 & 4000 & 6000 & $\mathrm{~mL}$ \\
\cline { 2 - 9 } & 63 & & & & & & 82 & $\mathrm{~mL} / \mathrm{Kg}$ \\
\hline
\end{tabular}

Um detalhe importante a ser notado na tabela acima é referente à frequência de respiração. É possível observar que, à medida que a pessoa envelhece, esse parâmetro tende a diminuir o que corrobora com a ideia de que as capacidades pulmonares aumentam com o envelhecimento. Consequentemente, oxigena-se o sangue de maneira mais efetiva a cada ciclo respiratório, logo não há necessidade de uma frequência respiratória mais elevada.

Os neonatos possuem características interessantes em seu padrão de respiração. Por exemplo, é possível identificar pausas recorrentes na respiração de um recém-nascido, em geral, de aproximadamente 5 a 10 segundos. Tal comportamento respiratório está relacionado, principalmente, a idade gestacional. Também é valido salientar que esse padrão é mais usual em crianças pré-termo do que a termo. A Figura 2.15 mostra ilustrativamente o padrão respiratório descrito acima. 


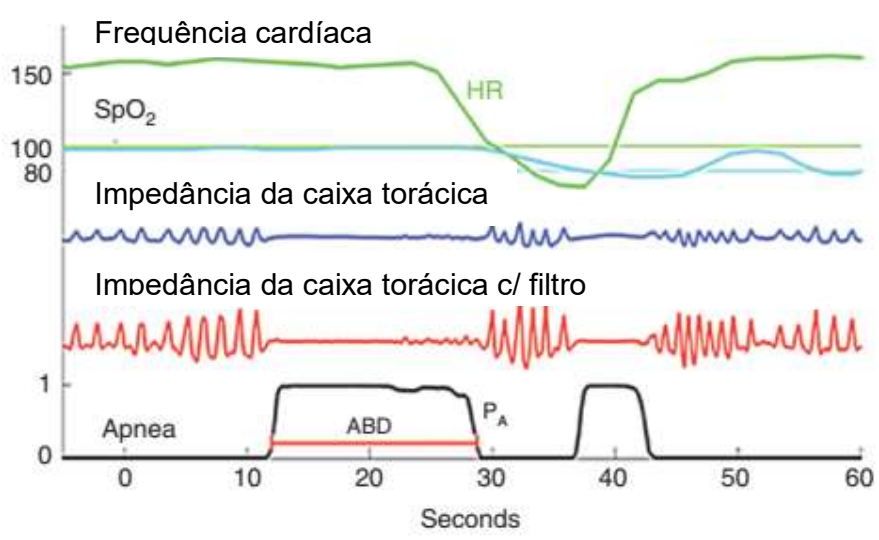

Figura 2.15 - Retrata um episódio de apneia, bradicardia ou desaturação. Note nessa figura que as pausas respiratórias podem ter durações distintas, no caso, 20 e 10 segundos. $O$ pneumograma acima retrata a frequência cardíaca, a oxigenação e as impedâncias da caixa torácica, onde se pode notar o padrão respiratório randômico característico de um neonato prétermo. (Fairchild, et al., 2016)

Uma condição também encontrada em neonatos é a chamada apneia neonatal. Diferentemente das pausas recorrentes na respiração, a condição de apneia proporciona pausas respiratórias maiores e pode ocasionar baixa saturação arterial de oxigênio, bradicardia e perda de tônus muscular. Essa patologia atinge aproximadamente $25 \%$ dos pré-termos. Além disso, quanto menor a idade dos bebês, maior a chance de adquirirem essa condição. A Figura 2.15 também llustra graficamente os padrões de respiração de um neonato com apneia.

\subsection{Ventilação mecânica}

Como já discutido nos capítulos anteriores, um dos objetivos do simulador respiratório é interagir com ventiladores mecânicos, ou seja, ser capaz de trabalhar em conjunto com os diversos modos e ciclos ventilatórios de um ventilador artificial. Portanto é valida uma breve apresentação sobre essas máquinas e seu funcionamento.

O ventilador mecânico é uma máquina na qual, através de um sistema de ventilação (Figura 2.16), oferece-se, total ou parcialmente, o trabalho respiratório que uma pessoa necessita para efetuar a respiração. Portanto, em geral, a ventilação 
mecânica é indicada para quando os pacientes não possuem capacidade de exercer os esforços musculares por conta própria.

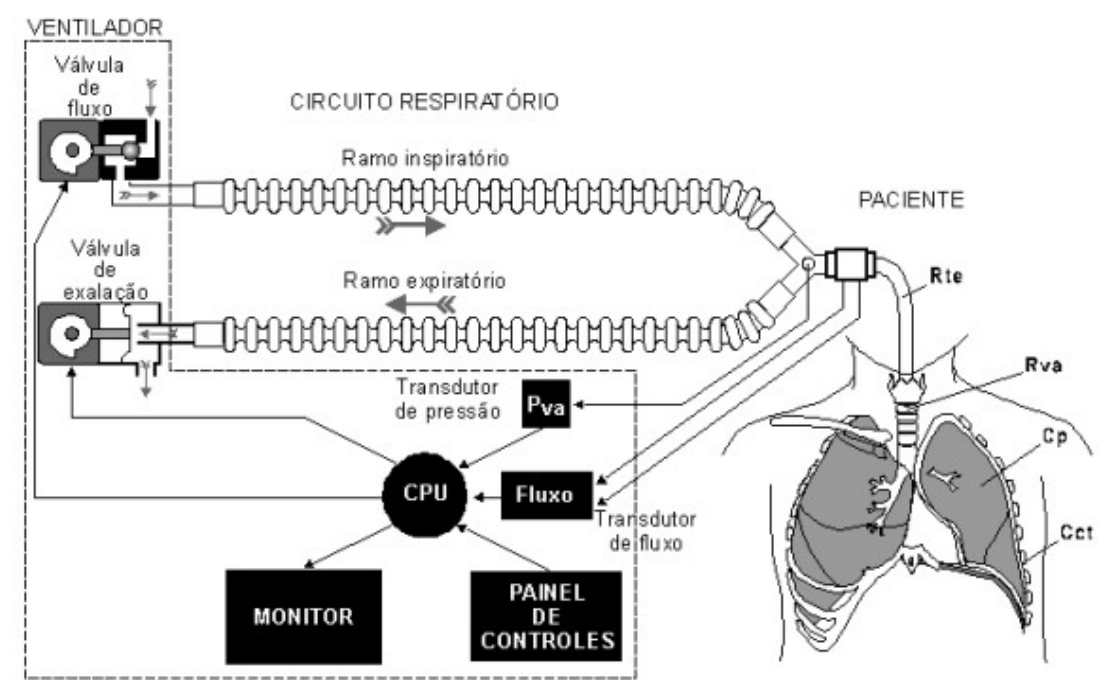

Figura 2.16 - Esquema ilustrativo de um sistema de ventilação mecânica. (Carvalho, Bonassa, Carvalho, Amaral, Beppu, \& Auler, 1997)

No aspecto funcional, os ventiladores mecânicos controlam os ciclos respiratórios a partir dos modos de ventilação, que é a forma na qual o ventilador entrega a carga respiratória ao paciente.

Os Tipos básicos de ventilação são:

- Espontâneo;

- Controlado;

- Assistido.

Ciclos espontâneos são disparados pelo paciente, entretanto, podem ou não ser assistidos/controlados e finalizados pelo ventilador. É o modo que permite total ou parcial independência às pessoas para respirar. 
Por outro lado, ciclos controlados são antagônicos aos ciclos espontâneos. Nesse caso, os ciclos são iniciados, controlados e finalizados exclusivamente pela máquina. Evidentemente, a utilização desses modos é recomendada quando o paciente não possui controle sobre os músculos diafragmáticos e intercostais para o processo de respiração.

Por último, o ciclo assistido mescla atributos de ambos os modos anteriores de tal forma que os ciclos são iniciados pelo paciente e controlados até seu final pelo ventilador. Ao detectar o esforço respiratório da pessoa a um nível pré-especificado (trigger), o ventilador assume o controle do respiratório. Observa-se que há diversos modos mais complexos baseado nesse mecanismo, porém esses não são detalhados no presente trabalho.

A Figura 2.17 ilustra o funcionamento de cada um dos tipos de ventilação descritos acima. 

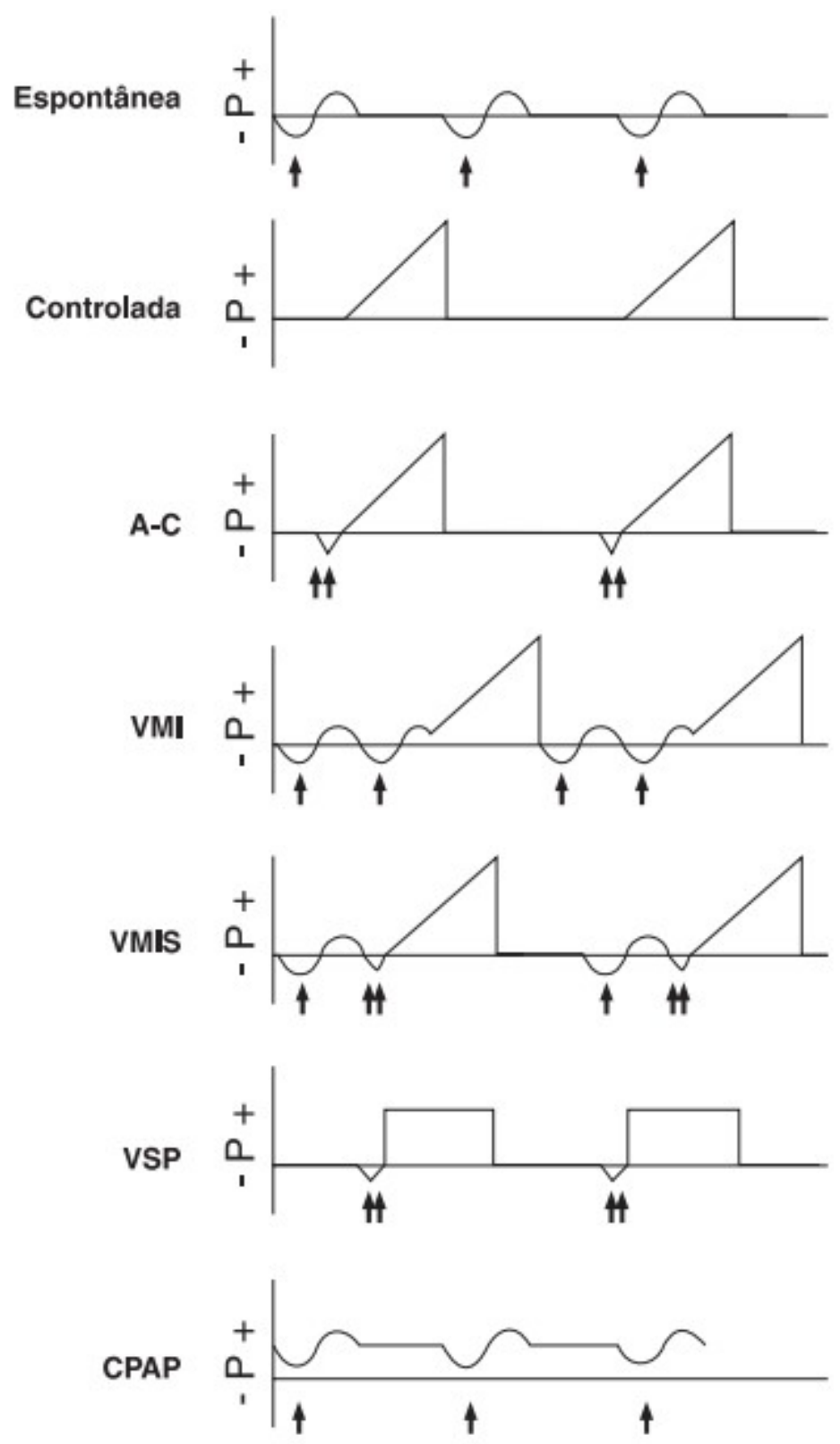

Figura 2.17 - Figura ilustrativa dos vários tipos e modos de ventilação mecânica, de acordo com o sinal de pressão. Importante salientar que uma seta representa o esforço inspiratório do paciente e duas setas representam os ciclos respiratórios com auxílio de um ventilador mecânico. A-C $\rightarrow$ Ventilação assistida-controlada; VMI $\rightarrow$ Ventilação mandatória intermitente; VMIS $\rightarrow$ Ventilação mandatória intermitente sincronizada; VSP $\rightarrow$ Ventilação com suporte de pressão; CPAP $\rightarrow$ Pressão positiva contínua em vias aérea. (Carvalho W. B., 1998)

Importante salientar que cada modo ventilatório é composto por 3 variáveis fundamentais: 
- Variáveis de disparo (trigger);

- Variáveis de controle;

- Variáveis que determinam início/fim de ciclos.

As variáveis de disparo determinam qual a grandeza, definida pelo usuário, será monitorada. Geralmente são utilizadas nos modos controlados e assistidos, onde caso a grandeza monitorada ultrapasse um determinado nível (trigger) a respiração é iniciada pelo ventilador. As variáveis de disparo podem ser de 3 tipos: tempo, pressão e fluxo. (Associação de Medicina Intensiva Brasileira, 2013)

Por sua vez, as variáveis de controle são os parâmetros que o ventilador mecânico irá controlar durante o ciclo respiratório, particularmente, durante a fase inspiratória do paciente. Em geral há duas opções, o fluxo controlado (volume controlado) e a pressão controlada.

As variáveis de início/fim de ciclos são sinais que indicam o fim da fase inspiratória ou do ciclo respiratório. Normalmente são: volume, fluxo e tempo.

Portanto, observa-se que um único modo ventilatório pode ser composto a partir de combinações diferentes. Por exemplo, pode-se definir um modo de ventilação controlado por pressão, onde a variável de disparo seja a pressão e, os finais dos ciclos definidos pelo tempo. Outra possibilidade seria um modo de ventilação controlado pela pressão, onde a variável de disparo seja o tempo e, os finais dos ciclos definidos pelo volume.

Um parâmetro importante para ventiladores mecânicos e relevante para a continuação do presente trabalho é o PEEP, pressão positiva expiratória final, sua função é evitar que ao final da expiração o pulmão possua 0 (zero) de pressão manométrica com o ambiente, dessa forma evita-se o colapso dos componentes do 
sistema respiratório. Em outras palavras, o PEEP é um parâmetro que estabelece qual a pressão positiva que o paciente terá no final de cada ciclo respiratório.

\subsection{Modelos dos sistemas respiratórios}

Modelos de mecânica respiratória estudam como as grandezas mecânicas, por exemplo, força, pressão, deslocamentos e volume, variam dentro de um ou mais ciclos de respiração. Autores destacam, majoritariamente, a 2 grupos de modelos:

- Modelos baseados em grandezas hidráulicas/pneumáticas;

- Modelos baseados em forças e deslocamentos.

Modelos baseados em forças e deslocamentos usualmente representam variáveis de forma mais específicas, consequentemente, tendem a ser sistemas não facilmente observáveis e/ou mensuráveis, como por exemplo, deslocamentos de tecidos específicos e forças de um determinado músculo. Além disso, essa metodologia costuma expressar as grandezas como componentes vetoriais e, por causa disso, pode-se dizer que é um método menos visual de modelagem do sistema respiratório humano. (Kaye, 1997)

Por outro lado, modelos baseados em grandezas hidráulicas/pneumáticas apresentam variáveis em sua forma escalar, com a possibilidade de realizar analogias, como volumes representando deslocamentos generalizados e pressões representando as forças generalizadas. É importante salientar que essa metodologia é baseada em variáveis observáveis, ou seja, são grandezas possíveis de serem medidas e/ou inferidas, como pressão pleural, variação volumétrica, pressão nas vias aéreas e etc.

Esse método leva a várias outras maneiras de modelagem, como por exemplo: 
- Modelos por analogia;

- Modelos compartimentais;

Observa-se que modelos por analogia são mais utilizados na comunidade acadêmica devido à simplificação da formulação das equações de movimento e por representar variáveis de possível verificação.

A utilização dessas técnicas de modelagem visa, sobretudo, 2 grandes
objetivos:

- A simulação de sistema respiratório humano;

- A identificação de parâmetros, dados modelos pré-determinados.

Entender o objetivo de seu estudo é importante, pois a escolha da técnica e do tipo de modelo pode depender disso.

\subsubsection{Modelos por analogia}

Modelos por analogia buscam comparar variáveis, sistemas e mecanismos distintos que apresentam comportamentos semelhantes. Por exemplo, sistemas mecânicos podem ser modelados a partir de uma correspondência com circuitos elétricos.

A analogia mais utilizada para modelagem do sistema respiratório é a com circuitos elétricos. Observa-se então que a análise do modelo pode ser feita com ferramentas matemáticas no domínio do tempo e no domínio da frequência. A Tabela 2, abaixo, representa a relação de variáveis entre os parâmetros respiratórios com as suas equivalentes nos circuitos elétricos. 
Tabela 2 - Tabela de analogia entre parâmetros respiratórios com parâmetros elétricos

\begin{tabular}{|c|c|c|c|}
\hline \multicolumn{2}{|c|}{ ParâmetrosRespiratórios } & \multicolumn{2}{c|}{ ParâmetrosElétricos } \\
\hline Quantidade & Unidade & Quantidade & Unidade \\
\hline Pressão & $\mathrm{cmH} 2 \mathrm{O}$ & Tensão & Volt \\
\hline Vazão & $\mathrm{L} / \mathrm{s}$ & Correnteelétrica & ampére \\
\hline Volume & $\mathrm{L}$ & Cargaelétrica & Coulomb \\
\hline Resistência das viasaéreas & $\mathrm{cmH} 2 \mathrm{O} / \mathrm{L} / \mathrm{s}$ & Resistênciaelétrica & Ohm \\
\hline Complacência & $\mathrm{L} / \mathrm{cmH} 2 \mathrm{O}$ & Capacitância & Farad \\
\hline Inércia & $\mathrm{cmH} 2 \mathrm{O} / \mathrm{L} / \mathrm{s}^{2}$ & Indutância & Henry \\
\hline
\end{tabular}

É válido salientar que a utilização dessa analogia pressupõe a hipótese de que as propriedades físicas, químicas e mecânicas são homogêneas nas várias partes do sistema respiratório.

Diversos modelos apresentados no presente trabalho utilizam a analogia descrita acima. Em adicional, podem construir seus modelos através de uma análise por impedância. Portanto, se faz necessário introduzir as definições e alguns conceitos básicos de impedância ao leitor.

\subsubsection{Impedância}

De forma geral e sintética, a impedância é um termo utilizado para se definir uma propriedade que gera oposição ou resistência a um sistema ou outras grandezas. Logo, há diversos tipos de impedância, como por exemplo, Impedância elétrica, impedância mecânica, impedância acústica entre outros.

Os sistemas respiratórios, como já explicitado, são usualmente representados por uma analogia aos circuitos elétricos. Portanto, se faz relevante detalhar a impedância elétrica.

Impedância elétrica define uma relação dinâmica entre a corrente elétrica e a tensão elétrica. A impedância é uma propriedade de qualquer circuito elétrico composto por capacitores, resistores e indutores. Para análise, pode-se condensar qualquer 
circuito elétrico em um único componente ligado a uma fonte de tensão, conforme a Figura 2.18. (Price, 2007)

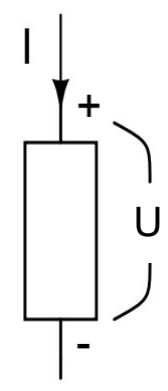

Figura 2.18 - Representação ilustrativa de um circuito elétrico condensado em um único componente de impedância $Z$.

Dessa forma, pode-se entender a impedância como uma lei de ohm generalizada, na qual a resistência elétrica é variável e dependente da freqüência de oscilação do sistema. Matematicamente, pode ser escrito de acordo com a Equação (6), abaixo

$$
Z(\omega)=\frac{U(\omega)}{I(\omega)}
$$

Onde:

$$
\begin{aligned}
& Z \rightarrow \text { Impedância elétrica } \\
& U \rightarrow \text { Tensão elétrica } \\
& I \rightarrow \text { Corrente elétrica }
\end{aligned}
$$

Algumas observações adicionais podem ser apresentadas. Primeiramente, a impedância elétrica é dependente da frequência de oscilação do sistema. Além disso, a impedância tem de ser descrita como um número complexo, ou seja, deve apresentar parte real e parte imaginária. Consequentemente, outra maneira de representar a impedância é por uma magnitude e um ângulo de fase. 
Cada componente de um circuito elétrico possui uma impedância associada. Logo, para se determinar a impedância equivalente de um circuito elétrico com diversos componentes é necessário utilizar as regras de associação em série e paralelo, assim como saber as impedâncias individuais de cada termo. Abaixo, segue uma breve descrição dos componentes fundamentais e suas respectivas impedâncias.

\section{Resistores:}

Resistores não possuem ângulo de fase, consequetemente são compostos exclusivamente por parte real.

$$
Z_{r}=R
$$

\section{Capacitores:}

Por outro lado capacitores possuem somente parte imaginária e possui dependência inversamente proporcional a capacitância do componente, ou seja, quanto maior a capacitância menor será a impedância. Matematicamente é descrito conforme a Equação (8)

$$
Z_{c}=\frac{1}{i \omega C}=\frac{1}{i 2 \pi f C}
$$

\section{Indutores:}

Possuem somente parte imaginária, entretanto, a impedância possui dependência proporcional a Indutância, e, é descrita conforme a seguinte relação.

$$
Z_{i}=i \omega L=i 2 \pi f L
$$




\subsubsection{Modelos compartimentais}

Compartimentos são regiões que apresentam as mesmas características físicas e comportamento dinâmico, consequentemente, com uma única constante de tempo. Entretanto podem não apresentar um contorno bem definido. Destaca-se também o fato de as partículas contidas em um compartimento terem uma mesma probabilidade de migrar a outros compartimentos. A origem física dessa migração vai depender do tipo de sistema em estudo. No caso do sistema respiratório, a pressão é o componente motor nas migrações de partículas para outros compartimentos.

Com isso pode-se concluir que um modelo compartimental consiste em um conjunto de compartimentos conectados entre si, onde há fluxo de matéria de um compartimento para outro. A Figura 2.19 representa ilustrativamente um modelo multicompartimental.

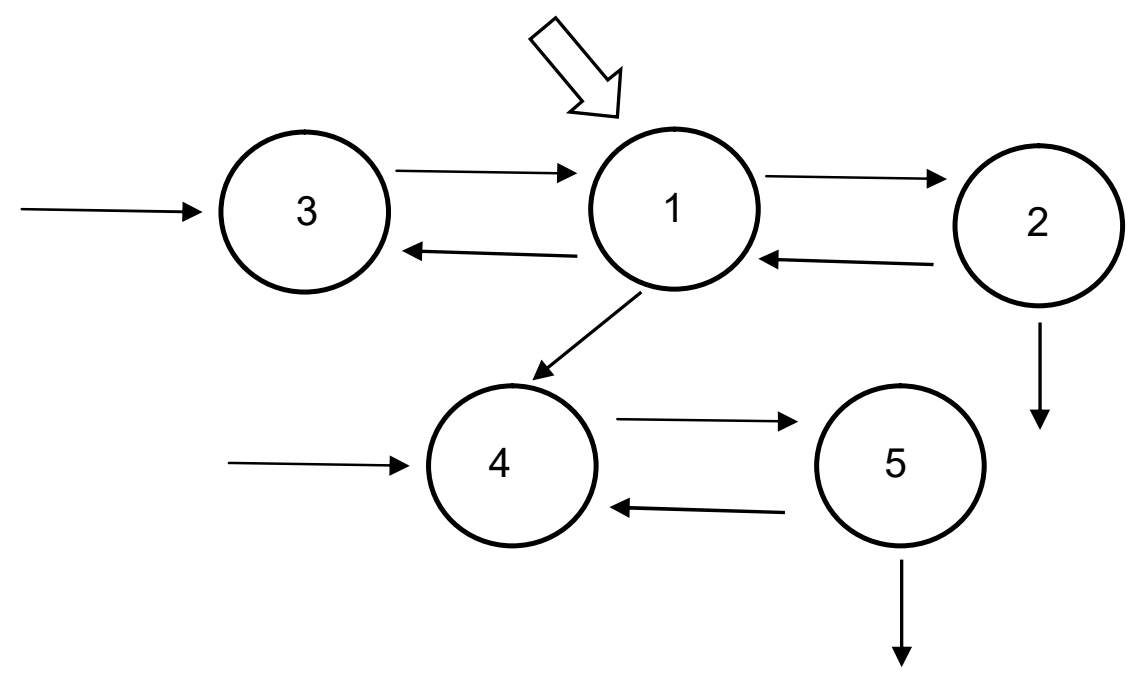

Figura 2.19 - Representação llustrativa de um modelo multicompartimental genérico. (Autor)

Note que, no caso onde se estuda as heterogeneidades do sistema respiratório, é necessária a inclusão de compartimentos adicionais ao modelo, cada um com propriedades diferentes. Tal técnica para representar o sistema respiratório vem sendo usualmente utilizada com o intuito de emular patologias que geram heterogeneidades 
nos pulmões, e assim conseguir reproduzir a falta de uniformidade nos compartimentos. É importante salientar que cada compartimento pode ter uma constante de tempo, $\tau$, diferente.

Um dos primeiros trabalhos em relação ao comportamento mecânico do sistema respiratório ocorreu quando Roher, 1915, mostrou que a pressão pulmonar é dividida em pressão estática e pressão dinâmica, e, assim, avaliar as propriedades de volume-elasticidade e vazão-resistência. (Otis, et al., 1956)

A partir desse princípio, Otis, 1956, propôs uma expressão relativa à variação da pressão pulmonar em função do volume e da vazão, e assim apresentou a Equação (10).

$$
\Delta P=K_{E L} V+K_{1} \dot{V}+K_{2} \dot{V}^{2}
$$

Onde:

$\Delta P \rightarrow$ Diferença de pressão através do pulmão;

$K_{E L} \rightarrow$ Razão da variação de pressão em relação à variação de volume quando não há escoamento;

$K_{1}, K_{2} \rightarrow$ São constantes que representam as propriedades de pressãovolume das vias aérea e resistivas dos tecidos.

Foram sugeridas algumas hipóteses e considerações com o intuito de simplificar a expressão acima:

- Os pulmões são compostos por várias vias aéreas independentes, cada uma com propriedade resistiva e elástica; 
- Fatores inerciais são desprezíveis, dada uma frequência respiratória abaixo de $2 \mathrm{~Hz}$;

- Características elásticas e resistivas de cada via aérea são lineares, ou seja, $K_{2}=0$;

Adicionalmente aos pontos citados, foi proposto um modelo de um único compartimento, conforme a Figura 2.20, onde se pode expressar a diferença de pressão nos pulmões como uma equação diferencial de primeira ordem, a Equação (11), abaixo. (Otis, et al., 1956)

$$
\Delta P=\frac{1}{C} V+R \dot{V}
$$

Onde:

$\Delta P \rightarrow$ Diferença de pressão através do pulmão;

$C \rightarrow$ Capacitância pulmonar;

$R \rightarrow$ Resistência do sistema pulmonar proposto.

É possível observar que a expressão acima pode se igualar à Equação (6) dada a condição de que $K_{E L}=1 / C, K_{1}=R$ e $K_{2}=0$.

Uma característica importante em sistemas dinâmicos é a constante de tempo, o que é valido para o sistema respiratório. Para essa aplicação, a constante de tempo é definida por $\tau=R C$, e está relacionada ao tempo que a pessoa leva para inspirar e expirar. Quanto maior a constante, maior será a duração do ciclo respiratório. Nota-se que pessoas que possuem doenças respiratórias apresentam mudanças na resistência 
e complacência, consequentemente, altera-se o valor da constante de tempo, ou, em outras palavras, altera-se comportamento dinâmico do sistema.

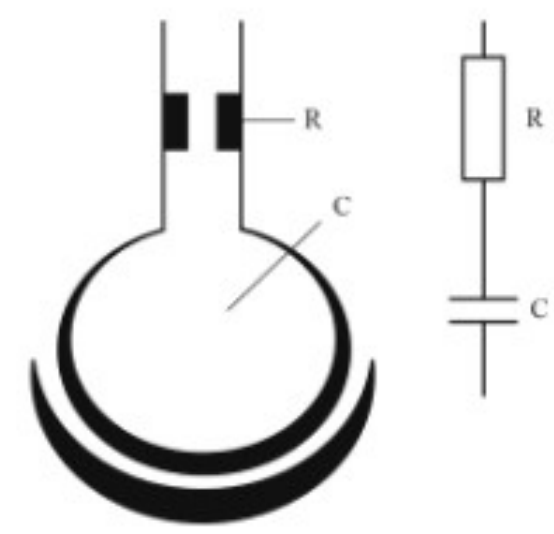

Figura 2.20 - Representação do modelo proposto por Otis em 1956. (Ghafarian, Jamaati, \& Mohammadreza, 2016)

Efeitos mecânicos que influenciam a distribuição da ventilação do sistema respiratório foram estudados, por Otis (1956) e Mead (1963), onde algumas conclusões foram consolidadas:

- A distribuição de ventilação não é influenciada pela frequência respiratória, caso as constantes de tempo em cada via aérea sejam as mesmas;

- No caso em que as constantes de tempo não são iguais, a frequência respiratória pode influenciar a distribuição de ventilação. Nessa situação, o aumento da frequência respiratória leva a uma diminuição da complacência e da resistência.

Destaca-se que esse modelo é recomendado para respiração basal, ou seja, respiração não-forçada. Entretanto, para situações onde a frequência respiratória é alta, esse modelo não é o mais adequado e, nesse caso, há a necessidade da inserção de um componente relativo à inércia do ar em movimento dentro do sistema respiratório. 
Com a realização de outros trabalhos, autores como Mead (1961), Dubois (1956), Woo (2004), entre outros entenderam ser necessário adicionar elementos à Equação (7), ou considerar hipóteses específicas às suas aplicações, como por exemplo, a utilização de uma resistência não-linear, segmentação do termo de complacência em estática e dinâmica e o uso do termo de inércia do ar.

Ao empregar as hipóteses e os modelos acima, foram observadas similaridades entre modelos respiratórios e circuitos elétricos, logo, uma nova maneira de se desenvolver as equações de movimento do sistema respiratório começou a ser implementada pela academia. Tal metodologia utilizava a analogia com circuitos elétricos, modelos compartimentais e análise de impedância.

O primeiro modelo multicompartimental foi também apresentado por Otis. Nesse caso, o sistema respiratório foi modelado como um circuito em paralelo com um componente resistivo em série a um componente elástico, circuito RC paralelo, conforme pode ser observado na Figura 2.21
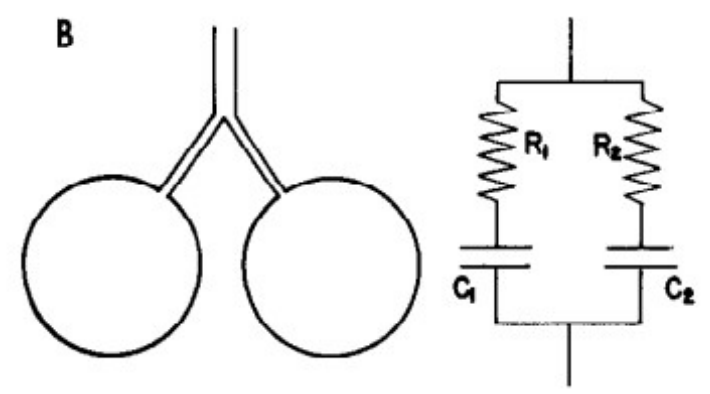

Figura 2.21 - Modelo de um sistema respiratório com 2 compartimentos. (Otis, et al., 1956)

Observa-se que cada ramo do modelo tem seu comportamento previsto de acordo com a Equação (11). Além disso, o fluxo em cada compartimento e as constantes de tempo irão depender das resistências e das capacitâncias encontradas (Impedâncias). 
Caso as resistências e capacitâncias de ambos os lados sejam iguais, o fluxo de ar e as constantes de tempo também serão semelhantes. Todavia observa-se o caso em que as capacitâncias são iguais e resistências distintas, o ramo com a menor resistência terá um fluxo maior, consequentemente, uma constante de tempo menor. Esse detalhe pode ser relevante no instante em que a inspiração acaba, e a exalação inicia. Nesse momento, os compartimentos possuem magnitudes de pressão diferentes e, dessa forma, há fluxo de um compartimento para o outro durante o início da exalação. O mesmo irá o ocorrer no final da exalação: o compartimento relacionado à maior resistência terá pressão mais elevada quando comparada ao outro ramo e, com isso há um fluxo de um compartimento para o outro. Vale salientar que esse padrão de comportamento é mais usual em frequências respiratórias elevadas. (Otis, et al., 1956)

Uma extensão do modelo $\mathrm{RC}$ inclui um termo referente à inércia de movimentação do ar e de tecidos do sistema. Nota-se que a inclusão de tal componente é usual para frequências respiratórias elevadas. Em analogia aos circuitos elétricos, a inércia pode ser emulada por elemento de indução (bobina elétrica). Configura-se então, um modelo do tipo RIC, como visto na Figura 2.22

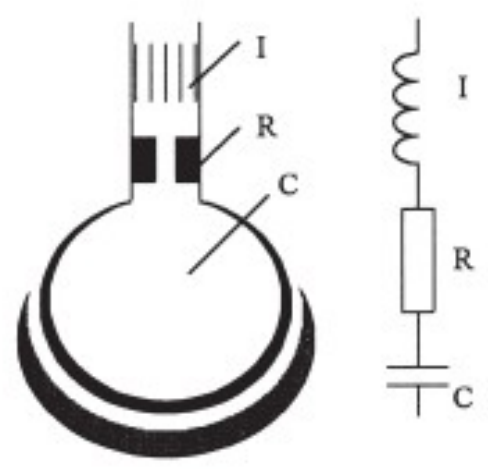

Figura 2.22 - Representação llustrativa do modelo RIC. (Schmidt, Foitzik, Hochmuth, \& Schmalisch, 2003) 
Os modelos subsequentes aos 3 fundamentais citados acima representam variações desses, ou seja, são adicionados alguns elementos e especificidades com o intuito de aprofundar o modelo em determinada característica de um estudo.

A fim de aprimorar o modelo RIC, Woo apresentou em 2004 o modelo RIC estendido, onde foi adicionada ao modelo original uma resistência em paralelo ao termo de capacitância, como se observa na Figura 2.23. Tal componente de resistência refere-se à resistência perimetral que tem a função de representar as resistências das pequenas vias aéreas. (Schmidt, Foitzik, Hochmuth, \& Schmalisch, 2003)

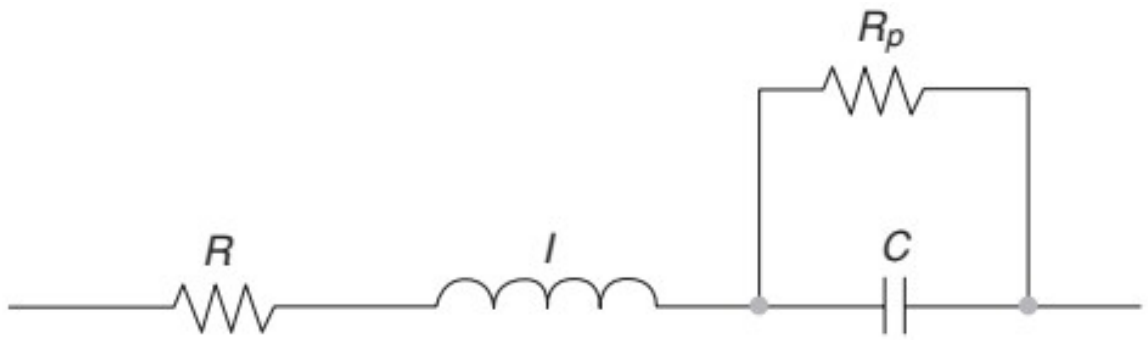

Figura 2.23 - Representação ilustrativa do modelo estendido RIC. Onde, R $\rightarrow$ resistência central; I $\rightarrow$ Indutor central; $\mathrm{R}_{p} \rightarrow$ resistência periférica; C $\rightarrow$ capacitância pulmonar (Diong, Nazeran, Nava, \& Goldman, 2007)

Vale salientar que em uma análise de frequência, esse novo componente permite que a parte real da impedância seja dependente da frequência.

Um dos modelos mais completos e complexos foi apresentado por Mead, 1961. Mead propôs uma forma de modelar o movimento do conjunto pulmão-tórax. Para isso, 7 parâmetros foram incluídos no modelo, e assim permite-se incluir efeitos extra pulmonares da mecânica respiratória como complacências torácicas, efeitos da boca e da máscara facial respiratória, além de poder emular as propriedades da caixa torácica, vazamento de ar ao redor da máscara facial ou tubo endotraqueal. (Ghafarian, Jamaati, \& Mohammadreza, 2016) 
Entretanto é válido salientar que uma desvantagem da utilização desse modelo a recém-nascidos é o fato de que a maioria dos parâmetros adotados pelo autor não possui valores de referência na literatura, e, em consequência, sua aplicação como simulador pode ser inviável ou pouco realista.

Outro aspecto importante do modelo é observado ao não ser possível a simulação de respiração alveolar não uniforme, pois o modelo possui somente uma única via aérea para simulação dos pulmões. Tais características podem ser observadas na Figura 2.24 abaixo.

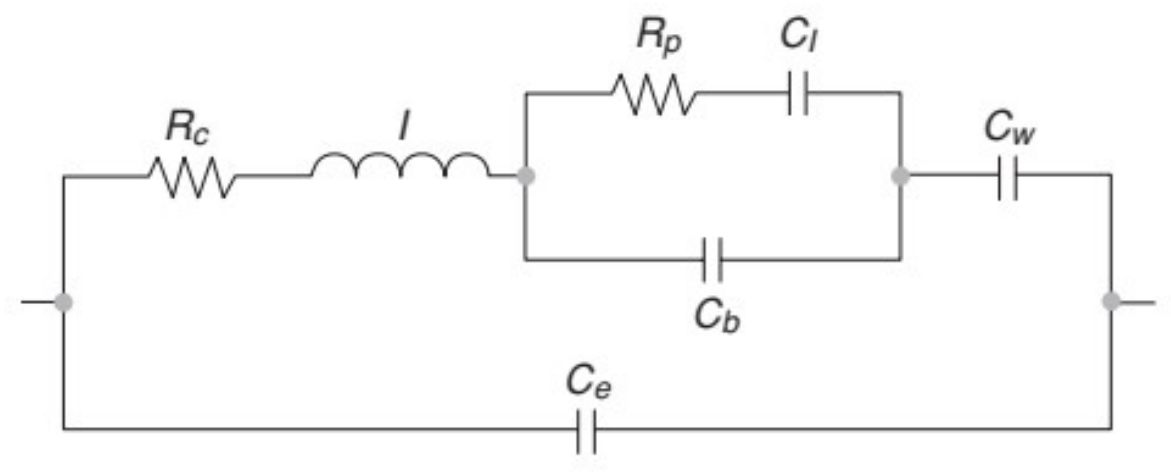

Figura 2.24 - Representação ilustrativa do modelo de Mead. Onde, $\mathrm{R}_{\mathrm{c}} \rightarrow$ resistência central; I $\rightarrow$ Indutor central; $\mathrm{R}_{p} \rightarrow$ resistência periférica; $C_{l} \rightarrow$ capacitância pulmonar; $C_{b} \rightarrow$ complacência dos brônquios; $C_{w} \rightarrow$ complacência da caixa torácica; $C_{l} \rightarrow$ complacência extratorácica. (Diong, Nazeran, Nava, \& Goldman, 2007)

Dubois, em 1956, propôs um modelo multicompartimental dividido em tecidos, vias aéreas e propriedades alveolares. O modelo é baseado em 6 parâmetros: resistência e inertância das vias aéreas, resistência, inertância e complacência dos tecidos, além da complacência alveolar, como é observado na Figura 2.25. (Diong, Nazeran, Nava, \& Goldman, 2007) 


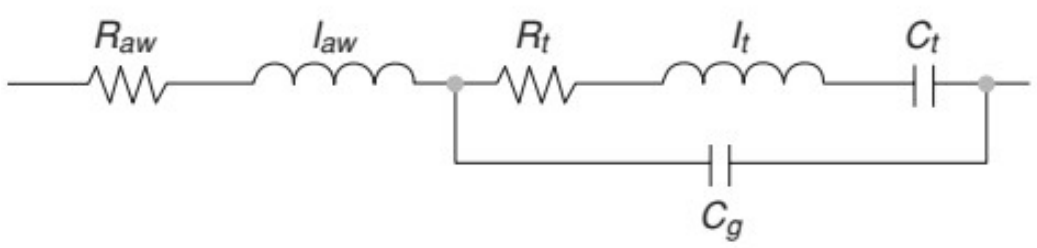

Figura 2.25 - Representação Ilustrativa do modelo de Dubois. Onde, $\mathrm{R}_{\mathrm{aw}} \rightarrow$ resistência das vias aéreas centrais; $I_{a w} \rightarrow$ indutor relativo às vias aéreas centrais; $R_{t} \rightarrow$ resistência dos tecidos pulmonares; $I_{t} \rightarrow$ Indutor relativo aos tecidos pulmonares; $C_{t} \rightarrow$ complacência dos tecidos; $\mathrm{C}_{\mathrm{g}} \rightarrow$ complacência alveolar. (Diong, Nazeran, Nava, \& Goldman, 2007)

O último modelo a ser descrito nessa secção é o modelo viscoelástico, proposto por Lutchen e Costa em 1990, onde o sistema respiratório é modelado por 4 parâmetros: a resistência das vias aéreas, a complacência estática, a resistência viscoelástica dos tecidos e a sua relativa complacência, conforme pode ser observado na Figura 2.26.

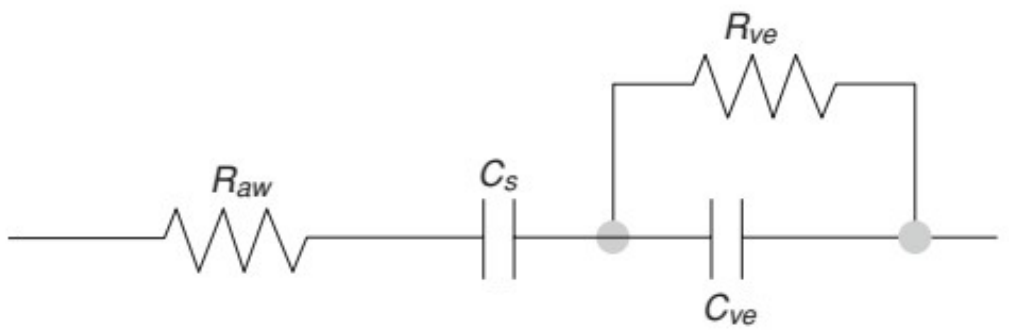

Figura 2.26 - Representação llustrativa do modelo viscolástico de Lutchen. Onde, $\mathrm{R}_{\mathrm{aw}} \rightarrow$ resistência da vias aéreas centrais; $\mathrm{C}_{\mathrm{s}} \rightarrow$ Complacência estática; $\mathrm{R}_{\mathrm{ve}} \rightarrow$ resistência viscoelática dos tecidos; $\mathrm{C}_{\mathrm{ve}} \rightarrow$ complacência viscoelástica dos tecidos. (Diong, Nazeran, Nava, \& Goldman, 2007)

Como já destacado anteriormente, o desafio de utilizar os modelos acima apresentados é de quantificar os parâmetros para a situação específica a ser estudada. No caso do presente trabalho, os parâmetros e constantes se concentram na faixa etária neonatal. Na literatura há dificuldade de encontrar tais dados e referências e, por consequência, há dificuldade em identificar quando um paciente possui uma patologia ou não. 
Ao focar nesse aspecto, uma das técnicas mais promissoras, para o teste de função pulmonar e identificação de parâmetros dos modelos respiratórios, é a técnica da oscilação forçada (FOT). Primeiramente introduzida por Dubois, em 1956, o procedimento busca, de maneira não-invasiva e com o mínimo de cooperação ativa do paciente, investigar sua mecânica respiratória de forma a determinar parâmetros e constantes, como resistências, indutâncias e capacitâncias a partir de um modelo a ser identificado (Schmidt, Foitzik, Hochmuth, \& Schmalisch, 2003). Devido a tais características, essa técnica é bastante promissora em neonatos, uma vez que não necessita de que o recém-nascido execute uma série de tarefas, em contraste, por exemplo, com a espirometria. A FOT proporciona a realização do exame de maneira rápida e passiva em relação ao paciente.

De forma sucinta, a técnica consiste em quantificar a impedância do sistema respiratório do paciente, para isso são impostas oscilações ao recém-nascido respirando espontaneamente. Em geral, essas oscilações são oriundas de caixas de som ou bombas de ar, e podem ser colocadas em diferentes localizações no paciente, conforme é mostrado na Figura 2.27. Nota-se que as oscilações podem ser aplicadas na boca, ou na região da boca, procedimento conhecido como impedância de entrada, e quando aplicado na região do tórax é denominado impedância de transferência. (Schmidt, Foitzik, Hochmuth, \& Schmalisch, 2003) 


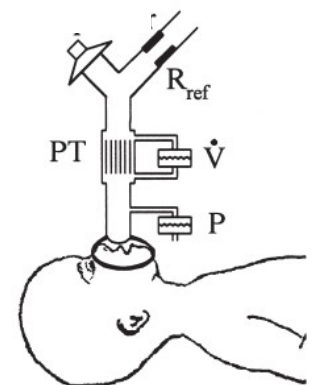

a)

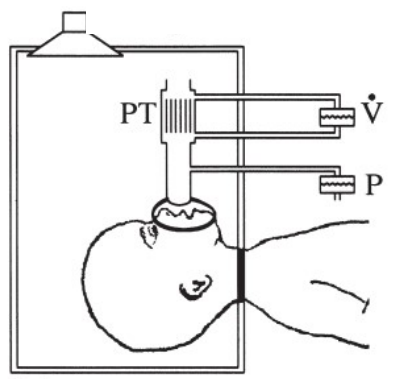

b)

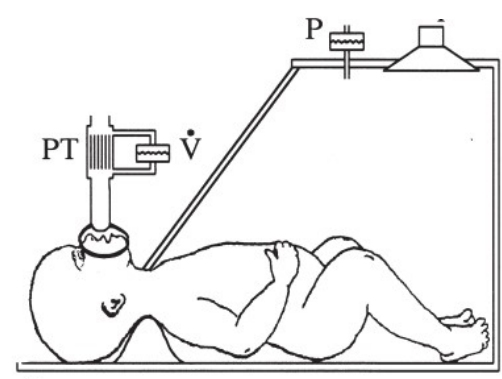

c)

Figura 2.27 - Representação ilustrativas das diversas técnicas de aplicação da FOT. a) Mede-se a impedância de entrada na boca no recém-nascido, ou seja a caixa de som está vibrando o ar para dentro da boca do R.N (b). Mede-se a impedância de entrada, porém, a caixa de som está na região da boca do paciente c). Por último, mede-se a impedância de transferência, onde a caixa de some está na região torácica do RN. (Schmidt, Foitzik, Hochmuth, \& Schmalisch, 2003)

Independentemente dos tipos que se opte por realizar, deve-se medir a pressão e o fluxo, para então calcular a impedância, de acordo com a Equação (12) abaixo:

$$
Z_{r s}(\omega)=P(\omega) / \dot{V}(\omega)
$$

Onde, $\omega=2 \pi f$.

Além disso, vale destacar que $P(\omega)$ e $\dot{V}(\omega)$ são as transformadas de Fourier da pressão e do fluxo de ar.

Como já introduzido em uma seção anterior a impedância do sistema respiratório é composta por uma parte real e imaginária. Na qual a parte real é composta pelas resistências e a parte imaginária é determinada pelo conjunto das impedâncias dos capacitores e dos indutores. Com isso é possível a construção de gráficos de impedância com o intuito comparar as curvas 'padrão' com as de pacientes com alguma doença, e assim, torna-se possível a identificação de algum distúrbio. 
Alguns estudos foram realizados a partir dessa técnica com o objetivo de avaliar os modelos respiratórios, e para a utilização desse recurso como uma base de dados para diagnosticar pacientes.

Schmidt et al, em 1998, foram responsáveis pelo primeiro estudo da impedância do sistema respiratório em neonatos. Foram investigados, utilizando simulações computacionais, os efeitos do desenvolvimento/crescimento dos pulmões, as nãohomogeneidades pulmonares e o equipamento de medida da impedância respiratória em recém-nascidos. (Ghafarian, Jamaati, \& Mohammadreza, 2016)

Alguns trabalhos, porém, utilizaram-se do estudo da impedância para realizações de simuladores, como será mostrado no decorrer desta revisão.

\subsection{Modelos e especificações técnicas de simuladores respiratórios atuais}

Nessa secção serão apresentados os modelos utilizados por cada um dos simuladores respiratórios mais recentes e/ou conceituados que tenham relevância para o trabalho.

\subsubsection{Simulador respiratório didático multicompartimental}

Lonardoni e Iwata introduziram um simulador didático com o intuito de treinar a ventilação artificial e de estudar os aspectos da pneumologia. O simulador proporciona ao usuário a capacidade de ajuste dos parâmetros do ventilador e acesso a uma interface gráfica para usuário (GUI) amigável e intuitiva, vide Figura 2.29.

Para gerar os resultados, os autores utilizaram um modelo de 2 compartimentos pulmonares baseado no modelo de Bonassa (1996). Com isso, o objetivo é de reproduzir a respiração alveolar não-homogênea. Pode-se observar na Figura 2.28 que o modelo pode ser dividido em 2 regiões: 
- Pulmonar: delimitada pela região entre $R_{a w}$ e a fonte de pressão espontânea, $P \operatorname{esp}(t)$, essa parte do modelo está associada ao sistema respiratório;

- Ventilador Mecânico: delimitada pelo restante do circuito elétrico. Busca-se emular o comportamento do ventilador mecânico, e inclui-se também as mangueiras que levam o ar até o paciente.

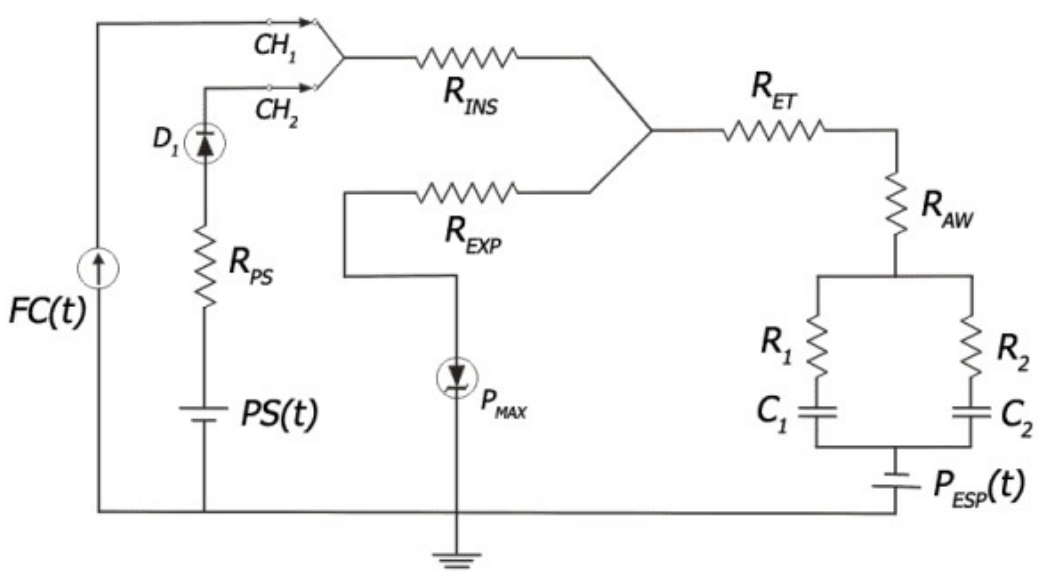

Figura 2.28 - Modelo de Lonardoni e Iwata. De forma resumida, o lado direito do modelo é referente ao sistema respiratório humano e o restante do circuito referente ao ventilador mecânico. (Lonardoni, Iwata, \& Fleury, 2003)

Onde, $\mathrm{R}_{\mathrm{aw}}$ refere-se à resistência das vias aéreas centrais, $\mathrm{R}_{1}$ e $\mathrm{R}_{2}$ referem-se às resistências periféricas do pulmão direito e esquerdo respectivamente, $C_{1}$ e $C_{2}$ são as complacências pulmonares do pulmão direito e esquerdo respectivamente, $P_{\text {esp }}(t)$ refere-se à pressão espontânea muscular, $\mathrm{R}_{E T}$ é a resistência relativa ao tubo endotraqueal, $\mathrm{R}_{I N S}$ e $\mathrm{R}_{E X}$ referem-se às resistências dos ramos inspiratórios e expiratório do ventilador mecânico respectivamente, $\mathrm{R}_{P S}$ resistência relativa à tubulação do ventilador mecânico, $\mathrm{P}_{\mathrm{PS}}(\mathrm{t})$ fonte de pressão suporte, $\mathrm{FC}(\mathrm{t})$ é a fonte de fluxo de ar constante. 
É valido salientar que nesse contexto os pulmões são tratados de maneira viscoelástica, onde cada um deles possui uma resistência e uma capacitância em série. Além disso, contempla-se uma resistência central referente à via aérea superior descrito pela variável $R_{a w}$.

Os autores focaram seus estudos em um único modo de ventilação, o volume controlado, ou seja, controla-se a pressão de ar emitida ao paciente a fim de lhe garantir um fluxo constante. Observa-se que o estudo se baseia em ciclos controlados. Dessa maneira, não há nenhum esforço espontâneo do recém-nascido.

A fim de gerar as equações de movimento do sistema utilizou-se a técnica de Bond Graphs, que de maneira resumida é uma representação gráfica de um sistema dinâmico que representa todas as trocas de energia do sistema. Com isso, pode-se calcular volumes, fluxos e pressões em cada pulmão e em regiões adicionais de interesse. As equações de movimento podem ser observadas abaixo, nas Equações (13) - (19).

$$
\dot{V}_{a w}=\frac{\frac{P S(t)}{R_{i n s}+R_{p s}}+\frac{F C(t)}{\left(1+\frac{R_{i n s}}{p s}\right)}-R_{e q}\left[\frac{V_{2}}{C_{2}}+R_{2} \dot{V}_{2}-P \operatorname{esp}(t)\right]}{1+R_{e q}\left(R_{e t}+R_{a w}\right)}
$$

$$
\dot{V}_{2}=\frac{\left\{\frac{V_{1}}{C_{1}}-\frac{V_{2}}{C_{2}}+R_{1}\left[\frac{\frac{P S(t)}{R_{i n s}+R_{p s}}+\frac{F C(t)}{\left(1+\frac{R_{i n s}}{p s}\right)}-R_{e q}\left[\frac{V_{2}}{C_{2}}+R_{2} \dot{V}_{2}-P e s p(t)\right]}{1+R_{e q}\left(R_{e t}+R_{a w}\right)}\right]\right\}}{R_{2}+R_{1}+R_{1} R_{1}\left(\frac{R_{e q}}{1+R_{e q}\left(R_{e t}+R_{a w}\right)}\right)}
$$




$$
\begin{gathered}
\dot{V}_{1}=\dot{V}_{a w}-\dot{V}_{2} \\
P_{a w}=R_{2} \dot{V}_{2}+\frac{V_{2}}{C_{2}}+\left(R_{e t}+R_{a w}\right) \dot{V}_{a w}-\operatorname{Pesp}(t) \\
P_{2}=\frac{V_{2}}{C_{2}} \\
R_{e q}=\frac{P_{1}=\frac{V_{1}}{C_{1}}}{R_{i n s}+R_{p s}}+\frac{1}{R_{\exp }}
\end{gathered}
$$

Importante salientar que as simulações foram feitas somente no âmbito computacional, ou seja, não houve um produto físico. Além disso, o foco no trabalho foi dado à pacientes adultos, e não em neonatos.

Dados os seguintes parâmetros foram usados: $\mathrm{R}_{\mathrm{aw}}=2 \mathrm{hPa} / \mathrm{Ls}^{-1} ; \mathrm{R}_{E T}=2 \mathrm{hPa} / \mathrm{Ls}^{-1}$ $\mathrm{R}_{1}=20 \mathrm{hPa} / \mathrm{Ls}^{-1} ; \mathrm{C}_{1}=0.025 \mathrm{~L} / \mathrm{hPa} ; \mathrm{R}_{2}=20 \mathrm{hPa} / \mathrm{Ls}^{-1} ; \mathrm{C}_{2}=0.025 \mathrm{~L} / \mathrm{hPa}$. Os resultados obtidos podem ser observados na Figura 2.29 abaixo: 

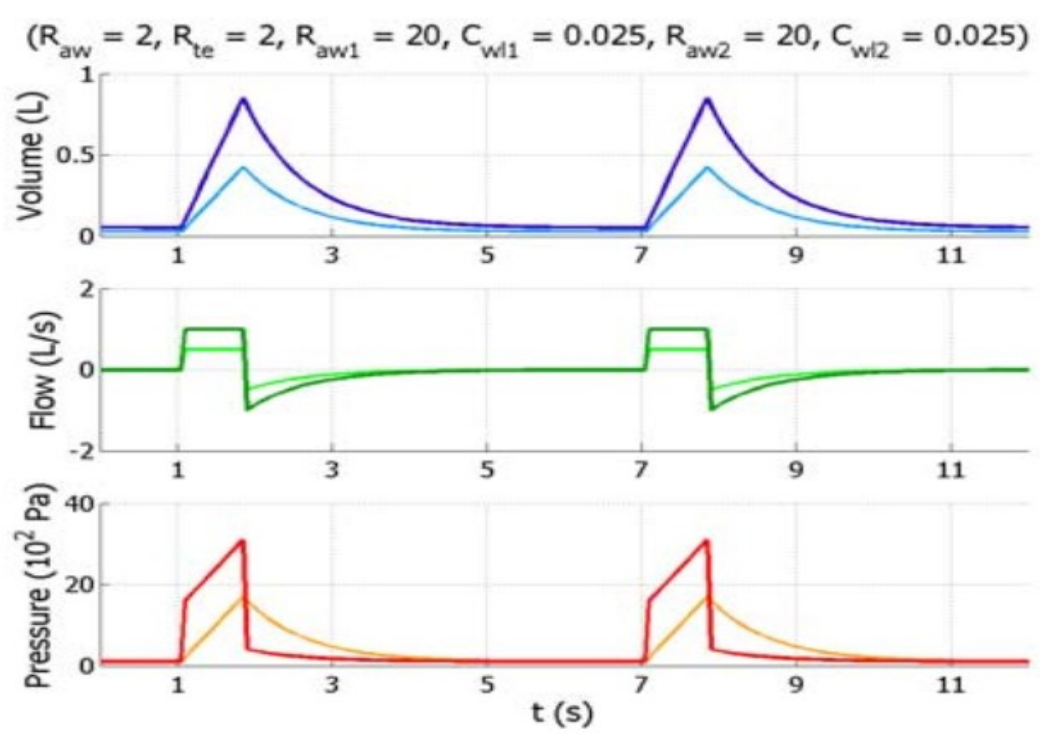

Figura 2.29 - alguns resultados obtidos por Lonardoni e Iwata para o modo de volume controlado, Dados os parâmetros acima mostrados. (Lonardoni, Iwata, \& Fleury, 2003)

Um detalhe que vale ressaltar é o fato de que o simulador foi desenvolvido em flash, uma linguagem de alto nível que permite a construção de interfaces gráficas de maneira prática.

\subsubsection{Simulador Mecânico respiratório de ventilação artificial}

O trabalho realizado por Schimidt (2003) consiste no desenvolvimento de um simulador respiratório capaz de emular algumas patologias, além de executar testes de função pulmonar. Para isso, foi utilizada uma abordagem de sistemas de controle, onde por via de um computador, um equipamento mecatrônico era controlado de forma a atuar semelhantemente ao sistema respiratório. Com isso, torna-se possível a simulação de propriedades estáticas e dinâmicas que podem ser ajustadas via software.

O modelo respiratório desenvolvido foi um monocompartimental, do tipo RC, de acordo com a Equação (11). Entretanto o diferencial do modelo vem do fato de incluir ao sistema propriedades não lineares, entre elas, a complacência estática não-linear, 
complacência dinâmica e resistência não-linear. Uma breve discussão é apresentada sobre cada termo.

Complacência Estática não-linear: esse termo foi incluído no estudo devido à grande variação de volume que o simulador pode emular. Foram utilizadas relações e expressões empíricas, juntamente com algumas simplificações para se obter a relação abaixo:

$$
V_{p u l}=C P_{A}+C R F
$$

Complacência Dinâmica: devido às propriedades de tecidos como pulmões e tórax, a complacência do sistema não pode ser descrita, de forma exata, somente pelo seu fator estático. Esses efeitos dinâmicos são incorporados usando modelos viscoelásticos, conforme a Figura 2.30.

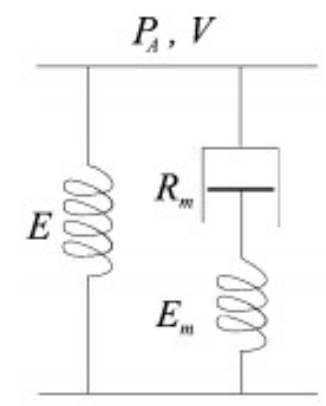

Figura 2.30 - Modelo viscolástico com elastância E, e o corpo de maxwell representado pela resistência, Rm e elastância, Em. (Schmidt, Foitzik, Hochmuth, \& Schmalisch, 2003)

Resistência das vias aéreas: nesse caso, como já explicado anteriormente, a resistência respiratória possui origem não linear no corpo humano, assim, considerouse a resistência como sendo dependente do fluxo de ar, de tal maneira que vale a Equação (21). 


$$
R=R_{o}+K_{V} V+K_{F}|\dot{V}|
$$

Onde, Kf e Kv são constantes arbitrárias. Note-se que a Equação (21) possui semelhança com a Equação (10).

A simulação e construção do modelo foram feitas em Simulink/Matlab, e pode ser observada na Figura 2.31 abaixo.

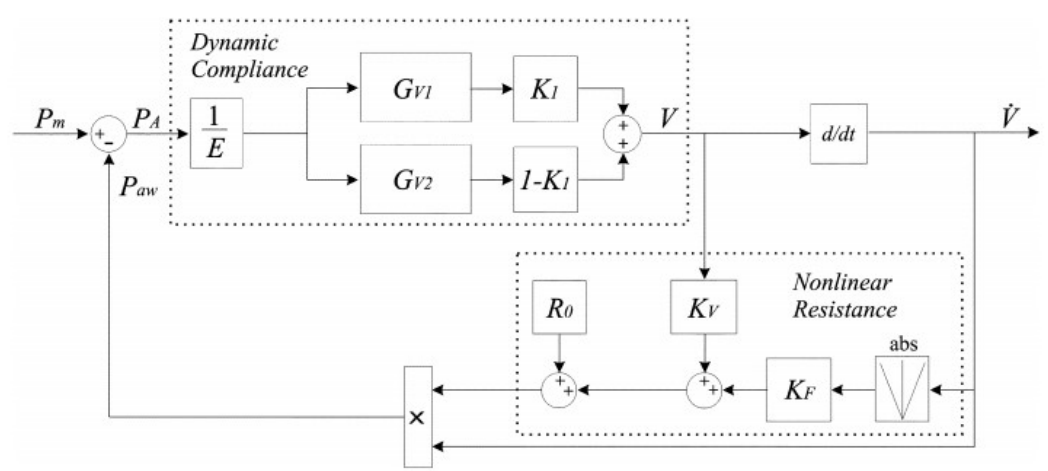

Figura 2.31 - Diagrama de bloco referente ao modelo descrito por Mesic. Note que é possível identificar 2 regiões distintas, uma relativa à complacência dinâmica e outra referente a resistência não linear. (Schmidt, Foitzik, Hochmuth, \& Schmalisch, 2003)

A planta desse simulador é constituída por um único compartimento na forma de pistão, onde a posição do pistão é controlada por alguns fatores, dentre eles um servo motor, um sistema de resistência de fluxo a ar e mais uma série de componentes eletrônicos a fim de obter os dados necessários para a implementação do sistema de controle. Um diagrama geral do sistema pode ser observado na Figura 2.32 


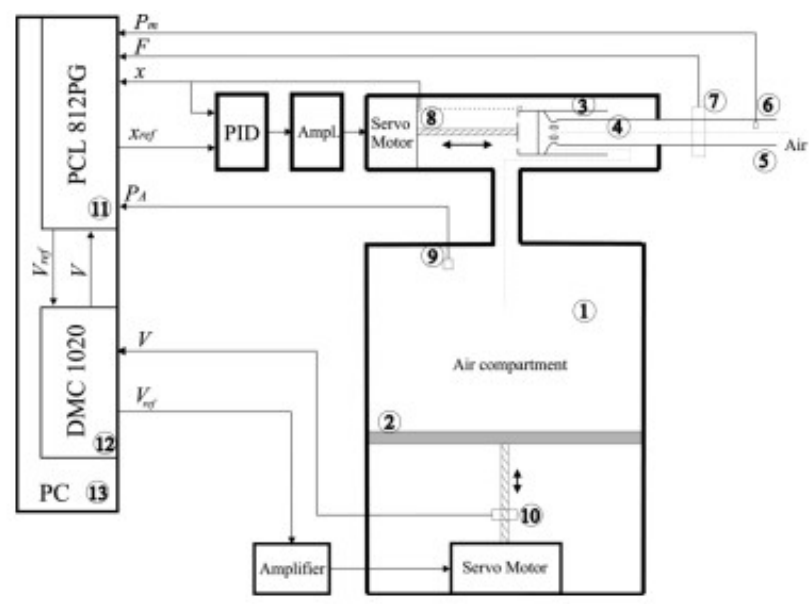

Figura 2.32 - Diagrama esquemático do simulador respiratório de Mesic. (Mesic, Babuska, Hoogsteden, \&Verbraak, 2003)

O compartimento de ar com o pistão tem função de simular o espaço alveolar e a elastância respiratória, onde a posição do pistão é controlada via um servo motor de acordo com a dinâmica respiratória do modelo estudado. A saída de ar do compartimento principal é ligada diretamente ao mecanismo de resistência do fluxo de ar que através de um sistema de um cilindro com furos em uma manga controla o fluxo de ar.

Um detalhe importante a se apontar é que o estudo identificou um significativo atraso no ciclo de controle de movimento do pistão, podendo causar oscilações e até mesmo a instabilidade. A fim de mitigar esses efeitos, um controlador baseado no preditor de Smith foi utilizado para o controle do movimento do pistão. Para fim de esclarecimento, o preditor de Smith é um tipo de controlador preditivo que pode modelar um significativo atraso devido à sua construção.

\subsubsection{MERESSINA}

Mechatronic respiratory system simulator for neonatal applications, ou então MERESSINA, é um dos simuladores neonatais mais modernos a se destacar na literatura, apresentado em 2015, que busca, através da utilização de mais 
compartimentos, permitindo uma emulação mais realista das patologias que causam a respiração não-uniforme em neonatos.

Para isso, o modelo baseia-se em uma representação pulmonar com 5 compartimentos, onde o pulmão direito possui 3 compartimentos e o pulmão esquerdo possui 2 compartimentos, de acordo com a anatomia humana, como foi apresentada nas secções anteriores.

Essa maneira de representar o sistema pulmonar permite a emulação da falta de uniformidade respiratória e das características pulmonares em cada compartimento, além de poder representarem as condições gerais de um barotrauma localizado e obstruções das vias aéreas.

Nota-se na Figura 2.33 que cada lobo pulmonar é representado por uma capacitância, e há também uma resistência linear para cada ramo principal do sistema. Sendo assim, é possível interpretar esse modelo como um circuito de 2 impedâncias em paralelo.
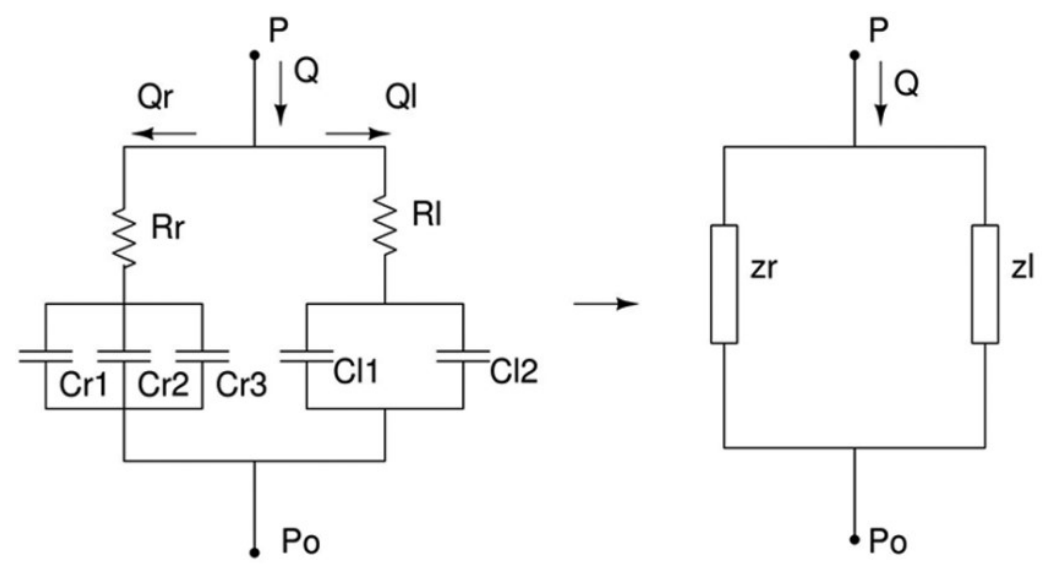

Figura 2.33 - a) Representação llustrativa do modelo respiratório de 5 compartimentos. b) Circuito equivalente com 2 impedâncias em paralelo. (Baldoli, et al., 2015)

Com isso, as seguintes equações podem ser obtidas:

$$
Z_{r s}=\left[R_{l}+\frac{1}{j \omega C_{l}}\right] \|\left[R_{r}+\frac{1}{j \omega C_{r}}\right]
$$


Desenvolvendo, tem-se:

$$
\begin{gathered}
\operatorname{Re}\left(Z_{r s}\right)=\frac{T_{1} C_{1}+T_{2} C_{2}+\omega^{2} T_{1} T_{2}\left(T_{1} C_{2}+T_{2} C_{1}\right)}{\omega^{2}\left(T_{1} C_{2}+T_{2} C_{1}\right)^{2}+\left(C_{1}+C_{2}\right)} \\
\operatorname{Im}\left(Z_{r s}\right)=-\frac{C_{1}+C_{2}+\omega^{2}\left(T_{1}^{2} C_{2}+T_{2}^{2} C_{1}\right)}{\omega\left[\omega^{2} C_{1}^{2} C_{2}^{2}\left(R_{1}+R_{2}\right)^{2}+\left(C_{1}+C_{2}\right)^{2}\right]}
\end{gathered}
$$

Onde:

$$
\begin{gathered}
\left\{\begin{array}{l}
T_{1}=R_{1} C_{1} \\
T_{2}=R_{2} C_{2}
\end{array}\right. \\
\left\{\begin{array}{l}
C_{1}=C_{r 1}+C_{r 2}+C_{r 3} \\
C_{2}=C_{l 1}+C_{l 2}
\end{array}\right.
\end{gathered}
$$

O MERESSINA foi desenvolvido para trabalharem 3 modos de simulação:

Simulador ativo: nesse caso é capaz de simular a respiração espontânea.

Simulador de ventilação controlada: o paciente possui uma respiração totalmente passiva, ou seja, a respiração é feita mecanicamente pelo ventilador; consequentemente, os ajustes para a configuração do padrão de ar injetado são diferentes. Os parâmetros principais nesse caso são: PIP, PEEP e CRF.

Ventilação assistida: inicialmente o infanto respira espontaneamente, porém, é assistido pelo ventilador mecânico a partir do ponto em que a pressão exercida pelo 
paciente ultrapassa um dado nível de disparo. O usuário impõe ao sistema os parâmetros como C, CRF, tempo de inspiração, VAC, assim como o modo de ventilação.

O nível de disparo (trigger), S, pode ser quantificado como sendo:

$$
S=P E E P+\triangle P
$$

Vale à pena salientar que o sincronismo entre ventilador e paciente é um tema de grandes esforços e estudos, uma vez que o mesmo pode beneficiar a respiração ou então diminuir sua eficiência e, com isso, pode ocasionar consequências mais sérias ao neonato.

Vale acrescentar que os dados e parâmetros utilizados para as simulações foram baseados em estudos em infantos com massa média de $3 \mathrm{~kg}$, segmentados em 2 grupos, o primeiro de infantos saudáveis e o segundo de recém-nascidos que possuem síndrome de desconforto respiratório (SDR).

A Figura 2.34 mostra como o GUI desse simulador foi construído, onde de maneira intuitiva, o usuário consegue impor várias características e parâmetros ao simulador, inclusive escolher algumas características físicas do paciente e qual a sua patologia.

Em relação ao equipamento, o protótipo MERESSINA é composto por 5 câmaras de ar com volume controlado, similar a um pistão, onde a posição de cada um dos pistões é controlada por servo motores lineares do modelo QUICKSHAFT $®$ LM2070-080-01. Cada câmara possui um diâmetro interno de $4 \mathrm{~mm}$, e está conectada a uma secção de resistência ao fluxo que é uma válvula capaz de modular o volume de ar que passa por ele. Vale destacar que o volume máximo das 5 seringas juntas totaliza $50 \mathrm{~mL}$, conforme pode ser observado nas Figura 2.35- 2.36. 


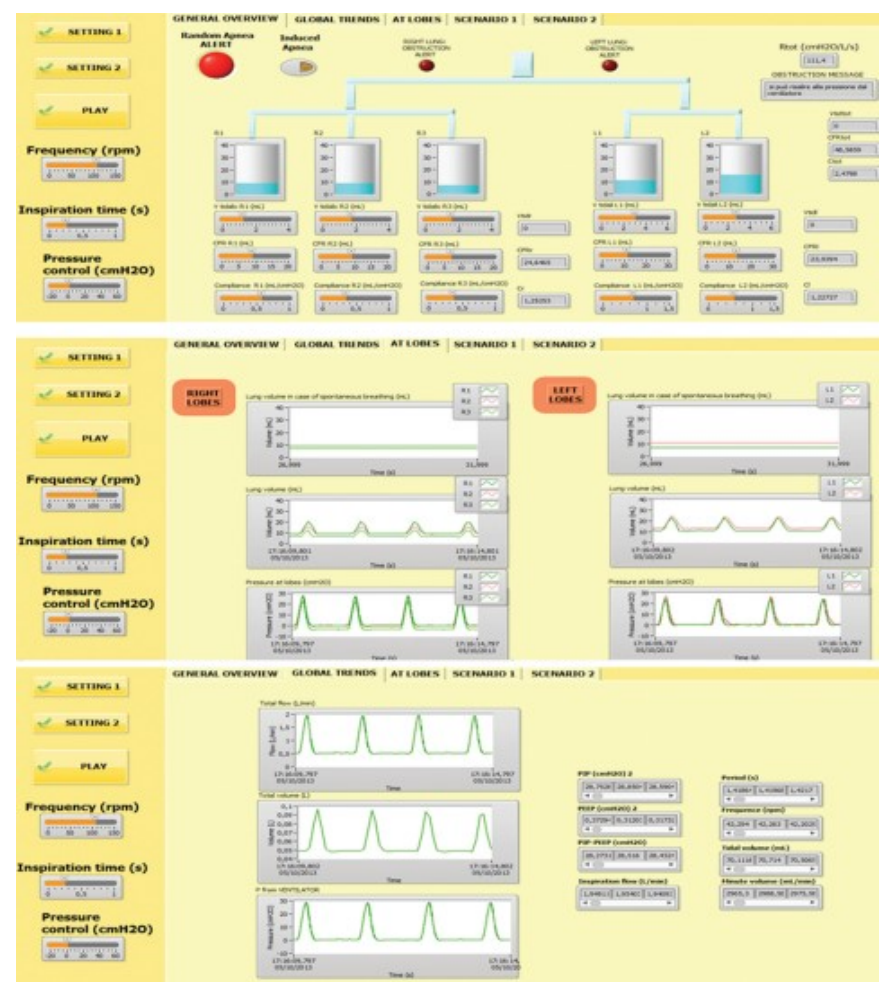

Figura 2.34 - GUI do simulador MERESSINA. (Baldoli, et al., 2015)

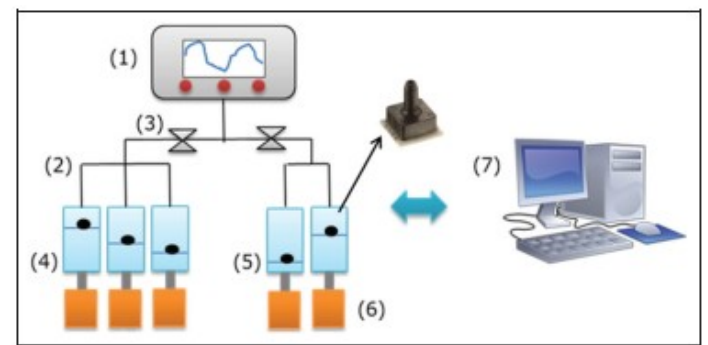

Figura 2.35 - Diagrama llustrativo do simulador respiratório neonatal (Baldoli, et al., 2015)

A instrumentação da planta é feita através de sensores de pressão dentro de cada uma das seringas, onde foram fixadas ao pistão. A aquisição dos dados é feita por um hardware multifunção da National Instruments ${ }^{\circledR}$ NI USB 6218 , e o processamento e o controle do sistema foram feitos via LabVIEW. 


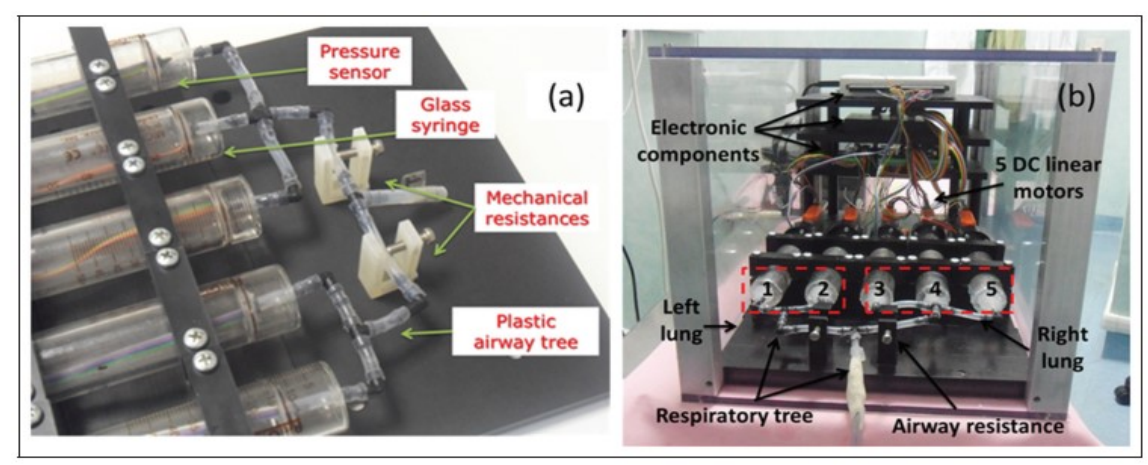

Figura 2.36 - Imagem do protótipo construído pelo trabalho. (Baldoli, et al., 2015)

\subsubsection{Simulador respiratório Híbrido de Infantos}

O mais recente dos simuladores respiratórios, Stankiewicz et al. (2017), projetou e construiu um protótipo de um simulador com o objetivo de emular respiração espontânea e ventilação artificial e assistida. O grande diferencial desse estudo é proveniente do foco a neonatos pré-termo e termos saudáveis, além da inclusão de alguns cenários através de diversas patologias.

Conforme se observa na Figura 2.37, o modelo implementado consiste em um modelo baseado em dois compartimentos pulmonares, onde cada compartimento alveolar é representado por um circuito RC. Além disso, são incluídos termos de inertância, resistência central e complacência do tórax, ou seja, é um dos modelos mais completos de sistemas respiratórios a ser implementado para simulação. Todas essas características permitem a emulação de diversas condições, como por exemplo, obstruções globais e perimetrais, não-homogeneidade pulmonar e a influência da variação da complacência do tórax de acordo com o envelhecimento. 


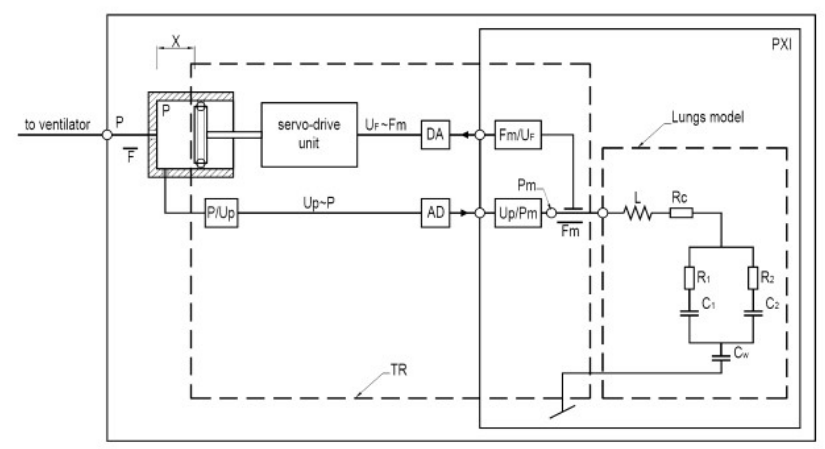

Figura 2.37 - Esquema llustrativo do simulador respiratório de Stankiewicz. (Stankiewicz, Palko, Darowski, Zielisnki, \& Kozarski, 2017)

O sistema respiratório foi modelado a partir de dois compartimentos pulmonares $\mathrm{RC}$, onde a introdução dos termos de resistência central é a diferença desse modelo para os outros já apresentados no presente trabalho. A modelagem foi desenvolvida via técnicas de impedância e, com isso, pode-se demonstrar o conjunto de Equações (26) como abaixo.

$$
\left\{\begin{array}{l}
Z_{R S}=\mathrm{Re}_{\text {total }}+X_{\text {total }} j \\
\mathrm{Re}_{\text {total }}=R_{c}+\frac{T_{2} C_{2}+T_{1} C_{1}+\omega^{2} T_{1} T_{2}\left(T_{1} C_{2}+T_{2} C_{1}\right)}{\omega^{2} C_{1}^{2} C_{2}^{2}\left(R_{1}+R_{2}\right)^{2}+\left(C_{1}+C_{2}\right)^{2}} \\
X_{\text {total }}=\omega I-\frac{1}{\omega C_{C T}}-\frac{C_{1}+C_{2}+\omega^{2}\left(T_{1}^{2} C_{2}+T_{2}^{2} C_{1}\right)}{\omega\left[\omega^{2} C_{1}^{2} C_{2}^{2}\left(R_{1}+R_{2}\right)^{2}+\left(C_{1}+C_{2}\right)^{2}\right]} \\
\omega=2 \pi f \\
\mid Z m=\sqrt{\mathrm{Re}_{\text {total }}^{2}+X_{\text {total }}^{2}} \\
T_{1}=R_{1} C_{1} \\
T_{2}=R_{2} C_{2}
\end{array}\right.
$$

Um conjunto complementar de Equações (27) é necessário para resolver o sistema de equações de forma completa. 


$$
\left\{\begin{array}{l}
\dot{V}_{\text {total }}=\frac{P m(t)}{\left|Z_{r s}\right|} \\
V_{i}=\int \dot{V}_{i} d t \\
I \dot{V}_{\text {total }}+R_{c} \dot{V}+R_{1} \dot{V}_{1}+\frac{V_{1}}{C_{1}}+\frac{V_{\text {total }}}{C_{C T}}=P_{b o c a} \\
\dot{V}_{\text {total }}=\dot{V}_{1}+\dot{V}_{2} \\
P_{\text {pleural }}=\frac{V_{\text {total }}}{C_{C T}} \\
P_{n}=\frac{V_{i}}{C_{n}}
\end{array}\right.
$$

Onde:

Zrs $\rightarrow$ Impedância do sistema respiratório;

$\mathrm{Re} \rightarrow$ Parte real da impedância;

$X \rightarrow$ Parte imaginária da impedância respiratória;

$L \rightarrow$ Indutância;

Rc $\rightarrow$ Resistência central;

$R_{1} \rightarrow$ Resistência perimetral para o lado direito;

$R_{2} \rightarrow$ Resistência perimetral para o lado esquerdo;

$C_{1} \rightarrow$ Complacência referente ao pulmão direito;

$C_{2} \rightarrow$ Complacência referente ao pulmão esquerdo;

$C_{C T} \rightarrow$ Complacência da caixa torácica;

$\mathrm{Pm} \rightarrow$ Pressão espontânea respiratória oriunda do diafragma;

$\dot{V}_{\text {todal }} \rightarrow$ Fluxo de ar total;

$\dot{V}_{1} \rightarrow$ Fluxo de ar referente ao ramo direito do sistema respiratório;

$\dot{V}_{2} \rightarrow$ Fluxo de ar referente ao ramo esquerdo do sistema respiratório. 
Como citado anteriormente, uma compilação de dados referentes a neonatos e os parâmetros respiratórios de acordo com cada situação foi coletado. Foram examinados os seguintes segmentos de pacientes:

- A termo saudáveis (sem patologias pré-existentes);

- Pré-termo de muito baixo peso (entre $1,5 \mathrm{Kg}$ e $1 \mathrm{Kg}$ ) com SRD;

- Pré-termo de muito baixo peso extubado com sucesso;

- Pré-termo de muito baixo peso extubado sem sucesso;

- Pré-termo de extremo baixo peso (menos de $1 \mathrm{Kg}$ ) sem sintomas de displasia bronco pulmonar (DBP);

- Pré-termo de extremo baixo peso (menos de $1 \mathrm{Kg}$ ) com displasia bronco pulmonar (Tipo 1 e 2);

Os dados podem ser observados nas Tabelas 3-4, abaixo:

Tabela 3 - Dados usados na simulação. Os cenários são segmentados em 2 grandes grupos, a termo e pré-termo. AT $\rightarrow$ a termo; ATp1 $\rightarrow$ a termo com maiores resistências e menores complacências; MBP ext $\rightarrow$ baixo peso com extubação realizada com sucesso; MBP F ext $\rightarrow$ baixo peso com falhas na extubação; EBP s/ DBP $\rightarrow$ extremo baixo peso sem broncodisplasia pulmonar; EBP c/ BDP $\rightarrow$ extremo baixo peso com broncodisplasia pulmonar. (Stankiewicz, Palko, Darowski, Zielisnki, \& Kozarski, 2017)

\begin{tabular}{|c|c|c|c|c|c|c|}
\hline \multirow{2}{*}{ Dados } & \multicolumn{2}{|c|}{ A Termo } & \multicolumn{4}{c|}{ Pré-termo } \\
\cline { 2 - 7 } & AT & ATp1* & MBP Ext & MBP F Ext & $\begin{array}{c}\text { EBP s/ } \\
\text { DBP }\end{array}$ & $\begin{array}{c}\text { EBP c/ } \\
\text { DBP }\end{array}$ \\
\hline Idade & $\begin{array}{c}6 \pm 1.5 \\
\text { (Meses) }\end{array}$ & $\begin{array}{c}6 \\
\text { (Meses) }\end{array}$ & $\begin{array}{c}13.5 \pm 5 \\
\text { (Dias) }\end{array}$ & $\begin{array}{c}17 \pm 8 \\
\text { (Dias) }\end{array}$ & $\begin{array}{c}5 \pm 2 \\
\text { (Dias) }\end{array}$ & $\begin{array}{c}6 \pm 1 \\
\text { (Dias) }\end{array}$ \\
\hline $\begin{array}{c}\text { Idade Gestacional } \\
\text { (Semanas) }\end{array}$ & $38 \pm 2$ & 39 & $29 \pm 2$ & $29 \pm 2$ & $\begin{array}{c}27.2 \pm \\
1.2\end{array}$ & $\begin{array}{c}25.5 \pm \\
1.2\end{array}$ \\
\hline Peso (Kg) & $4.5 \pm 1.5$ & 4.5 & $\begin{array}{c}1.241 \pm \\
0.262\end{array}$ & $\begin{array}{c}1.130 \pm \\
0.197\end{array}$ & $\begin{array}{c}0.820 \pm \\
1.2\end{array}$ & $\begin{array}{c}0.793 \pm \\
0.1\end{array}$ \\
\hline Quantidade & 7 & 1 & 35 & 16 & 21 & 25 \\
\hline Resistência (kPa s/L) & $8.5 \pm 3.7$ & $\begin{array}{c}11.1 \pm \\
0.7\end{array}$ & $17.7 \pm 2.6$ & $22.1 \pm 2.7$ & $\begin{array}{c}26.9 \pm \\
5.6\end{array}$ & $\begin{array}{c}34.8 \pm \\
9.3\end{array}$ \\
\hline Complacência (mL/Kpa) & $31 \pm 21$ & $13.2 \pm 1$ & $15.7 \pm 4$ & $10.5 \pm 2.7$ & $8.6 \pm 5$ & $6.7 \pm 2.7$ \\
\hline
\end{tabular}


Tabela 4 - Parâmetros do sistema respiratório utilizados na simulação. Note que os cenários abaixo são os mesmos da tabela 3, acima. (Stankiewicz, Palko, Darowski, Zielisnki, \& Kozarski, 2017)

\begin{tabular}{|c|c|c|c|c|c|c|c|}
\hline Grupo & $\begin{array}{c}\mathrm{Rc}(\mathrm{kPa} \\
\mathrm{s} / \mathrm{L})\end{array}$ & $\begin{array}{c}\mathrm{R} 1 \text { (kPa } \\
\mathrm{s} / \mathrm{L})\end{array}$ & $\begin{array}{c}\mathrm{R} 2 \text { (kPa } \\
\mathrm{s} / \mathrm{L})\end{array}$ & $\begin{array}{c}\mathrm{C} 1 \\
(\mathrm{~mL} / \mathrm{kPa})\end{array}$ & $\begin{array}{c}\mathrm{C} 2 \\
(\mathrm{~mL} / \mathrm{kPa})\end{array}$ & $\begin{array}{c}\mathrm{Cw} \\
(\mathrm{mL} / \mathrm{kPa})\end{array}$ & $\begin{array}{l}\mathrm{L}(\mathrm{kPa} \\
\left.\mathrm{s}^{2} / \mathrm{L}\right)\end{array}$ \\
\hline AT & 6.8 & 3.4 & 3.4 & 20.5 & 20.5 & 124 & 0.002 \\
\hline ATp1 & 8.9 & 4.4 & 4.4 & 8.8 & 8.8 & 52.8 & 0.002 \\
\hline $\begin{array}{c}\text { MBP } \\
\text { Ext }\end{array}$ & 14.2 & 7 & 7 & 9 & 9 & 89.4 & 0.002 \\
\hline $\begin{array}{c}\text { MBP F } \\
\text { Ext }\end{array}$ & 17.7 & 8.8 & 8.8 & 6.3 & 6.3 & 63 & 0.002 \\
\hline $\begin{array}{c}\text { EBP s/ } \\
\text { DBP }\end{array}$ & 21.5 & 10.8 & 10.8 & 5.2 & 5.2 & 51.6 & 0.002 \\
\hline $\begin{array}{c}\text { EBP c/ } \\
\text { DBP }\end{array}$ & 27.9 & 13.8 & 13.8 & 4 & 4 & 40.2 & 0.002 \\
\hline
\end{tabular}

Com isso, os autores realizaram algumas simulações em modo de ventilação assistida, com pressão controlada. A Figura 2.38 é dividida em 2 grupos: o primeiro, à esquerda, são neonatos pré-termo de extremo baixo peso sem sintomas de BDP e o segundo grupo, a direita, representa neonatos pré-termo com sintomas de BDP.Nota-se que, devido à patologia, o segundo grupo necessita de uma assistência ventilatória maior.

A planta do simulador é composta de um cilindro de $100 \mathrm{~mL}$ conectado a um pistão, onde sua posição é controlada via uma unidade servo-mecânica. O setup é composto pelos seguintes equipamentos: um transformador de impedância, uma placa de processamento e aquisição de dados, um monitor $\mathrm{CO} 2 \mathrm{MO}$ plus e um computador host, vide Figura 2.39 . 
EBP s/ BDP

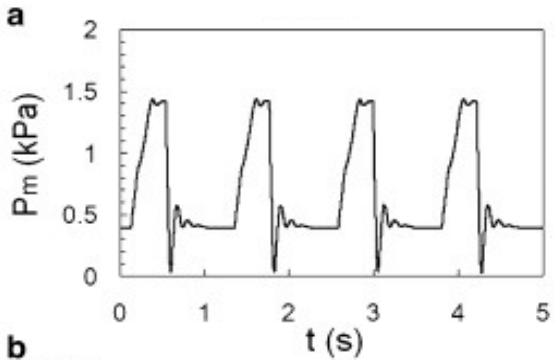

b
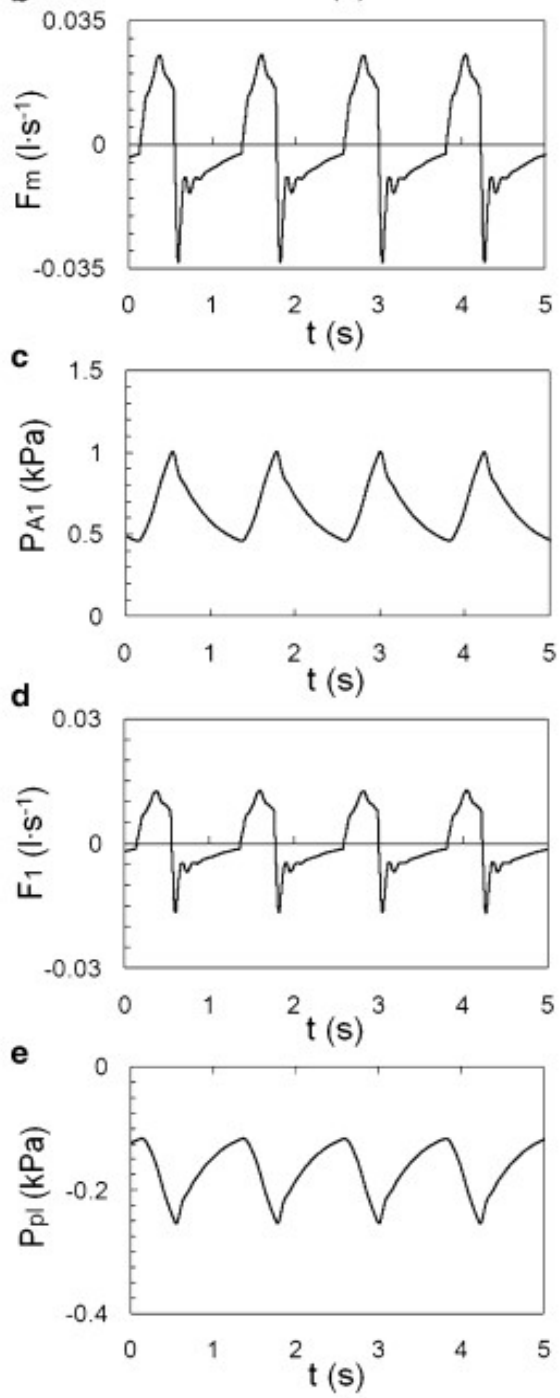

EBP c/ BDP
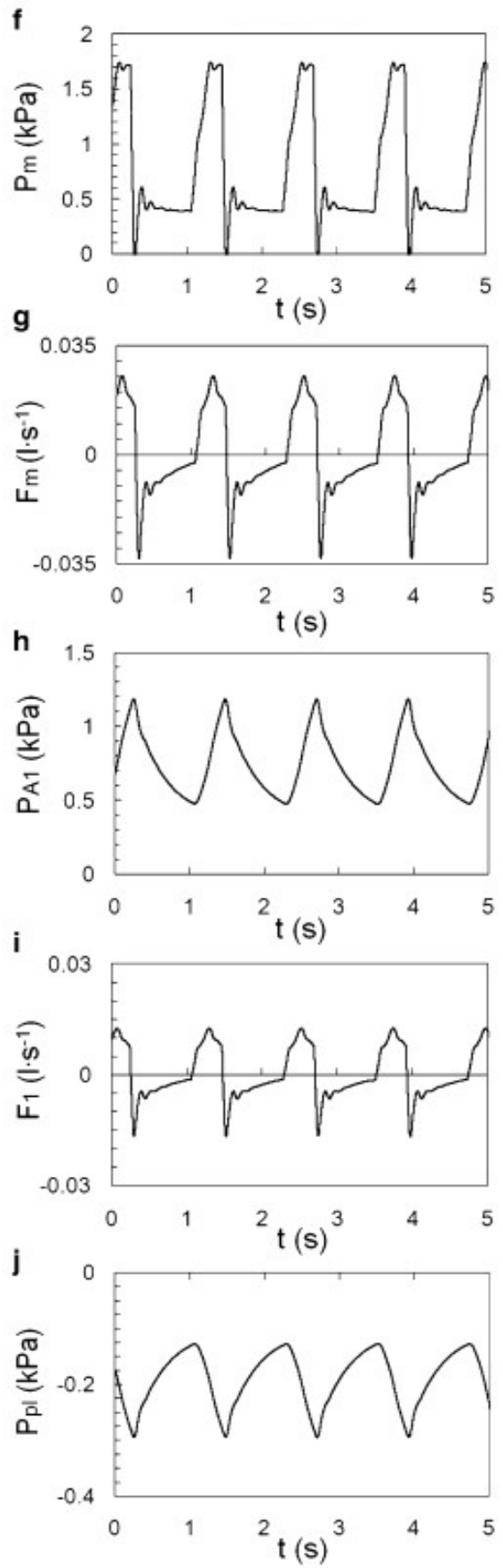

Figura 2.38 - Simulação de pressão e fluxos para os casos de R.N pré-termos: a) Sem sintomas de broncodisplasia pulmonar e b) Com sintomas broncodisplasia pulmonar .(Stankiewicz, Palko, Darowski, Zielisnki, \& Kozarski, 2017) 


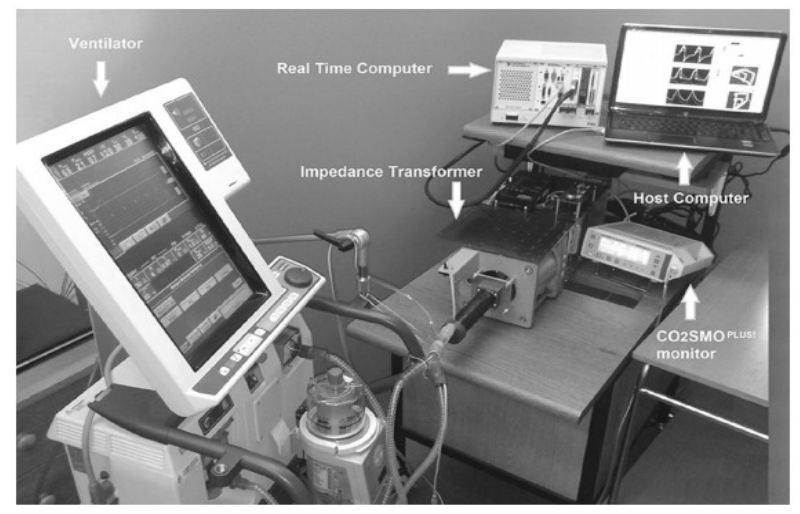

Figura 2.39 - Setup do simulador respirador neonatal. (Stankiewicz, Palko, Darowski, Zielisnki, \&Kozarski, 2017)

Os valores de pressão, Pm, e fluxo de ar, $\dot{V}_{\text {total }}$, do modelo, são calculados e processados pelo transformador de impedância, e assim converte-se esses sinais para a impedância da planta, ou seja, em termos de pressão, P e Fluxo de ar, F, da planta de simulação.

O transformador de impedância trabalha seguindo as seguintes Equações (27) abaixo:

$$
\left\{\begin{array}{l}
Z_{\text {sim }}=K_{c o n v} \cdot Z_{r s} \| Z_{x} \\
Z_{\text {sim }}=\frac{P}{F} \\
Z_{r s}=\frac{P_{m}}{\dot{V}_{\text {total }}}
\end{array}\right.
$$

Onde:

$K_{\text {conv }} \rightarrow$ Constante de conversão;

$Z_{\text {sim }} \rightarrow$ Impedância de entrada do simulador físico;

$Z_{r s} \rightarrow$ Impedância de entrada do modelo;

$Z x \rightarrow$ impedância do capacitor pneumático representando a complacência do gás dentro do pistão. 


\section{METODOLOGIA}

\subsection{Modelo do sistema respiratório}

Vistos os conceitos e ideias discutidos ao longo do presente trabalho, alguns pontos devem ser destacados em relação à respiração neonatal a fim de se construir um modelo matemático representativo.

Primeiramente, a mecânica ventilatória neonatal se baseia, majoritariamente, na movimentação do diafragma. Devido ao pouco desenvolvimento dos músculos intercostais, a expansão da caixa torácica não auxilia de maneira significativa na respiração. Tal fato pode ser traduzido, para analogia com circuitos elétricos, na utilização de uma única fonte de tensão elétrica, equivalente ao diafragma.

Outra característica importante é a frequência respiratória que um recémnascido pode apresentar. De maneira geral, situa-se na faixa de 50 a $80 \mathrm{cpm}$. Dessa forma, não é necessária a introdução de um termo relativo à inércia do ar e de tecidos.

Muitas das patologias que um recém-nascido possui ocasionam em respiração heterogênea, ou seja, regiões distintas do pulmão podem ter níveis de oxigenação diferentes. Consequentemente, se faz necessário a utilização de um modelo que apresente tais características, ou seja, um modelo multicompartimental pulmonar. No presente trabalho, apresenta-se um modelo inicial com 5 compartimentos ( 3 no pulmão direito e 2 no pulmão esquerdo) de acordo com a anatomia pulmonar, entretanto, podese entender também o seguinte modelo como sendo um modelo de 2 compartimentos (1 no pulmão direito e 1 no pulmão esquerdo), através de associações de capacitores em paralelo.

Dado os argumentos acima, o seguinte modelo é proposto: 

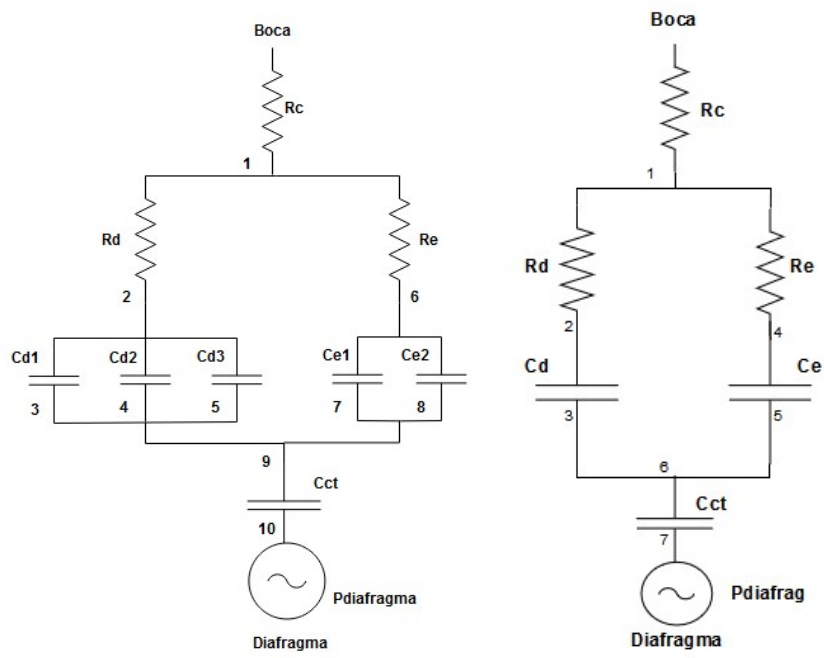

Figura 3.1- - Modelo respiratório proposto desenvolvido por analogia com sistemas elétricos. 3.1a - Modelo do sistema respiratório neonatal com 5 compartimentos. $3.1 \mathrm{~b}$ - Modelo do sistema respiratório neonatal com 2 compartimentos. (Autor)

As equações de movimento do sistema foram obtidas através da análise de impedância do sistema elétrico análogo. Assim, os seguintes sistemas de Equações (28)-(29) foram encontrados.

$$
\left\{\begin{array}{l}
Z_{R S}=\mathrm{Re}_{\text {total }}+X_{\text {total }} j \\
\operatorname{Re}_{\text {total }}=R_{c}+\frac{T_{E} C_{E}+T_{D} C_{D}+\omega^{2} T_{D} T_{E}\left(T_{D} C_{E}+T_{E} C_{D}\right)}{\omega^{2} C_{D}^{2} C_{E}^{2}\left(R_{D}+R_{E}\right)^{2}+\left(C_{E}+C_{E}\right)^{2}} \\
X_{\text {total }}=-\frac{1}{\omega C_{C T}}-\frac{C_{D}+C_{E}+\omega^{2}\left(T_{D}^{2} C_{E}+T_{E}^{2} C_{D}\right)}{\omega\left[\omega^{2} C_{D}^{2} C_{E}^{2}\left(R_{D}+R_{E}\right)^{2}+\left(C_{D}+C_{E}\right)^{2}\right]} \\
\omega=2 \pi f \\
|Z m|=\sqrt{\operatorname{Re}_{\text {total }}^{2}+X_{\text {total }}^{2}} \\
T_{D}=R_{D} C_{D} \\
T_{E}=R_{E} C_{E}
\end{array}\right.
$$


Além disso,

$$
\left\{\begin{array}{l}
\dot{V}_{\text {total }}=\frac{P m(t)}{\left|Z_{r s}\right|} \\
V_{i}=\int \dot{V}_{i} d t \\
R_{c} \dot{V}_{\text {total }}+R_{D} \dot{V}_{D}+\frac{V_{D}}{C_{D}}+\frac{V_{\text {total }}}{C_{C T}}=P_{\text {diafragma }}-P_{\text {boca }} \\
\dot{V}_{\text {total }}=\dot{V}_{D}+\dot{V}_{E} \\
P_{\text {pleural }}=\frac{V_{\text {total }}}{C_{C T}} \\
C_{d}=C_{d 1}+C_{d 2}+C_{d 3} \\
C_{e}=C_{e 1}+C_{e 2}
\end{array}\right.
$$

Onde:

Zrs $\rightarrow$ Impedância do sistema respiratório;

$\mathrm{Re} \rightarrow$ Parte real da impedância respiratória;

$X \rightarrow$ Parte imaginária da impedância respiratória;

$\mathrm{Rc} \rightarrow$ Resistência central;

$R_{d} \rightarrow$ Resistência perimetral para o lado direito;

$R_{e} \rightarrow$ Resistência perimetral para o lado esquerdo;

$C_{d} \rightarrow$ Complacência referente ao pulmão direito;

$C_{e} \rightarrow$ Complacência referente ao pulmão esquerdo;

$C_{w} \rightarrow$ Complacência da caixa torácica;

$\mathrm{Pm} \rightarrow$ Pressão espontânea respiratória oriunda do diafragma;

$\dot{V} \rightarrow$ Fluxo de ar total;

$\dot{V}_{1} \rightarrow$ Fluxo de ar referente ao ramo direito do sistema respiratório;

$\dot{V}_{2} \rightarrow$ Fluxo de ar referente ao ramo esquerdo do sistema respiratório. 
É válido acrescentar que o modo de ventilação simulado impacta o modelo respiratório, especificamente, no termo da fonte de tensão. Caso em modo espontâneo o fator que aciona a respiração é pressão diafragmática. Entretanto, quando nos modos controlado, a pressão que aciona a respiração é oriunda do ventilador mecânico. No presente estudo, a variável de controle do ventilador será a pressão, que será admitida constante ao longo de toda a fase inspiratória.

\subsection{Definição e modelagem da planta}

Além do alto custo dos simuladores respiratórios comerciais, como o ASL 500, uma característica que dificulta a simulação respiratória neonatal é a de se trabalhar com volumes e pressões relativamente baixos. Soma-se esse ponto ao fato de que os simuladores desenvolvidos emulam respiração de pessoas em uma faixa etária grande, desde neonatos a adolescentes e/ou até adultos. Como já citado anteriormente, há uma mudança relevante da capacidade pulmonar entre adultos e bebês. Note que, enquanto um recém-nascido a termo possui volume de ar corrente em torno de $21 \mathrm{~mL}$, adultos atingem, em média, $575 \mathrm{~mL}$. Portanto, equipamentos que emulam respiração de adultos tendem a não possuir alta precisão quando utilizado para respiração de RN.

Como o presente trabalho apresenta um foco evidente em respiração neonatal, foi escolhida uma planta de simulação na qual o volume seja adequado àqueles em recém-nascidos, consequentemente, capaz de obter o alto nível de precisão que outros simuladores comerciais não possuem.

Dentro do contexto descrito acima, o mecanismo de bomba de infusão (ou bomba de seringa) se mostrou, a princípio, ideal para a aplicação desse projeto, uma vez que consegue operar o equipamento na faixa de volume e vazão desejada, além de ser um mecanismo de relativa simplicidade em sua descrição física e em seu controle. (Pagatini, 2017) 
De maneira geral, o mecanismo de uma bomba de infusão é composto por uma seringa na qual o êmbolo é conectado a um fuso, que por sua vez é acionado pela rotação de um motor que pode ou não estar acoplado a uma caixa de engrenagens. Tal mecanismo pode ser observado na Figura 3.2.

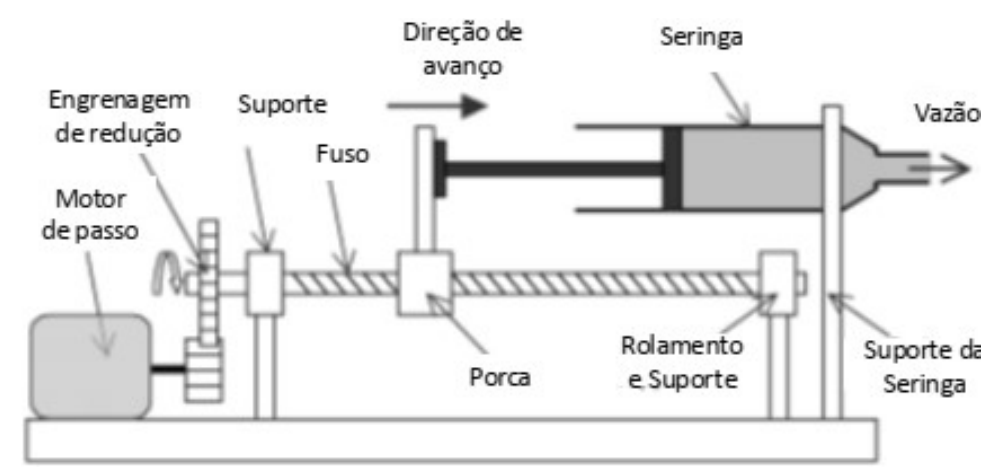

Figura 3.2 - Mecanismo bomba de infusão. (Pagatini, 2017)

O conjunto do simulador completo é composto por: um pistão (seringa), um reservatório de fluido (modo espontâneo), uma fonte de pressão externa (modo controlado) e um sistema de acionamento e controle. A movimentação do êmbolo é calculada através da malha de controle e acionada pelos motores. Devido ao deslocamento do êmbolo, gera-se um fluxo de ar que passa pelas mangueiras conectadas ao reservatório de ar/fonte de pressão. Observa-se que o fluxo de ar e a pressão que o pistão emite estão relacionados ao cálculo dessas variáveis no modelo respiratório neonatal. Dois esquemas ilustrativos descrevem os conjuntos acima são apresentados na Figura 3.3, representado o modo controlado e a Figura 3.4, representa o modo espontâneo. 


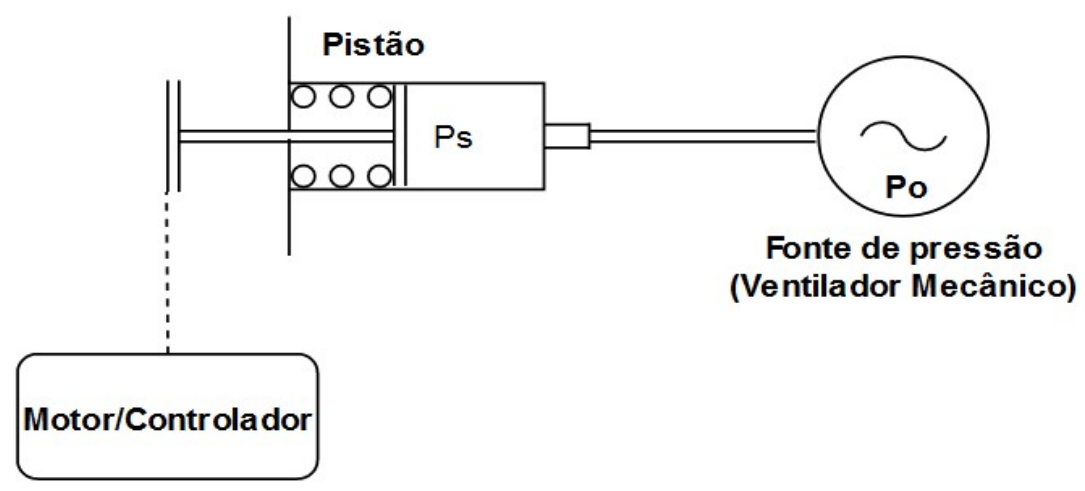

Figura 3.3 - Representação ilustrativa do conjunto simulador respiratório no tipo de ventilação controlada por pressão. O simulador é composto por 1 ou vários pistões contendo molas com dureza, Ks, um sistema de acionamento e controle do motor e uma fonte de pressão externa, que pode ou não ser um ventilador mecânica. (Autor)

É importante salientar nesse ponto, que a planta de simulação pode ser diferente dependendo do tipo de simulação que se quer realizar. Quando utilizado no tipo espontâneo, o pistão é conectado a um reservatório ar, como por exemplo, uma bexiga, Figura 3.4. Por outro lado, quando atuando no tipo controlado por pressão, o pistão estará conectado diretamente a uma fonte de pressão, conforme já ilustrado pela Figura 3.3. Tal diferença ocorre devido ao objetivo de cada tipo, no espontâneo, buscase fazer com que os usuários, identifiquem visualmente a diferença que as variações dos parâmetros respiratórios devido às patologias podem gerar nos fluxos e volumes de cada compartimento. Entretanto, no tipo controlado, o objetivo é reproduzir a pressão pulmonar do recém-nascido devido à interação do ventilador mecânico com o paciente.

Uma característica relevante de projeto é o material do êmbolo (pistão) e da seringa (cilindro). Caso utilizado o conjunto de uma seringa usual, ou seja, de material polimérico, o atrito causado pela frequência respiratória pode aquecer o equipamento, e, consequentemente pode deformá-lo, reduzindo a qualidade das simulações. A fim de evitar tal comportamento é necessário empregar materiais cujos fatores de atrito sejam baixos, e/ou então, que possuam alta condutividade térmica, e assim, transferir calor para o ambiente rapidamente. Dito isso, um material adequado para essa aplicação é um material metálico, como por exemplo, o alumínio. 


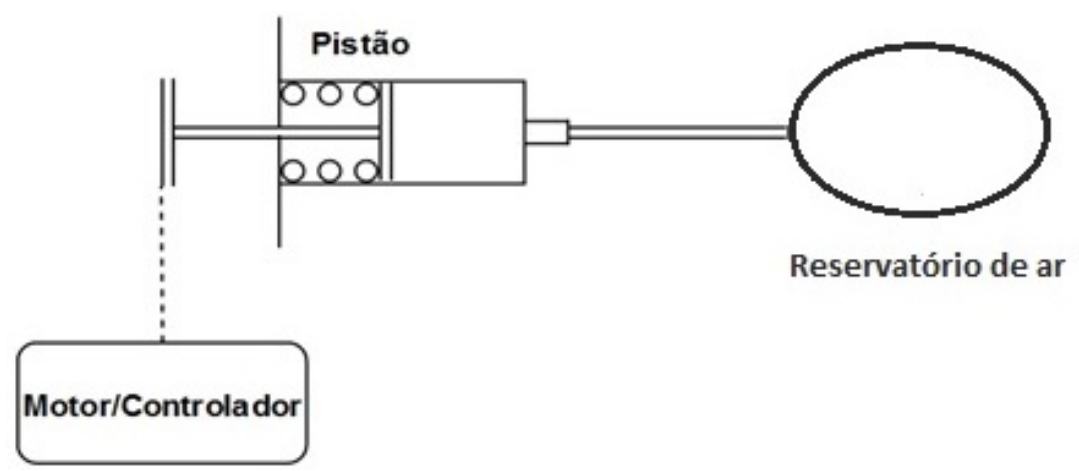

Figura 3.4 - Representação ilustrativa do conjunto simulador respiratório no tipo de ventilação espontânea, onde agora, a fonte de pressão é substituída por um reservatório de ar a fim de tornar a simulação mais visual para os seus usuários. (Autor)

No aspecto físico, pode-se descrever o mecanismo de bomba de infusão de acordo com a lei de conservação de massa, e assim determina-se a vazão de saída da seringa conforme a Equação (30).

$$
\dot{q}_{\text {seringa }}(t)=A_{\text {Seringa }} T \omega(t)=A_{\text {Seringa }} \dot{x}_{\text {pistão }}
$$

Onde:

$\dot{q}_{\text {seringa }}=$ Vazão de saída da seringa $\left[\mathrm{m}^{3} / \mathrm{s}\right]$;

$A_{\text {Seringa }}=$ Área referente ao corpo da seringa $\left[\mathrm{m}^{2}\right]$;

$T=$ Passo do fuso $[\mathrm{m} /$ volta $]$;

$\omega=$ Velocidade angular do fuso [voltas/s];

$\dot{x}_{\text {pistão }} \rightarrow$ Velocidade Linear do Pistão [m/s].

Nota-se que, com essa equação, torna-se possível relacionar diretamente a vazão da seringa ( $\left.\dot{q}_{\text {seringa }}\right)$ com a rotação do motor $(\omega)$. 
Para o modo respiratório de pressão controlada é necessário calcular a pressão de ar dentro da seringa, $P_{\text {seringa }}$. No entanto, para isso é necessário realizar algumas hipóteses e considerações. De acordo com o conhecimento obtido em relação aos fluxos e pressões da respiração em um neonato, as seguintes hipóteses e considerações foram pontuadas:

1 - Fluido incompressível;

2 - Diferença de pressão entre a saída da seringa e o interior da seringa é pequena;

3 - Escoamento laminar;

Admitindo as hipóteses acima se pode relacionar a vazão à diferença de pressão utilizando a Equação (31). (Merrit, 1991)

$$
\dot{q}_{\text {seringa }}=\frac{2 \delta^{2} D_{h} A_{o}}{\mu}\left(P_{o}-P_{\text {seringa }}\right)
$$

No qual:

$$
\begin{gathered}
C_{d}=\delta \sqrt{\text { Reynolds }} \\
\text { Reynolds }=\frac{\rho\left(q_{\max } / A_{o}\right) D_{h}}{\mu}
\end{gathered}
$$

Onde:

$\delta \rightarrow$ Coeficiente de escoamento laminar;

$D_{h} \rightarrow$ Diâmetro Hidráulico, que é o diâmetro do orifício [m];

$A_{o} \rightarrow$ Área referente ao orifício $\left[\mathrm{m}^{2}\right]$;

$\mathrm{Po} \rightarrow$ Pressão da fonte externa de pressão [KPa];

$P_{\text {seringa }} \rightarrow$ Pressão dentro da seringa [KPa]; 
$\mu \rightarrow$ Viscosidade dinâmica do ar a $20^{\circ} \mathrm{C}[\mathrm{Kg} / \mathrm{m} . \mathrm{s}]$;

$C_{d} \rightarrow$ Coeficiente de descarga.

Reynolds $\rightarrow$ Número de Reynolds, dado pela Equação (33)

$\rho \rightarrow$ Densidade do ar $\left[\mathrm{Kg} / \mathrm{m}^{3}\right]$.

Importante salientar que na ausência de informações adicionais sobre o coeficiente de descarga, $\mathrm{Cd}$, para quinas não arredondadas o mesmo pode ser considerado como sendo 0,61 .

Observa-se agora que é necessário relacionar a pressão da seringa com a pressão do reservatório de ar. Se tratado de maneira ideal, a variação de pressão dentro da seringa, Figura 3.5, pode ser descrita de maneira linear, de acordo com a Equação (34). (Kulakowski, Gardner, \& Shearer, 2007)

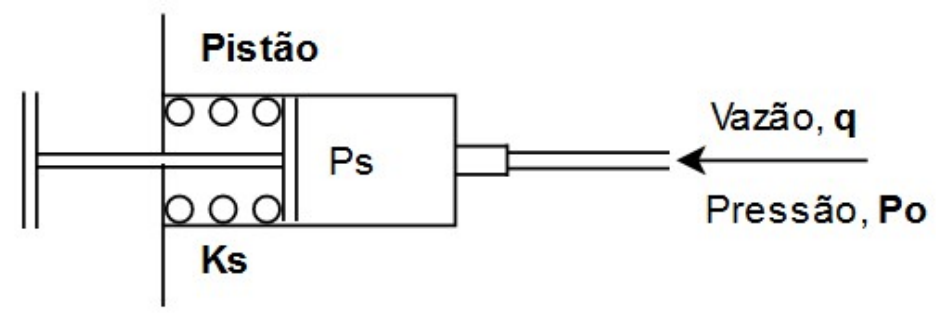

Figura 3.5 - Representação llustrativa de um capacitor de fluido. Adaptado de Kulakoswski, 2007

$$
\dot{q}_{\text {seringa }}=C_{f} \frac{d P_{r}}{d t}=C_{f} \dot{P}_{\text {seringa }}
$$

Onde:

$\dot{q}_{\text {seringa }} \rightarrow$ Fluxo de ar que entra/sai da seringa. $\left[\mathrm{m}^{3} / \mathrm{s}\right]$

Cf $\rightarrow$ Capacitância compartimento $\left[\mathrm{m}^{3} / \mathrm{KPa}\right]$; 
$\dot{P}_{\text {seringa }} \rightarrow$ Variação de pressão do reservatório em relação ao tempo. [KPa]

Note que para o reservatório de em questão, a complacência pode ser descrita em função da área do pistão e da rigidez da mola dentro da seringa, de acordo com a seguinte Equação (35) abaixo:

$$
C_{f}=\frac{A_{\text {seringa }}^{2}}{K_{\text {mola }}}
$$

Devido à lei de conservação de massa, a vazão que sai da seringa é a mesma que entra no reservatório de ar. Portanto, pode-se igualar a Equação (31) à (34).

$$
C_{f} \dot{P}_{r}=\frac{2 \delta^{2} D_{h} A_{o}}{\mu}\left(P_{i}-P_{r}\right)
$$

Rearranjando tem-se.

$$
\dot{P}_{\text {seringa }}=-\frac{2 \delta^{2} D_{h} A_{o}}{\mu C_{f}} P_{\text {seringa }}+\frac{2 \delta^{2} D_{h} A_{o}}{\mu C_{f}} P_{o}
$$

Nota-se que agora se pode determinar a pressão dentro da seringa de ar, o que será importante, principalmente durante do modo controlado do simulador.

Com a pressão do reservatório definida pode-se calcular o deslocamento necessário do pistão a fim de respeitar a Equação (35), utilizando para tal finalidade a Equação (30). 


\subsection{Projeto do sistema de controle}

Projeto de controle via variáveis de estado foi determinada como sendo a vertente utilizada para projetar o sistema de controle do presente trabalho. A abordagem de controle moderno possui certas vantagens sobre a clássica, tais como, trabalhar diretamente com equações diferenciais, em sua forma de variáveis de estado, além de facilitar a utilização de sistemas com vários de sinais de entrada e mais de uma variável observada (MIMO). (Friedland, 2012)

De maneira geral, pode-se escrever um sistema dinâmico da seguinte forma, vide sistema de Equações (36):

$$
\left\{\begin{array}{l}
\dot{x}(t)=A x(t)+B u(t) \\
y(t)=C x(t)
\end{array}\right.
$$

Onde:

$x(t) \rightarrow$ Vetor de estados do sistema;

$A, \mathrm{~B}$ e $\mathrm{C} \rightarrow$ São matrizes de parâmetros conhecidos sobre a dinâmica do sistema;

$\mathrm{u}(\mathrm{t}) \rightarrow$ Vetor de variável de entrada do sistema;

$y(t) \rightarrow$ Vetor de observação;

Uma vez verificadas a controlabilidade e a observabilidade do sistema, pode-se implementar um projeto de controle a malha, onde agora o sinal de entrada deverá garantir a estabilidade e convergência do sistema de acordo com a lei de controle, Equação (37).

$$
u(t)=-K_{c t r} x(t)
$$


Onde, o ganho $K_{c t r}$ é um ganho que depende da estratégia de controle do projeto. Como a equação de movimento para a planta é linear, as estratégias de controle mais utilizadas para tal abordagem são: alocação de polos e LQR, no qual a última é uma estratégia de controle baseada na otimização de um funcional que envolve precisão e consumo de energia de controle.

Para seguir as referências dadas pelo modelo do sistema, é inserido à lei de controle um termo referente ao sinal de referência. Com isso uma nova lei de controle pode ser obtida.

$$
u(t)=\text { referência }-K_{c t r} x(t)
$$

Ao ser calculado na malha de controle, a variável $u(t)$ é utilizada para determinar o novo vetor de estados do sistema. Em aplicação real, sensores determinam o valor das variáveis de controle que serão comparadas com a referência, gerando assim um erro, Equação (39).

$$
\operatorname{erro}(t)=\text { referência }-x(t)
$$

O objetivo do sistema de controle é que ao longo dos ciclos, o erro do sistema tenda a 0 (zero), ou seja, erro(t) $\rightarrow 0$. Consequentemente, a planta segue o modelo de referência sem quaisquer erros. Note que em geral estes desvios não chegam à zero. Constantemente, engenheiros determinam um patamar aceitável de erro que o sistema pode suportar, por exemplo, $\pm 5 \%$ de desvio do modelo. A fim de clarificar o funcionamento da malha de controle, o seguinte diagrama de blocos é apresentado, Figura 3.6 


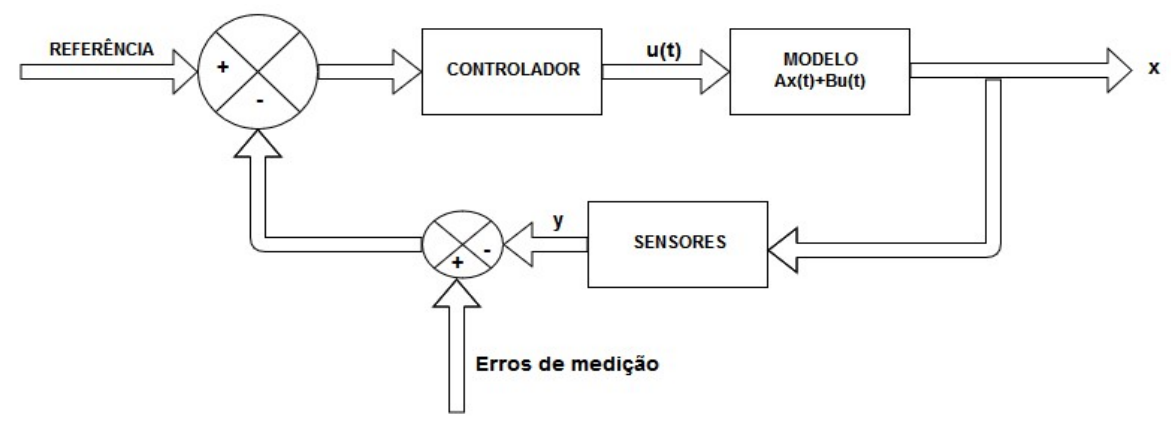

Figura 3.6 - Diagrama de blocos relativo ao projeto de controle via variáveis de estado. (Autor)

As estratégias de controle citadas acima acarretam erros em regime permanente em relação ao sinal de referência. Para mitigar essas complicações é preciso modificar as leis de controle, de tal forma que garanta uma ação de controle que anule esse tipo de erro na variável observada. Com isso, o seguinte sistema de equações matriciais deve ser resolvido. (Franklin, Powell, \& Emami-naeini, 2002)

$$
\left[\begin{array}{ll}
A & B \\
C & D
\end{array}\right]\left[\begin{array}{l}
N_{x} \\
N_{u}
\end{array}\right]=\left[\begin{array}{l}
1 \\
0
\end{array}\right]
$$

Resolve-se o sistema para $\mathrm{Nx}$ e $\mathrm{Nu}$, e assim constrói-se uma nova lei de controle, conforme a Equação (41).

$$
u(t)=-K_{c t r} x(t)+\left(K N_{x}+N_{u}\right) x_{r e f}
$$

Nota-se que o segundo termo da Equação (42) é uma pré-alimentação da malha de controle.

Faz-se necessário agora, elucidar de maneira detalhada o funcionamento do modelo, incluindo a malha de controle. Importante citar que para cada modo de ventilação há um modelo diferente, ou ao menos, uma troca do vetor de referência que 
irá alimentar o sistema de controle. Com isso, uma concisa explicação sobre funcionamento em cada modo será feita adiante.

Como já explicitado anteriormente, o simulador respiratório tem a função de simular a respiração de um neonato espontaneamente e simular a respiração de um neonato quando utilizando assistência respiratória de um ventilador mecânico. Abaixo segue uma cuidadosa explicação sobre os dois modos de funcionamento do simulador respiratório.

\subsubsection{Modo espontâneo}

Nesse modo não há intervenção de um ventilador mecânico, logo, todo o ciclo respiratório é baseado no esforço muscular diafragmático do recém-nascido. O objetivo do simulador nesse modo é fazer com que a seringa se comporte de acordo com o modelo respiratório, Equações (28-29), ou seja, que os fluxos e volumes respiratórios da planta de simulação sejam os mesmo do modelo respiratório.

É válido destacar que as seringas podem ser conectadas a reservatórios de ar, como por exemplo balões de ar, a fim de tornar a simulação mais visuais para os usuários.

O processo de simulação pode ser explicitado nos seguintes passos abaixo:

1. O modelo de esforço diafragmático de Kaye (1997) é utilizado como sinal de entrada para o modelo respiratório, Equações (28-29);

2. O modelo respiratório determina o fluxo e volume de referência que a planta deve seguir;

3. O fluxo de ar pulmonar é introduzido na Equação (30) de maneira direta para determinar a velocidade, e consequentemente, a posição do pistão;

4. Caso, o simulador esteja trabalhando com os 5 compartimentos, cálculos adicionais serão realizados a fim de determinar os deslocamentos de cada 
um dos 5 pistões, de maneira individual respeitando o modelo respiratório. Conforme a Figura 3.7.

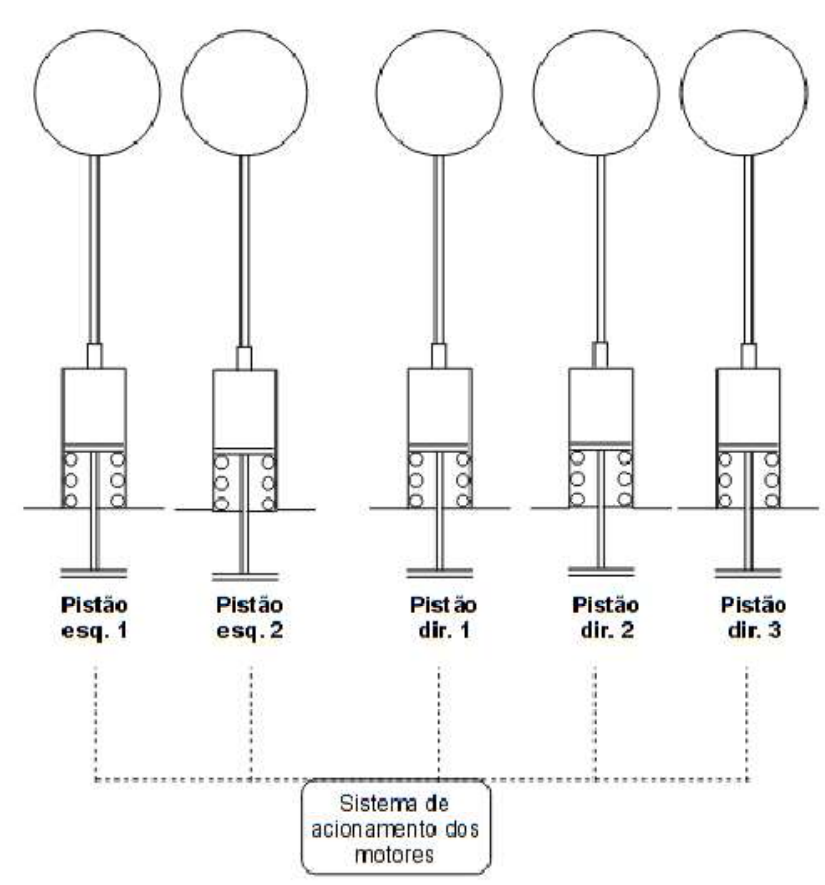

Figura 3.7 - Representação llustrativa da planta de simulação com 5 seringas sendo controladas através do sistema de acionamento dos motores. (Autor)

Observa-se que no modo espontâneo não há sistema de controle. A atuação do motor é estabelecida de maneira direta através da Equação (30). Outra ponderação que pode ser feita é em relação à variável de "controle". Note que para esse modo, volumes e fluxos são as variáveis mais relevantes, uma vez que a simulação busca reproduzir a respiração espontânea.

Em uma aplicação real, se faz necessário acompanhar o erro que o sistema pode acumular ao longo de seu funcionamento, para o que se fazem necessários sensores. Esse erro pode ser verificado através da Equação (43) abaixo.

$$
e(t)=V_{\text {referencia }}-V_{\text {planta }}
$$


Nota-se que para a utilização da Equação (43) em uma aplicação real, se faz necessária a instalação de sensores de fluxo na saída de cada seringa.

\subsubsection{Modo controlado}

Diferentemente do modo espontâneo, o ventilador mecânico inicia e controla a fase de inspiração do ciclo respiratório através da emissão de uma pressão de ar para o infanto. Entretanto, durante a fase expiratória, o ventilador para de emitir ar, permitindo assim, que o relaxamento muscular do paciente faça a exalação de maneira autônoma. Observa-se então que agora, o modelo respiratório será alimentado pelo sinal de pressão do ventilador, na fase inspiratória, e pelo relaxamento muscular (Kaye, 1997) durante a fase expiratória. As simulações nesse modo serão implementadas com pressão constante, ou seja, durante um determinado tempo, o ventilador mecânico emite uma pressão constante de ar para o paciente.

Para facilitar o entendimento nesse modo, é possível fazer uma analogia entre a planta de simulação e o sistema respiratório. O pistão pode ser comparado ao diafragma, o êmbolo da seringa é análogo ao espaço alveolar, a seringa é análoga a traquéia e as vias aéreas centrais, e a fonte de pressão externa é o ventilador mecânico.

Nesse modo, como já observado na Figura 3.3, a seringa(s) são conectadas a uma bomba externa. A pressão emitida por esse equipamento será a variável de entrada do sistema de controle, $\mathrm{u}(\mathrm{t})$.

É importante salientar que a planta de simulação durante o modo pressão controlada pode ter 5 compartimentos conforme o modelo, ou então, somente um compartimento, uma vez que, nesse modo, apenas o volume total injetado de ar é importante para o respirador. O volume injetado é a integral no tempo da vazão, que 
está diretamente relacionada à pressão do reservatório, $P_{\text {seringa }}$, através da Equação (34).

Pode-se dividir o procedimento em modo controlado em 2 fases:

\section{Fase inspiratória:}

a) A pressão emitida pelo ventilador mecânico serve de entrada para o modelo respiratório, Equação (28-29);

b) $\mathrm{O}$ modelo respiratório determina a pressão pulmonar de referência que a planta deve seguir;

c) A pressão pulmonar de referência é introduzida à malha de controle, Figura 3.4, onde em seguida é calculado o erro, e(t), Equação (43);

d) Através da técnica de controle escolhida, alocação de polos, calcula-se a pressão da fonte de pressão e o deslocamento do pistão para que a pressão pulmonar de referência determinada pelo modelo respiratório seja semelhante à pressão dentro da seringa.

\section{Fase expiratória:}

a) O modelo de esforço diafragmático de Kaye (1997) é utilizado como sinal de entrada para a fase expiratória do modelo respiratório, Equações (28-29);

b) $\mathrm{O}$ modelo respiratório determina a pressão pulmonar de referência que a planta deve seguir;

c) A pressão pulmonar de referência é introduzida à malha de controle, Figura 3.4, onde, em seguida, é calculado o erro, e(t), Equação (44);

e) Através da técnica de controle escolhida, alocação de polos, calcula-se a pressão da fonte de pressão e o deslocamento do pistão para que a pressão pulmonar de referência determinada pelo modelo respiratório seja semelhante à pressão dentro da seringa.

Caso a simulação para o modo controlado por pressão seja realizado com 5 compartimentemos, tem-se o seguinte arranjo de equipamentos, conforme a Figura 3.8. 


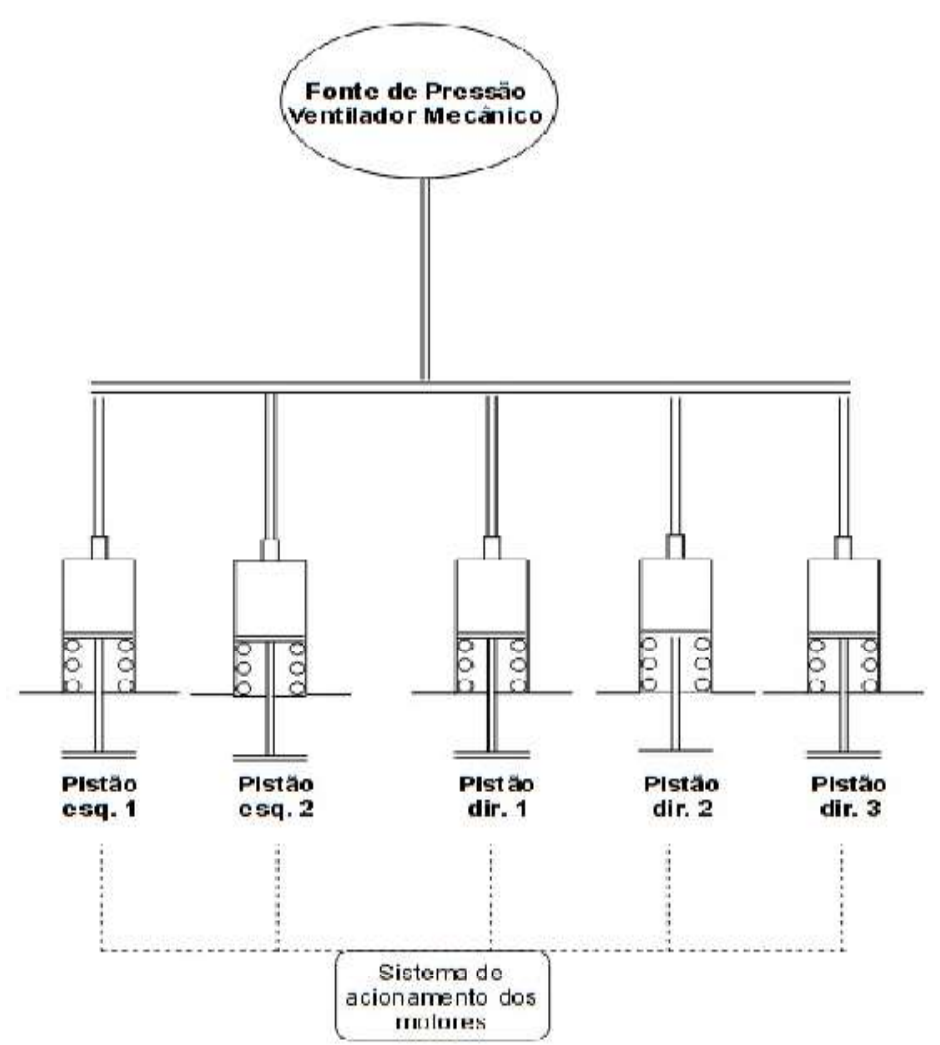

Figura 3.8 - Representação llustrativa da planta de simulação com 5 seringas sendo controladas através do sistema de acionamento dos motores no tipo de ventilação controlada por pressão constate. Observa-se que as seringas estão conectadas a uma fonte de pressão simulando um ventilador mecânico. (Autor)

A equação da planta de simulação é dada pela Equação (35) que, escrita em variáveis de estado, leva às seguintes relações: 


$$
\left\{\begin{array}{l}
\dot{x}=\dot{P}_{\text {seringa }} \\
x=P_{\text {seringa }} \\
u(t)=P_{o} \\
A=-\frac{2 \delta^{2} D_{h} A_{o}}{\mu C_{f}} \\
B=\frac{2 \delta^{2} D_{h} A_{o}}{\mu C_{f}} \\
C=1
\end{array}\right.
$$

É possível notar que a variável controlada é a pressão de ar dentro da seringa, $P_{\text {seringa }}$, logo, para a implementação real desse sistema é necessário utilizar sensores de pressão dentro desse componente.

A fim de acompanhar os desvios da planta de simulação em relação ao modelo, a Equação (45) pode ser utilizada.

$$
e(t)=P_{\text {referência }}-P_{\text {seringa }}
$$

\subsection{Sensoriamento}

Com o sistema de controle projetado é possível observar que o volume (no modo espontâneo) e a pressão da seringa (no modo controlado) são as únicas variáveis para os quais seus monitoramentos são obrigatórios. Portanto, para o todo o projeto é necessário o monitoramento de 2 grandezas, o fluxo/volume da seringa e a pressão do reservatório.

Com o intuito de enriquecer o presente trabalho, alternativas para o sensoriamento do fluxo e pressão são apresentadas abaixo, incluindo exemplos de produtos que podem executar essa função. 


\subsubsection{Medição do fluxo de ar}

Existem 3 maneiras principais de se medir a vazão de ar em locais com pouco espaço e/ou com baixas vazões.

\section{- Sensores de vazão:}

De maneira geral é a opção mais prática para implementação, porém custosa financeiramente. Como a aplicação do presente trabalho enfoca vazões baixas, os sensores que possuem precisão necessária pra trabalhar nessa faixa de operação são de alta sensibilidade, consequentemente mais caros. Um exemplo para essa classe de sensores é o TSI OEM Mass Flow Sensor 840205, apresentado na Figura 3.9

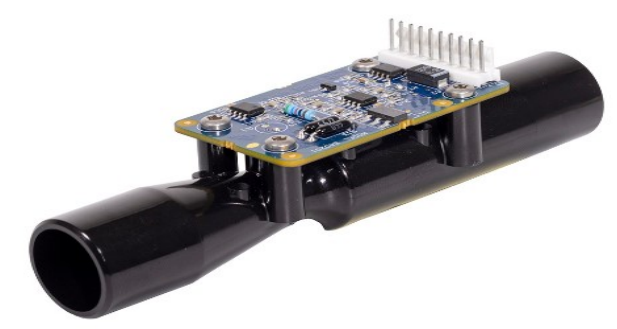

Figura 3.9 - Sensor de medição de vazão mássica de ar OEM Mass Flow Sensor 840205 da TSI. (TSI Incorporated, 2020)

\section{- Anemometria térmica}

É uma técnica amplamente utilizada para mensurar a velocidade instantânea de um fluido em escoamento. O método consiste na conversão da perda de calor por convecção de uma sonda em tensão elétrica. Quanto maior o fluxo de ar maior a perda de calor na sonda e vice-versa (Hodson, 2020). Por ser muito utilizada, essa opção é financeiramente mais viável que a anterior, entretanto, a diferença não é significativa. Por outro lado, devido à utilização de uma sonda não são necessários espaços amplos para sua implementação. 


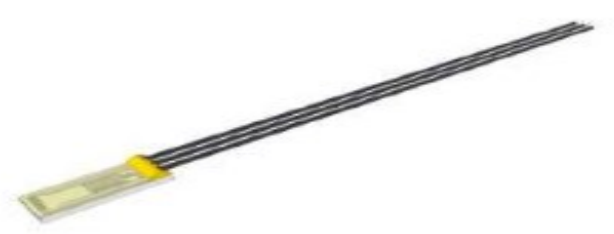

Figura 3.10 - Sensor térmico e de vazão mássica FS5 da IST. (IST - Innovative Sensor Technology, 2020)

\section{- Sensores de pressão e de gradientes de pressão}

Esse método consiste em uma medição indireta da vazão através do conhecimento da queda de pressão entre dois pontos. Naturalmente, como já discutido na equação da resistência ao fluxo, Equação (1), é necessário conhecer a resistência do local de medição, e tal tarefa é geralmente executada por um processo de calibração. Há 2 possibilidades de sensoriamento: a utilização de 2 sensores de pressão individuais ou a utilização de um único sensor com 2 bornes que calcula a queda de pressão de maneira automática. Por exemplo, tem-se o sensor de pressão e temperatura da Bosch BMP180, Figura 3.9a e o sensor de gradiente de pressão AMS5915-0100-D da National Controle Devices®, Figura 3.9b.
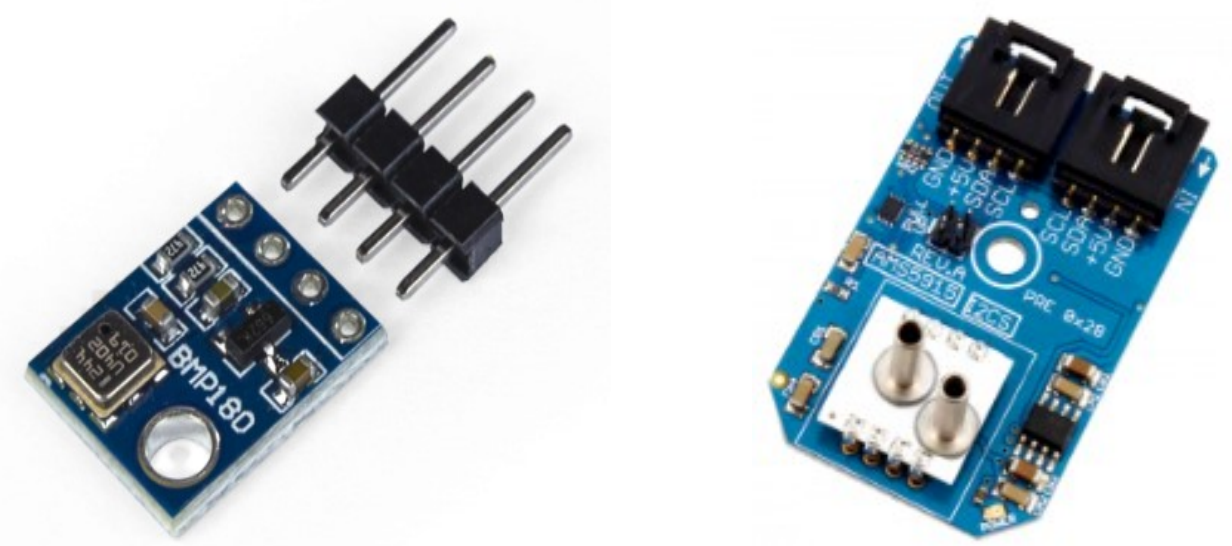

Figura 3.11 - a) Sensor de temperatura e pressão Bosch BMP180. b) Sensor de gradiente de pressão AMS5915-0100-D da NCD®

Nota-se que ambos os sensores trabalham dentro da faixa de pressão absoluta para sua implementação no trabalho. 


\subsubsection{Medição de pressão}

Evidentemente, aqui serão recomendados os mesmos tipos de sensores de pressão da seção anterior.

É importante ressaltar que a escolha adequada de um sensor em relação aos outros dependerá de uma avaliação prática, pois é necessário conhecer a placa de processamento e a forma de comunicação entre os sensores e o processador. Além disso, a construção geométrica do produto final pode restringir a utilização de um sensor perante o outro. 


\section{RESULTADOS}

Os resultados das simulações são apresentados a seguir, onde os mesmos foram segmentados de acordo com o tipo de ventilação. Cada modo irá exibir cenários diferentes referentes às patologias e condições críticas pré-determinadas. Importante salientar que os valores dos parâmetros de cada situação baseiam-se na literatura.

Diferentemente dos parâmetros respiratórios, as características físicas e alguns parâmetros do modelo da planta permanecem os mesmos durante todas as experimentações. Com isso, a Tabela 5 explicita os parâmetros gerais da planta e seus respectivos valores.

Tabela 5 - Parâmetros da planta para as simulações. (Autor)

\begin{tabular}{|c|c|c|c|c|c|}
\hline \multicolumn{7}{|c|}{ PARÂMETROS DA PLANTA } \\
\hline Parâmetro & D1 (mm) & D2 (mm) & Cd & Cf (m $\left.\mathbf{m}^{\mathbf{3}} / \mathbf{k P a}\right)$ & T (m/volta) \\
\hline & 26.89 & 5.0 & 0.61 & $3.5 \mathrm{e} 10-5$ & 0.08 \\
\hline
\end{tabular}

É válido ressaltar que apesar da pressão pulmonar ser negativa durante a fase inspiratória, os resultados aqui apresentados exibem a pressão pulmonar como positiva, com o intuito de compatibilizar os gráficos com os encontrados em ventiladores mecânicos encontrados no mercado, tornando-se, assim, mais eficientes para o treinamento dos profissionais.

A complacência da seringa, Cf, foi inicialmente arbitrada de modo à ser semelhante a dos pulmões dos neonatos, dessa forma, sendo possível uma comparação direta com os resultados do modelo respiratório.

Além disso, um parâmetro importante que se permanece o mesmo durante as simulações é o tempo de inspiração, no presente trabalho, tal parâmetro será 
semelhante do simulador MERESSINA (Baldoli, et al., 2015), onde o tempo de inspiração foi escolhido como sendo 0,35.

Com os parâmetros gerais da planta identificados e especificados podem-se apresentar os resultados.

\subsection{Modo espontâneo}

Como já explicado anteriormente, a respiração espontânea é um processo que se inicia na contração dos músculos que consequentemente causam a expansão dos pulmões. Portanto, para simular esse processo é necessária a introdução de um sinal de entrada referente aos esforços dos músculos diafragmáticos. Para tal papel, a função matemática escolhida foi o quarto de seno, introduzida por Kaye (1997), representada aqui na Figura 4.1, onde o mesmo busca emular o esforço diafragmático de um paciente durante a respiração basal espontânea. (Kaye, 1997)

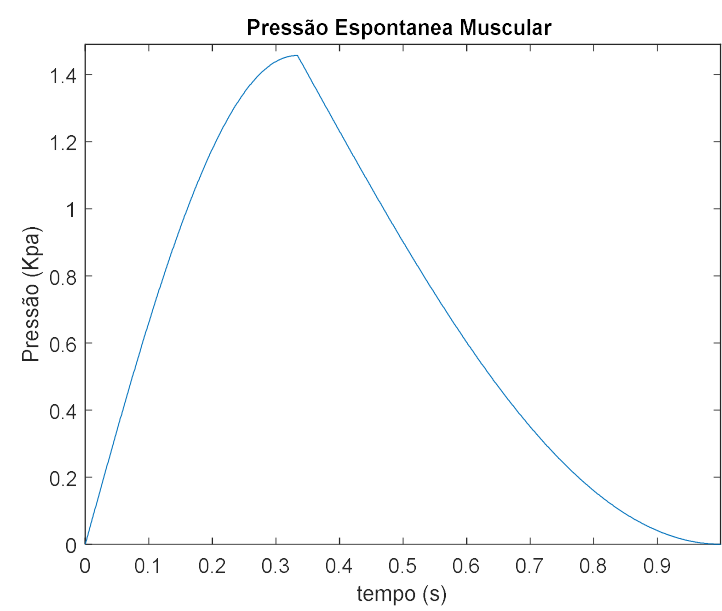

Figura 4.1 - Gráfico de pressão muscular espontânea.

Importante destacar que a falta de estudos sobre os esforços diafragmáticos em recém-nascidos fez com que a amplitude do sinal quarto de seno fosse determinada de acordo com os fluxos e volumes gerados por ele através do modelo do sistema respiratório, ou seja, a amplitude foi especificada através de experimentações, com o intuito de compatibilizar o volume e vazão com seus respectivos dados de referência na 
literatura. Com isso, nota-se que a amplitude da pressão muscular pode sofrer alterações conforme o cenário em que o paciente se encontra.

A apresentação dos resultados para esse modo está segmentada em três conjuntos: parâmetros do modelo respiratório, parâmetros da planta de simulação e atuação dos motores para 5 compartimentos. As variáveis do modelo explicitados são: o volume e fluxos pulmonares do modelo, pressão pulmonar e pressão muscular espontânea. Por outro lado, os parâmetros da planta de simulação apresentados são, O volume deslocado, o fluxo de saída da seringa, a velocidade angular do motor e a posição do pistão dentro da seringa considerando um único compartimento. Por último, são mostradas as posições e os fluxos das seringas, entretanto, considerando 5 compartimentos.

É importante salientar que nesse tipo de simulação os pulmões dos recémnascidos são representados pelos reservatórios de ar, logo, os ciclos de inspiração são o período de tempo necessário para que os reservatórios de ar inflem, ou seja, quando há um deslocamento positivo das seringas. Por outro lado, a expiração ocorre quando há a exalação do ar do reservatório, nesse caso há um retorno do pistão a sua posição inicial.

Baseado na Tabela 4, dois cenários de simulação são apresentados abaixo: o primeiro relativo a um neonato a termo saudável (AT) e outro de um pré-termo de extremo baixo peso (MBP Ext.).

\subsubsection{Recém-nascido a termo saudável (AT)}

Destacam-se abaixo os valores usados para a simulação referente à respiração espontânea de recém-nascidos a termo saudável. 
Tabela 6 - Parâmetros do modelo respiratório para o cenário de R.N saudável.

(Stankiewicz, Palko, Darowski, Zielisnki, \& Kozarski, 2017)

\section{PARÂMETROS DO MODELO RESPIRATÓRIO}

\begin{tabular}{|c|c|c|c|c|c|c|}
\hline Grupo & $\operatorname{Rc}(\mathrm{kPa} / \mathrm{L})$ & $\operatorname{Re}(\mathrm{kPa} / \mathrm{L})$ & $\mathrm{Rd}(\mathrm{kPa} / \mathrm{L})$ & $\mathrm{Ce}(\mathrm{mL} / \mathrm{kPa})$ & $\mathrm{Cd}(\mathrm{mL} / \mathbf{k P a})$ & $\mathrm{Cct}(\mathrm{mL} / \mathrm{kPa})$ \\
\hline AT & 6,8 & 3,4 & 3,4 & 20,5 & 20,5 & 124,0 \\
\hline
\end{tabular}

A Figura 4.2 ilustra os resultados referentes a um recém-nascido a termo saudável. Em uma análise superficial observa-se que o volume pulmonar máximo foi de aproximadamente $20 \mathrm{~mL}$, fluxo máximo próximo de $5 \mathrm{~L} / \mathrm{min}$ e pico de pressão pulmonar do modelo atingiu valores acima de $0.5 \mathrm{KPa}$. Importante salientar que para respiração espontânea está sendo considerado PEEP $=0$.

Variáveis do Modelo Respiratório
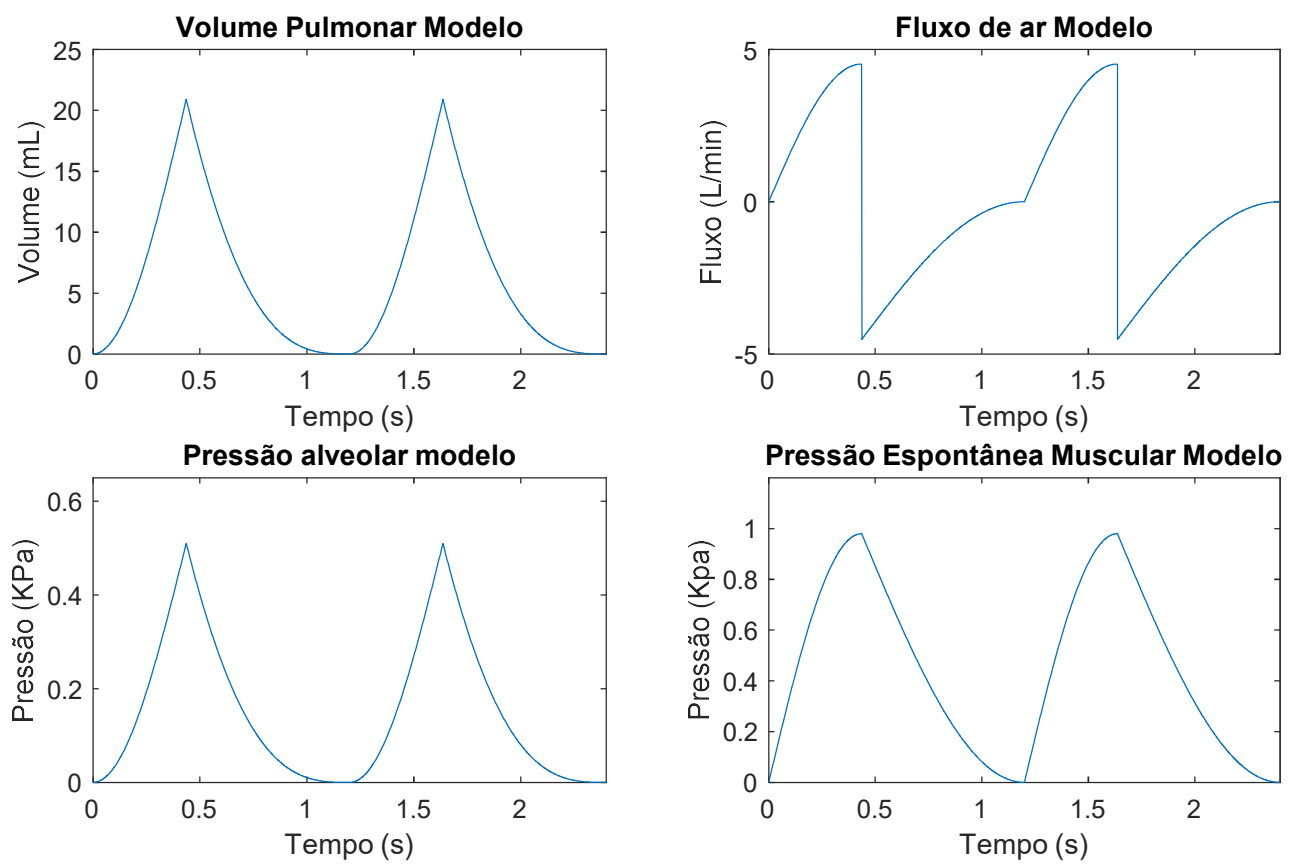

Figura 4.2 - Variáveis do modelo respiratório para recém-nascidos a termo saudável para o modo espontâneo de respiração. (Autor) 
Variáveis da Planta de Simulação
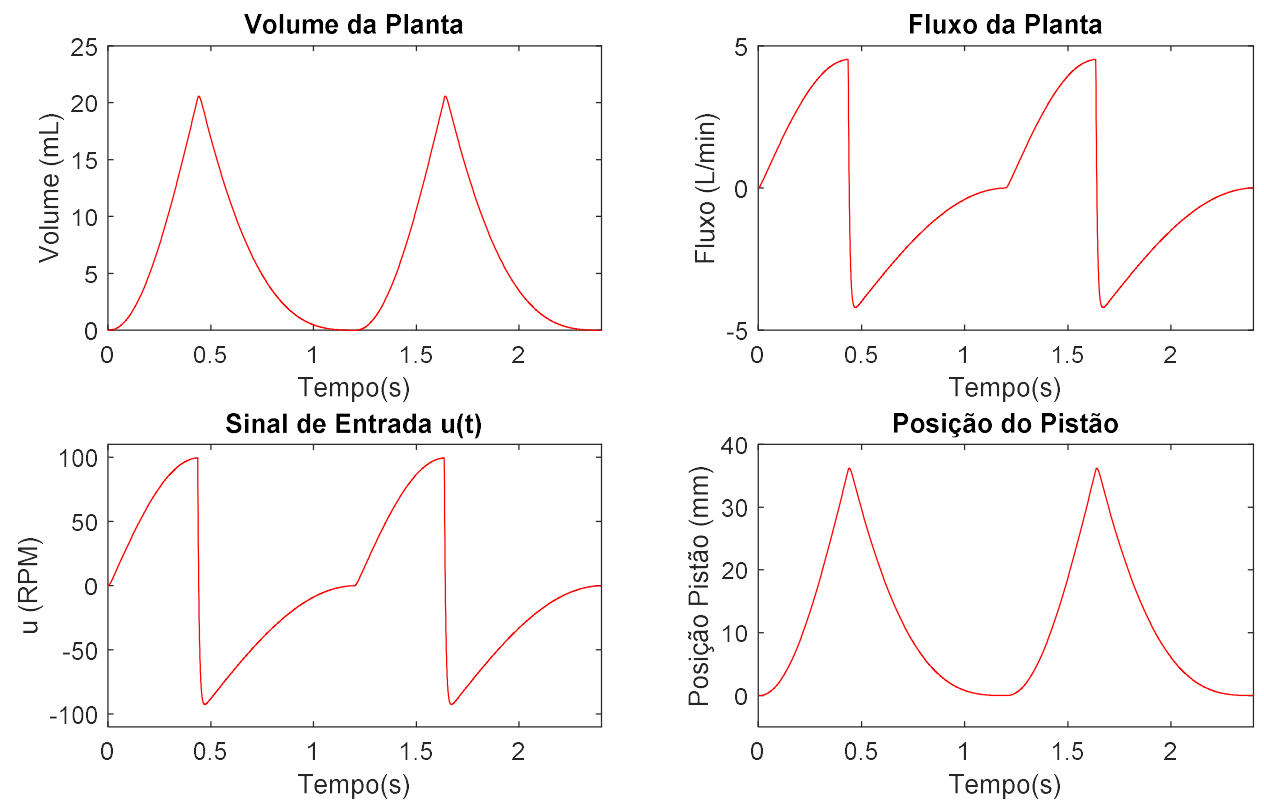

Figura 4.3 - Variáveis da planta de simulação referentes a um recém-nascido a termo saudável para o modo espontâneo de respiração. (Autor)

Observa-se na Figura 4.3 que o pistão se desloca aproximadamente $37 \mathrm{~mm}$ a cada ciclo respiratório e que a velocidade angular do motor não excede a 100 RPM. Ao utilizar 5 compartimentos, Figura 4.4, nota-se que os valores de fluxo, e consequentemente, o deslocamento do pistão são decompostos entre as 5 seringas de maneira proporcional a complacência pulmonar de cada compartimento. 

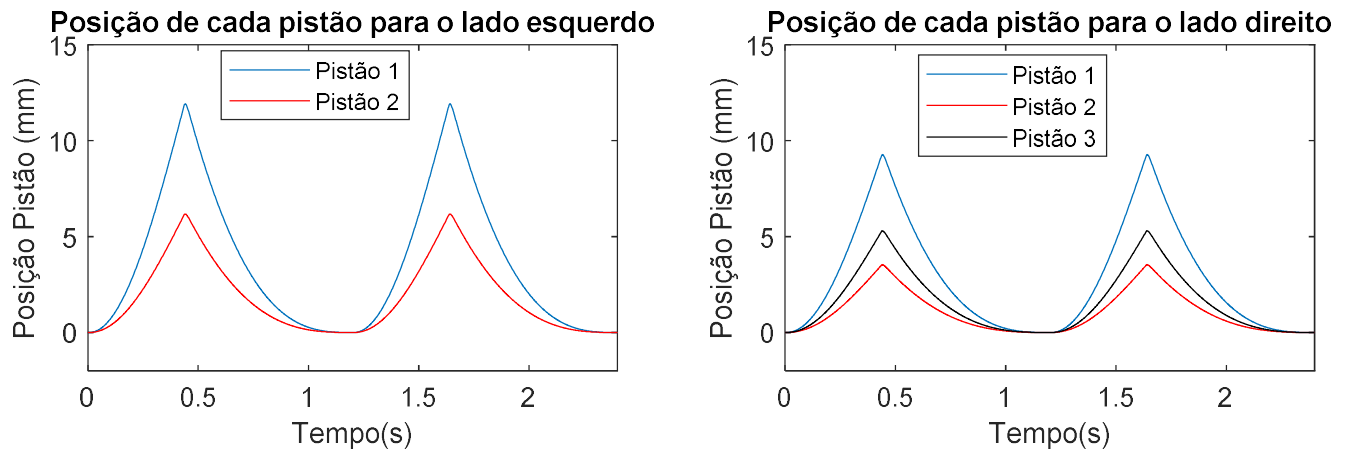

Fluxo de ar para cada pistão para o lado esquerdo

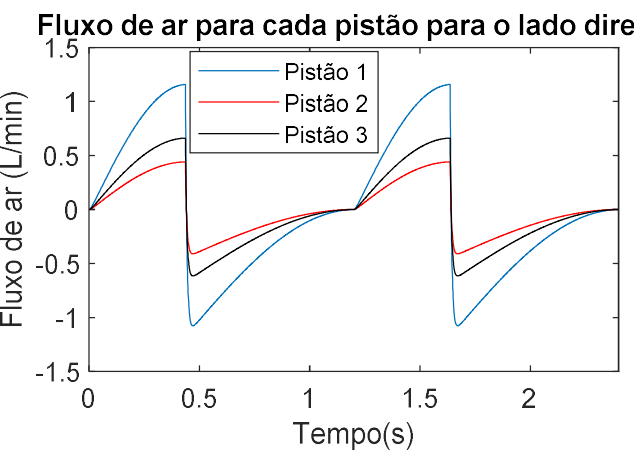

Figura 4.4 - Gráfico referente ao deslocamento e aos fluxos de ar gerados pelas 5 seringas da planta de simulação. (Autor)

Uma ilustração simples em Matlab foi feita a fim de elucidar o funcionamento do simulado em modo espontâneo, Figura 4.5. O fator didático é o mais importante a ser salientado aqui, pois, através da segmentação da planta em 5 seringas distintas é possível observar o efeito da complacência de cada compartimento de acordo com o volume deslocado de cada seringa e de acordo com o aumento do volume no reservatório de ar. É válido salientar que as linhas em azul claro marcadas dentro seringa indicam a posição inicial do pistão. 


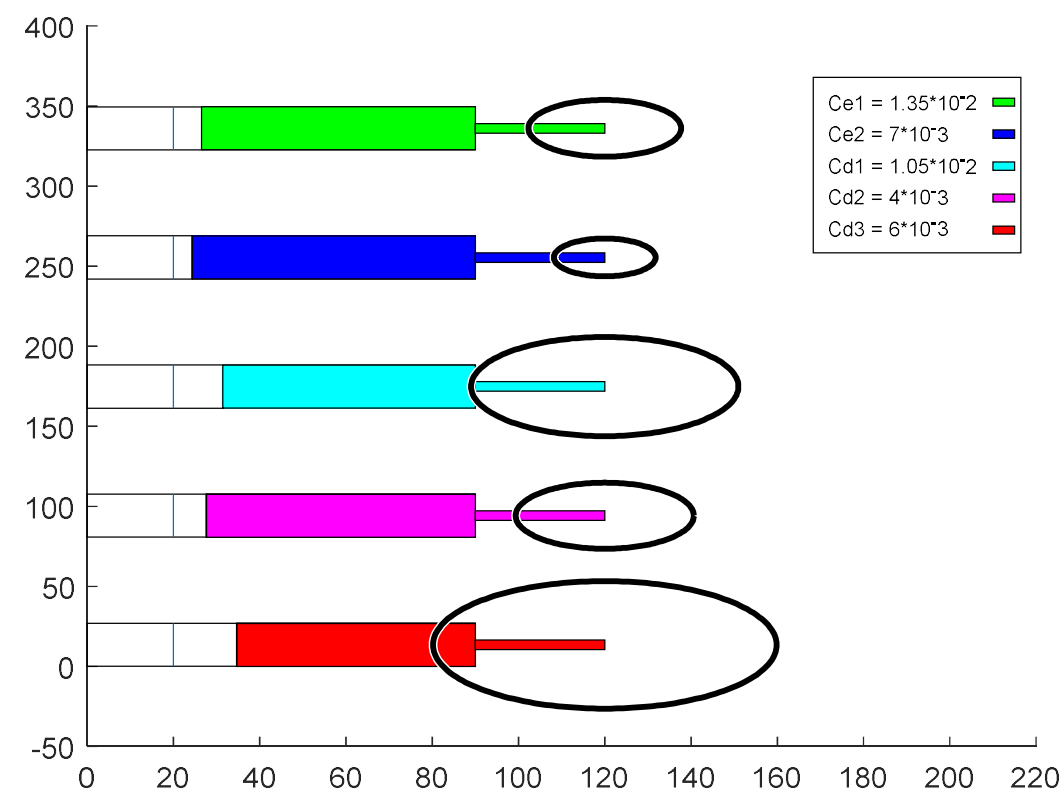

Figura 4.5 - Representação ilustrativa do funcionamento do simulador respiratório em modo espontâneo com 5 compartimentos. A figura apresenta uma fotografia do instante relativo ao final da inspiração e o volume de cada compartimento é ilustrado com o volume final do reservatório de ar em cada um dos compartimentos. Além disso, a linha azul em cada seringa representa a posição inicial do pistão. (Autor)

\subsubsection{Pré-termo de extremo baixo peso (MBP Ext.)}

De maneira análoga à seção anterior, destacam-se abaixo os valores usados para a simulação referente à respiração espontânea de um pré-termo de extremo baixo peso.

Tabela 7 - Parâmetros do modelo respiratório. (Stankiewicz, Palko, Darowski, Zielisnki, \& Kozarski, 2017)

\begin{tabular}{|c|c|c|c|c|c|c|}
\hline \multicolumn{7}{|c|}{ PARÂMETROS DO MODELO RESPIRATÓRIO } \\
\hline Grupo & $\operatorname{Rc}(\mathbf{k P a}$ s/L) & $\operatorname{Re}(\mathbf{k P a} \mathrm{s} / \mathrm{L})$ & $\mathrm{Rd}(\mathrm{kPa} / \mathrm{L})$ & $\mathrm{Ce}(\mathrm{mL} / \mathrm{kPa})$ & $\mathrm{Cd}(\mathrm{mL} / \mathrm{kPa})$ & $\mathrm{Cct}(\mathrm{mL} / \mathrm{kPa})$ \\
\hline AT & 21,5 & 10,8 & 10,8 & 5,2 & 5,2 & 51,6 \\
\hline
\end{tabular}

É possível notar uma redução significativa de volume e fluxo máximo em relação ao caso anterior, a termo saudável. Por outro lado, percebe-se que a pressão 
muscular diafragmática sofre um aumento. Os resultados são apresentados nas Figura 4.6-4.7

Variáveis do Modelo Respiratório
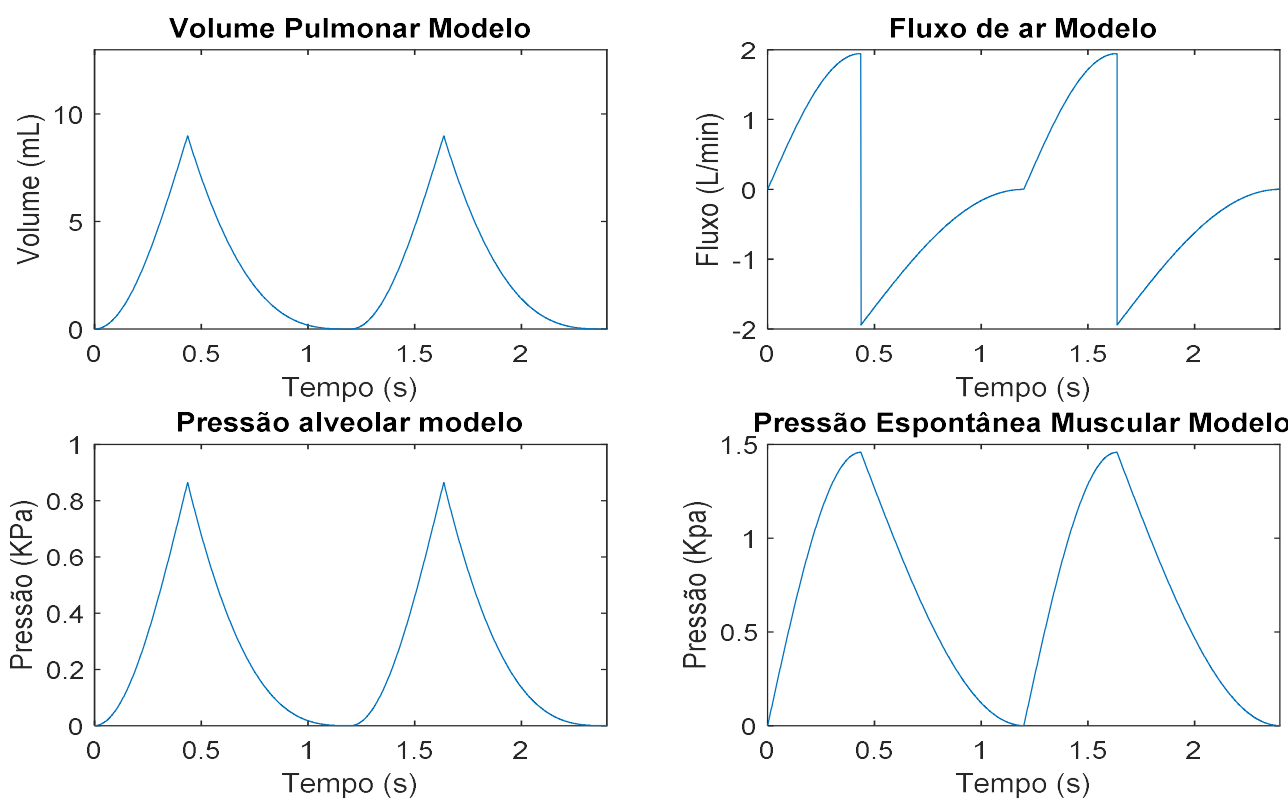

Figura 4.6 - Variáveis do modelo respiratório referente a um recém-nascidos com extremo baixo peso sem sintomas para o modo espontâneo de respiração. (Autor)

Variáveis da Planta de Simulação
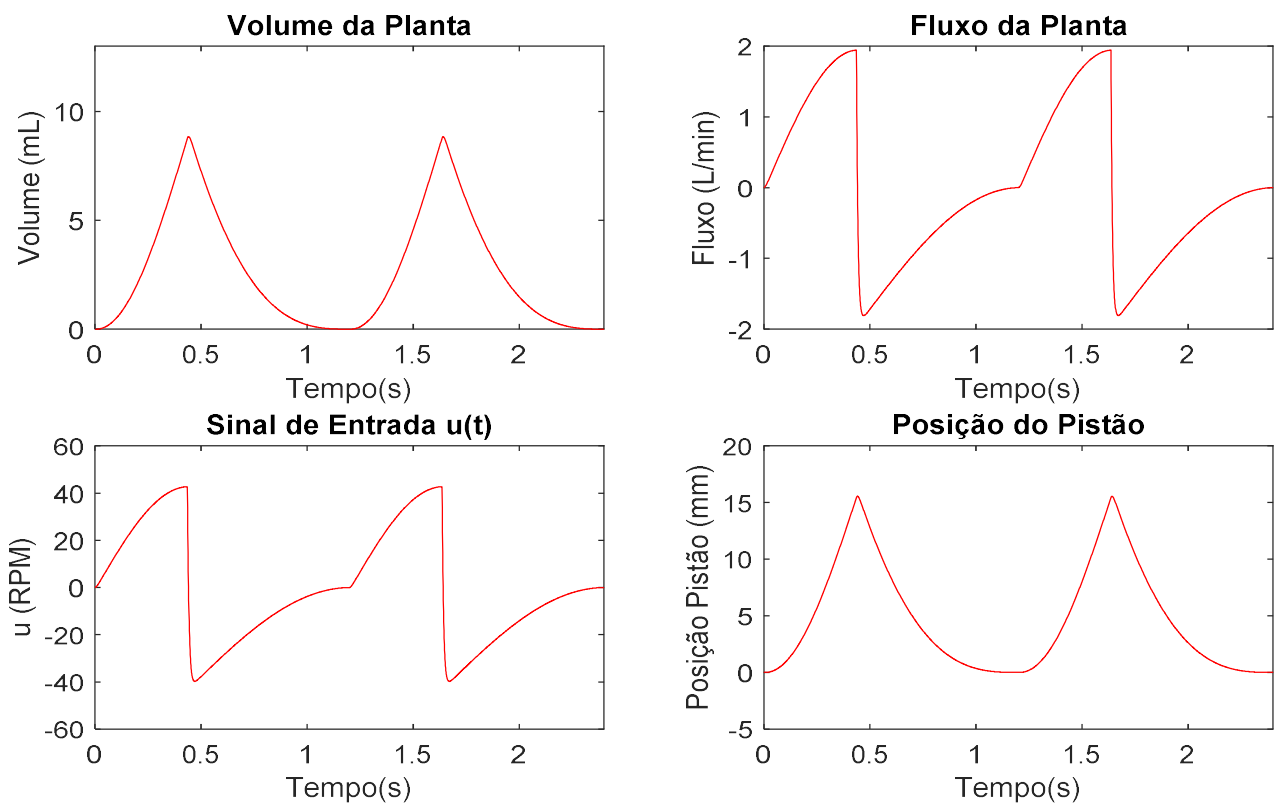

Figura 4.7 - Variáveis da planta de simulação referente a um recém-nascido de extremo baixo peso sem sintomas para o modo espontâneo de respiração. (Autor) 
Observa-se na Figura 4.7 que o pistão se desloca aproximadamente $15 \mathrm{~mm}$ a cada ciclo respiratório e que a velocidade angular do motor não excede a 50 RPM.
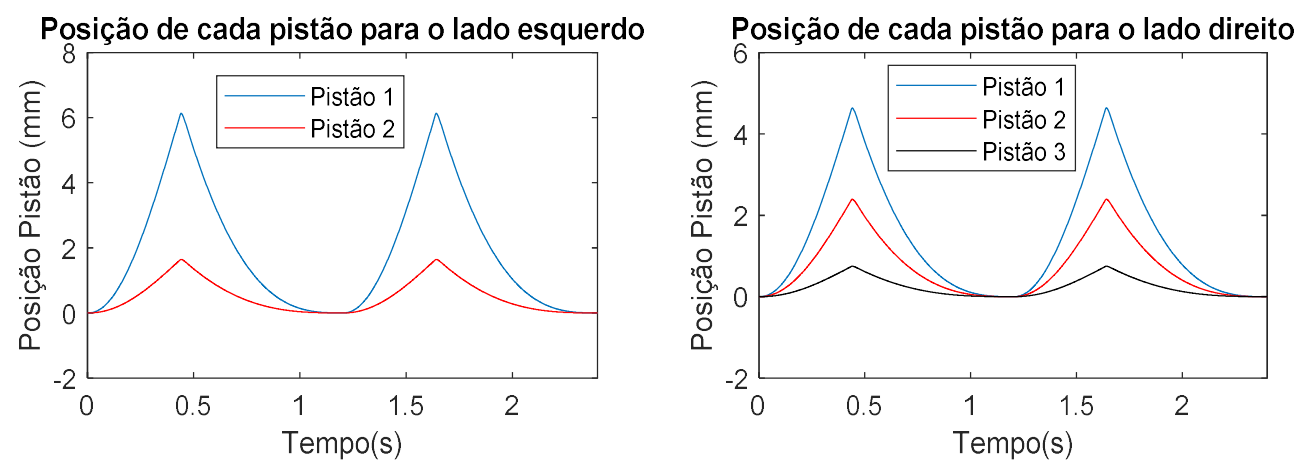

Fluxo de ar para cada pistão para o lado esquerdo Fluxo de ar para cada pistão para o lado direito
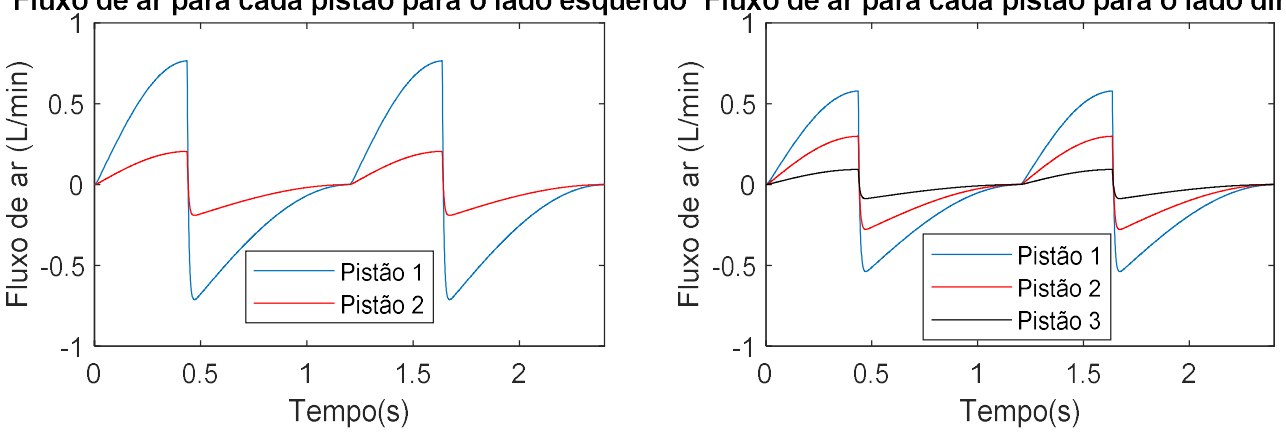

Figura 4.8 - Gráfico referente ao deslocamento e aos fluxos de ar gerados pelas 5 seringas da planta de simulação.

Novamente, uma ilustração simples em Matlab foi feita a fim de elucidar o funcionamento do simulador em modo espontâneo, Figura 4.9. Agora, é importante atentar à diminuição dos volumes dentro dos reservatórios de ar no caso de um neonato de extremo baixo peso quando comparado a um neonato saudável. 


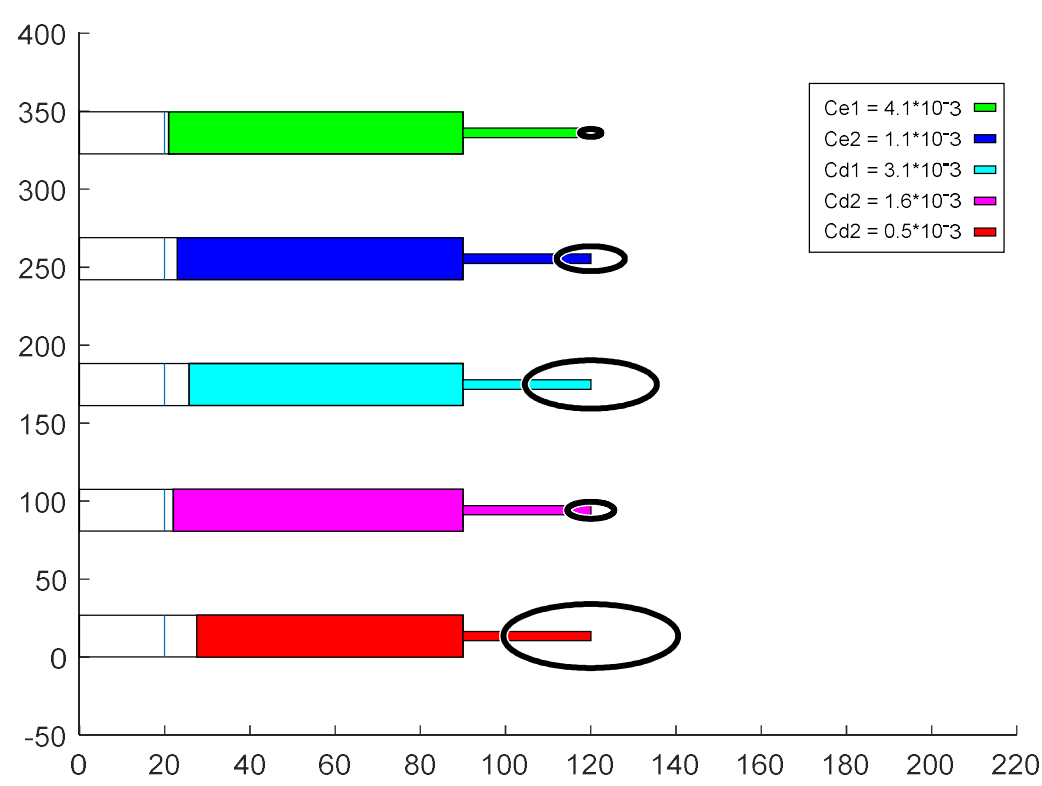

Figura 4.9 - Representação ilustrativa do funcionamento do simulador respiratório em modo espontâneo com 5 compartimentos. A figura apresenta uma fotografia do instante relativo ao final da inspiração e o volume de cada compartimento é ilustrado com o volume final do reservatório de ar em cada um dos compartimentos. Além disso, a linha azul em cada seringa representa a posição inicial do pistão. (Autor)

\subsection{Modo controlado - Pressão controlada}

Antagonicamente ao modo espontâneo, onde o recém-nascido inicia e controla a respiração, no modo controlado os ciclos são iniciados e mantidos sob controle exclusivamente do ventilador mecânico. Portanto, o sinal que dará início a respiração do paciente será a pressão emitida pelo respirador. Somente a função pressão controlada será apresentada. De maneira geral, quando nesse modo,ventiladores exercem pressão constante durante a fase inspiratória; em seguida, a pressão é retirada de forma que a exalação seja feita pelo próprio paciente devido ao relaxamento dos músculos diafragmáticos e intercostais. A Figura 4.10 ilustra um sinal de pressão emitido pelo ventilador. 
Diferentemente do modo espontâneo, agora, os pulmões dos neonatos são análogos ao volume dentro da seringa. Logo, a inspiração é realizada quando as seringas puxam o ar para dentro de si, ou seja, há um deslocamento negativo do pistão. Consequentemente, a expiração ocorre quando a seringa expulsa o ar para fora, portanto, ocorre um deslocamento positivo dos pistões.

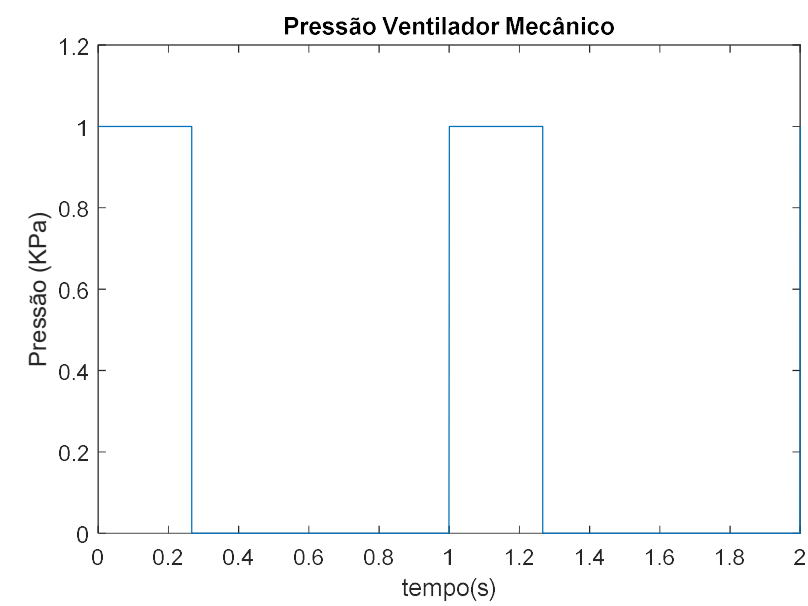

Figura 4.10 - Pressão exercida pelo ventilador mecânico no modo controlado em pressão constante. (Autor)

Primeiramente é necessário verificar se as hipóteses colocadas anteriormente, para o desenvolvimento das equações de movimento da planta de simulação, são válidas. Para isso, os resultados encontrados de respiração espontânea de um recémnascido saudável serão utilizados como base para os cálculos das propriedades do escoamento. Uma vez que um neonato saudável possui os maiores fluxos de ar no sistema respiratório, é coerente supor que também apresente os maiores números de Reynolds e números de Mach. Sendo assim, são informações relevantes para a avaliação do escoamento.

A Tabela 8 apresenta os parâmetros utilizados para realizar a análise do escoamento de ar através da seringa. 
Tabela 8 - Propriedades físicas, geométricas e de escoamento da planta de simulação. (Autor)

\begin{tabular}{|c|c|c|c|c|}
\hline \multicolumn{5}{|c|}{ PARÂMETROS PARA ANÁLISE DO ESCOAMENTO } \\
\hline Parâmetro & $\boldsymbol{\rho}\left(\mathrm{Kg} / \mathbf{m}^{\mathbf{3}}\right)$ & q_max (L/min) & $\mathrm{Dh}(\mathbf{m m})$ & $\boldsymbol{\mu}(\mathbf{P a} . \mathbf{s})$ \\
\hline & 1,225 & 6 & 5 & $1,802^{*} 10^{\wedge}-5$ \\
\hline
\end{tabular}

A fim de clarificar alguns parâmetros, q_max é a vazão de ar máxima encontrada em ambos os cenários no modo espontâneo, nesse caso, a vazão máxima foi encontrada no cenário de R.N a termo. O termo Dh é o diâmetro hidráulico, ou seja, o menor diâmetro por onde o ar irá escoar dentro da planta de simulação, no caso, na seringa. Note que os cálculos foram realizados no cenário mais critico possível, considerando uma única seringa, com a maior vazão e o menor diâmetro. Assim, garantimos que as condições calculadas serão mantidas em outros cenários.

A compressibilidade do escoamento pode ser teoricamente verificada através do número de Mach do escoamento. Um fluido pode ser considerado incompressível caso a razão entre a velocidade do fluido em escoamento e a velocidade do som seja menor do que 0.3, Equação (42). (Pritchard, 2011)

$$
\frac{M_{\text {fluido }}}{M_{a r}}<0.3
$$

A partir da Tabela 8 é possível verificar que:

$$
\frac{\dot{q}_{\max } / A_{h}}{343}=0.0148<0.3
$$

Portanto, pode-se considerar que o escoamento da seringa, dada essas condições específicas, é incompressível. 
Deve-se agora, realizar um estudo sobre o tipo de escoamento encontrado na saída da seringa, ou seja, se é turbulento ou laminar. O teste para verificar essa classificação envolve o número de Reynolds, Equação (33). De maneira sintética, o escoamento pode ser considerado laminar caso o número de Reynolds seja menor do que 2300 (Reynolds < 2300) e turbulento quando o número for maior que 4000 (Reynolds > 4000). Dito isso, e a partir da Tabela 8 é possível observar que:

\section{Reynolds $\approx 1731<2300$}

Logo, pode-se considerar que o escoamento é laminar.

Portanto, é possível notar que as hipóteses e as suposições consideradas durante o desenvolvimento do modelo são coerentes.

Importante citar que a técnica de controle utilizada no projeto foi alocação de pólos, no qual o único polo foi designado sobre o eixo real, $\xi=-50$. Tal valor foi escolhido através de experimentações, onde se buscou um ganho capaz de fazer com que a planta rapidamente seguisse a referência, entretanto, utilizando velocidades angulares razoáveis para um motor de passo.

Um parâmetro relevante para esse modo de ventilação é o PEEP, que, como já dito anteriormente, tem a função de determinar um nível de pressão final a cada ciclo respiratório, evitando-se assim, complicações adicionais ao sistema respiratório do paciente. Para essas simulações, o PEEP foi determinado como $0.3 \mathrm{KPa}$.

De forma análoga ao modo de ventilação espontâneo, os resultados serão segmentados em 2 grupos, recém-nascidos a termo saudável, Figuras 4.11-4.12, e recém-nascidos de extremo baixo peso, Figuras 4.13-4.14. Os parâmetros respiratórios utilizados para as simulações foram as mesmas da seção anterior, Tabela 6 e Tabela 7. 


\subsubsection{Recém-nascidos a termo saudável (AT)}

Variáveis Respiratórias
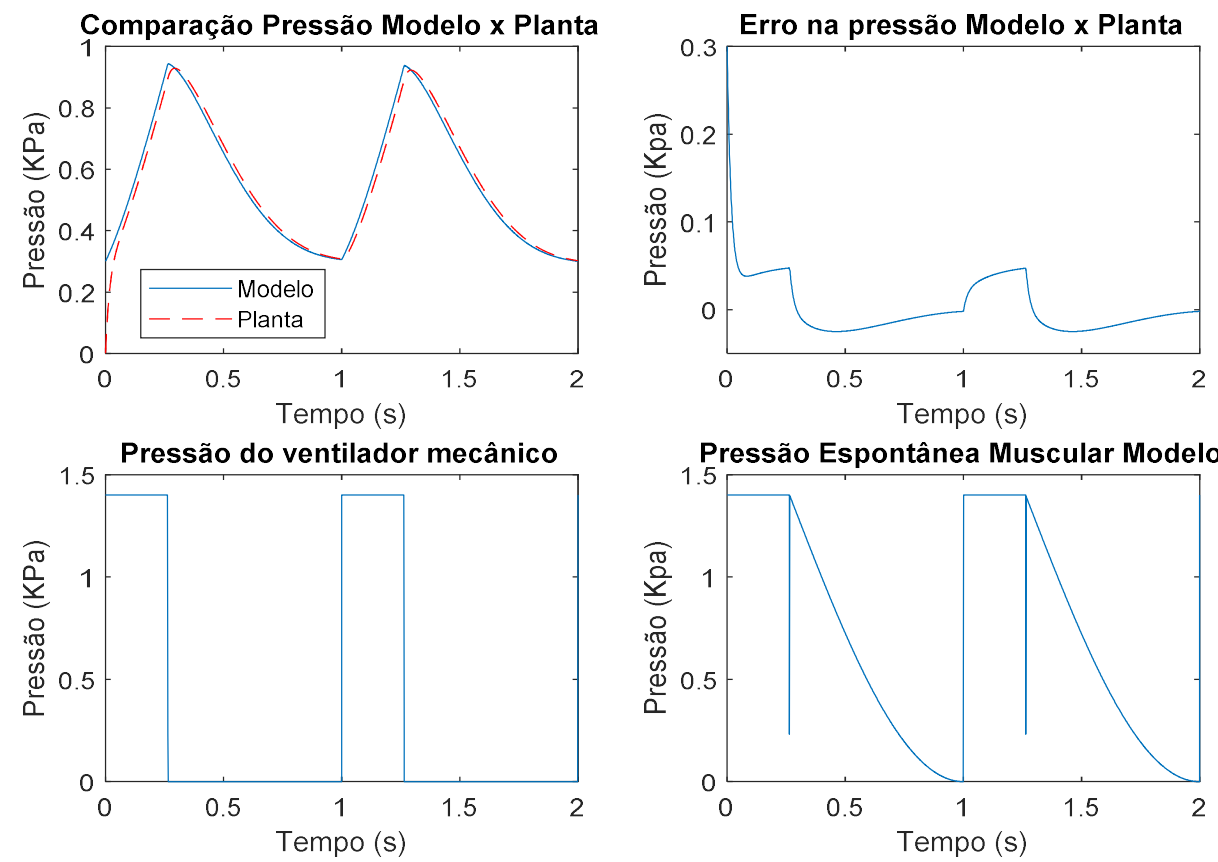

Figura 4.11 - Variáveis respiratórioas para recém-nascidos à termo saudável para o modo controlado de respiração. (Autor)

\section{Variáveis de Controle}
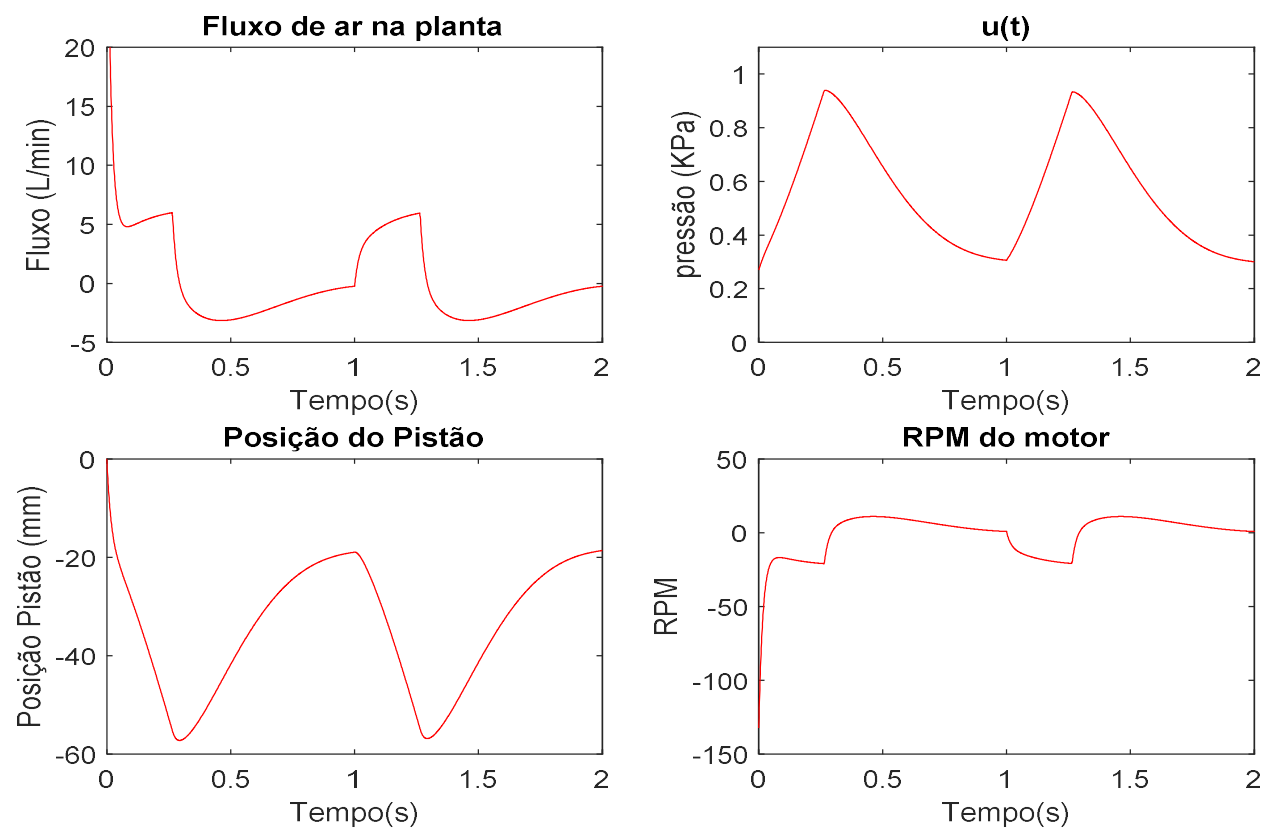

Figura 4.12 - Variáveis de controle para recém-nascidos à termo saudável para o modo controlado de respiração. (Autor) 


\subsubsection{Pré-termo de extremo baixo peso (MBP Ext.)}

Variáveis Respiratórias
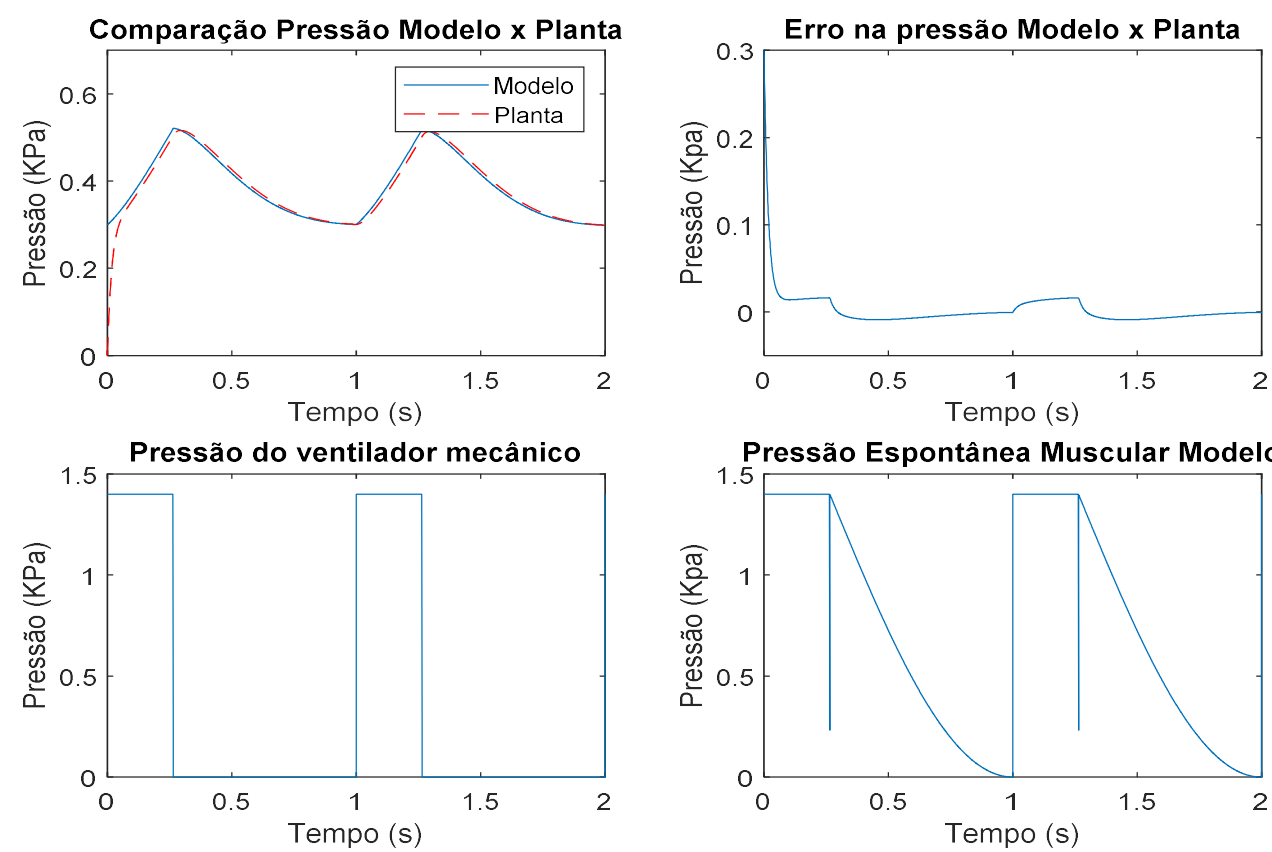

Figura 4.13 - Variáveis respiratórios referente a um recém-nascidos com extremo baixo peso sem sintomas para o modo controlado de respiração. (Autor)

Variáveis de Controle
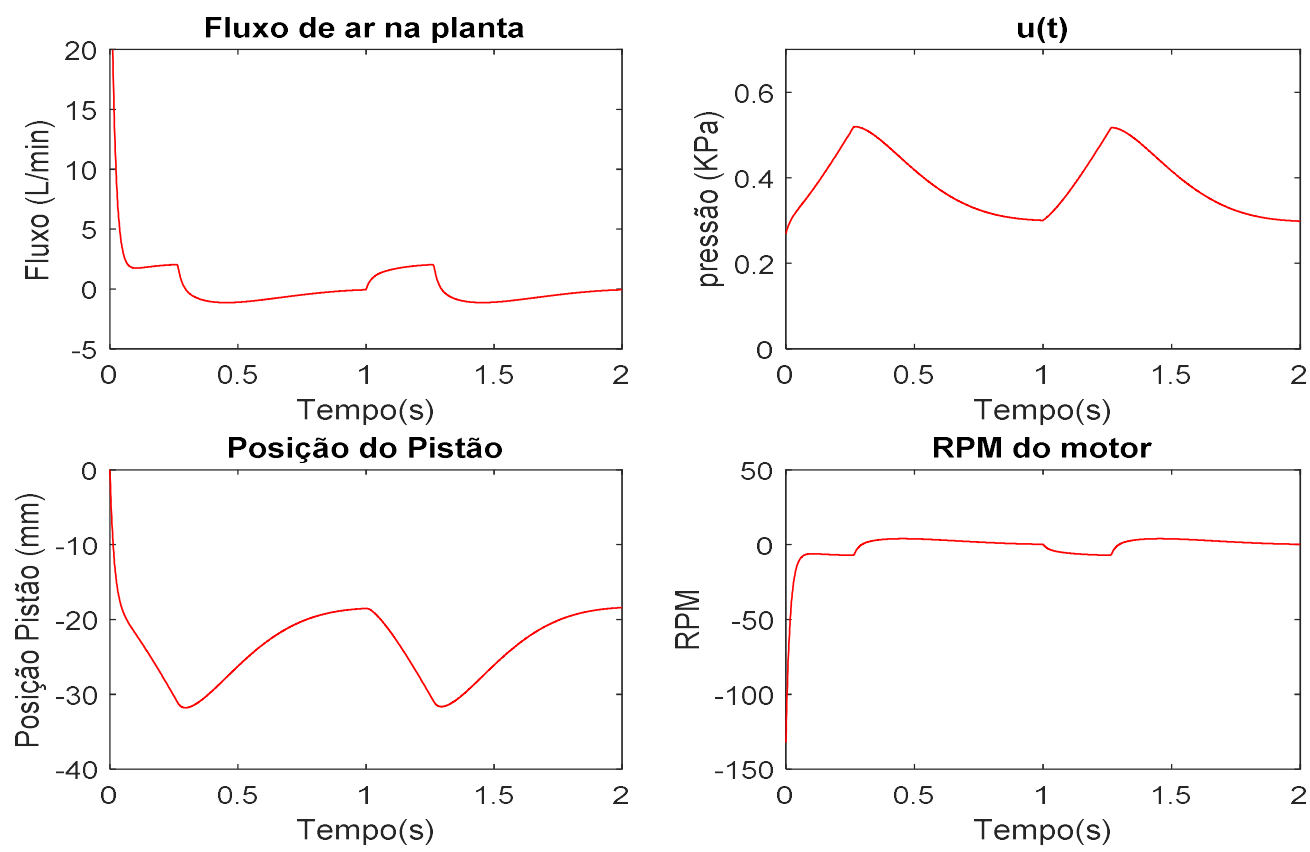

Figura 4.14 - Variáveis de controle referente a um recém-nascido com extremo baixo peso sem sintomas para o modo controlado de respiração. (Autor) 


\section{DISCUSSÃO DOS RESULTADOS}

Nas seguintes seções apresenta-se uma discussão geral dos principais resultados obtidos. O capítulo consiste em duas vertentes: análise do modelo respiratório neonatal, seguido pela análise sob a perspectiva da planta e de controle.

\subsection{Modelo Respiratório Neonatal}

Como proposto na seção 3.1, os conjuntos de Equações (28-29) foram desenvolvidos com o intuito de simular o sistema respiratório neonatal. Com isso, a literatura foi consultada a fim de se obter os valores de referência como capacidades pulmonares, frequência respiratória e parâmetros do modelo, como resistência e capacitâncias (Tabela 1 e Tabelas 3-4).

Durante as simulações emergiram questionamentos referentes a como reproduzir a pressão diafragmática realisticamente, de maneira a obter resultados fidedignos. A solução encontrada foi a de implementar a função quarto de seno, apresentada na Figura 4.1, introduzida por Kaye (1997). Porém, informações relativas à amplitude do sinal diafragmático neonatal ainda não foram amplamente estudadas pela comunidade acadêmica. Com poucos dados sobre o tema, decidiu-se realizar diversas experimentações via simulação como uma maneira de variar a amplitude do esforço e verificar se as variáveis de volume, fluxo e pressão pulmonares estavam de acordo com a literatura, e assim compatibilizando-as com as referências da literatura apresentadas durante o presente trabalho.

Devido aos diversos cenários e modos respiratórios que o simulador pode apresentar, somente duas condições críticas foram ressaltadas, recém-nascidos a termo saudável e recém-nascidos pré-termo com extremo baixo peso. Adicionalmente, vale salientar que a fim de analisar as perspectivas biológicas do modelo respiratório, somente o modo espontâneo e seus respectivos cenários são observados durante essa fase. 
Recém nascidos a pré-termo não possuem sistema respiratório com o mesmo nível de maturidade que recém-nascidos a termo, consequentemente possuem uma complacência menor. Além disso, as vias aéreas são menores, logo valores de resistências das vias centrais e periféricas do sistema respiratório aumentam. Dessa forma, menos ar circula dentro sistema respiratório desses pacientes quando comparados a RN a termo.

Ao avaliar o volume das simulações em ambas as situações, vide Figura 4.2 e Figura 4.6, nota-se uma redução de aproximadamente $60 \%$ entre os cenários, no qual o paciente AT possui VAC de $21 \mathrm{~mL}$ e o paciente PT apresenta VAC de $8,5 \mathrm{~mL}$. Uma redução igualmente expressiva pode ser notada nas variáveis de fluxo de ar, o RN AT apresentou picos de fluxo de 5,5 L/min, por outro lado, o RN pré-termo exibiu picos de fluxo próximos de 2,25 L/min. Nota-se que tal resultado se mostra alinhado com as expectativas teóricas de cada caso, e com as referências da literatura. Uma redução significativa do volume também pode ser observada no modo controlado, Figura 4.124.14, onde utilizando do mesmo sinal de pressão do ventilador, observa-se uma redução muito significativa do volume e fluxos pulmonares. Por exemplo, o fluxo pulmonar é reduzido de aproximadamente $5 \mathrm{~L} / \mathrm{min}$ para $1.9 \mathrm{~L} / \mathrm{min}$.

Entretanto, um aspecto inusitado foi observado em relação à pressão diafragmática durante as simulações. É possível notar que o esforço muscular que o paciente pré-termo de extremo baixo peso faz é maior que os de recém-nascidos a termo, com picos de pressão de aproximadamente 1,5 KPa (Figura 4.2), contrapondo os 1,2 KPa dos RN a termo (Figura 4.2) . Ou seja, mesmo após efetuar uma pressão muscular maior, o volume e fluxo pulmonares são menores, o que indica maiores níveis de resistência nas vias aéreas e uma diminuição da complacência dos pulmões, logo uma evidente dificuldade respiratória.

Por último observa-se a pressão pulmonar, no caso do RN EBP (Figura 4.6) a pressão atinge picos próximos de $0,9 \mathrm{KPa}$, em contraste com paciente AT (Figura 4.2) 
que apresentaram picos de pressão pulmonares por volta de $0,57 \mathrm{KPa}$. O fato corrobora com a literatura, pois a baixa complacência e a deficiência de surfactantes apresentada por RN pré-termo gera baixa deformação elástica dos tecidos dos pulmões, e, consequentemente, sem poder se deformar, a pressão pulmonar é elevada. Observa-se que um comportamento semelhante pode ser detectado a respiração no modo controlado, onde a amplitude da pressão pulmonar em relação ao PEEP é de aproximadamente 0,6 KPa para pacientes AT e 0,2 KPa para pacientes RN EBP.

\subsection{Planta e sistema de controle}

A análise a seguir estuda a capacidade da planta de simulação de acompanhar a variável de referência do modelo respiratório neonatal. Como já apresentado nas seções anteriores somente o modo controlado possui um sistema de controle, portanto, nesse capítulo somente o mesmo será avaliado.

Uma das melhores formas de avaliar o projeto de sistema de controle via variáveis de estado, é através da análise de erros das variáveis de controle, Equação (41), no caso, pressão de ar dentro da seringa. As Figura 4.11-4.13 exibem o erro da pressão pulmonar do modelo em relação à pressão de ar dentro da seringa. É possível notar que no cenário de $\mathrm{RN}$ a termo o erro máximo encontrado foi de $0.047 \mathrm{KPa}$, por outro lado, no cenário RN EBP o erro máximo determinado foi de $0.016 \mathrm{KPa}$.

Pode-se tratar os erros percentualmente, a fim de se obter uma percepção melhor do nível dos erros em relação ao sinal de referência. Com isso, os seguintes resultados foram obtidos: para RN AT o erro máximo percentual é de $4,8 \%$, no caso de RN EBP o erro máximo percentual é de 2,7\%. Portanto, nota-se que os erros estão abaixo do patamar de $5 \%$, o que em geral é um resultado satisfatório.

É importante citar aqui, os aspectos da planta de simulação. Observa-se que no cenário mais exigente, no aspecto de atuação dos motores, a velocidade angular inicial é de aproximadamente -130 RPM com a finalidade de se aproximar do sinal de 
referência enviado pelo modelo respiratório. Posteriormente, o motor entra em ciclo de operação padrão, durante esse período a velocidade angular opera entre -20 a 10 RPM. Onde, o sinal negativo indica uma mudança no sentido de rotação do motor. Observa-se que as rotações negativas indicam a inspiração e as rotações positivas indicam os ciclos expiratórios.

Além disso, o deslocamento do pistão é um fator importante para a construção de um produto físico. Percebe-se que no caso crítico, em termos de movimentação do pistão, RN AT, o pistão se desloca inicialmente realizar a PEEP, ou seja, a cada ciclo, a posição mínima do pistão é de $-20 \mathrm{~mm}$. Ao longo dos ciclos respiratórios, o pistão atinge uma amplitude máxima de movimento até aproximadamente $-60 \mathrm{~mm}$. Portanto, pode se concluir que para simular as condições predeterminadas é necessário um êmbolo de no mínimo $60 \mathrm{~mm}$ de comprimento, o que é usualmente encontrado em seringas de $50 \mathrm{~mL}$. 


\section{CONCLUSÕES}

O presente trabalho desenvolveu o projeto de um simulador respiratório neonatal capaz de emular os principais tipos de ventilação: espontâneo e controlado por pressão constante.

Em conjunto com o Laboratório Neonatal de UNIFESP foram determinadas as necessidades do mercado, assim como as características de projeto que atenderiam a demanda.

A extensa e multidisciplinar revisão bibliográfica traz o alicerce necessário para o desenvolvimento de modelos respiratórios de acordo com a aplicação requerida. Em adição, compila uma série de parâmetros respiratórios neonatais que auxiliaram na construção do simulador e como uma forma de referência para os resultados. A revisão bibliográfica também apresentou uma base de conhecimento para o desenvolvimento de uma construção física apta a emular o comportamento respiratório neonatal.

O modelo RC paralelo de 5 compartimentos, inclui uma resistência central referente às vias aéreas maiores e uma complacência associada à caixa torácica. $\mathrm{O}$ modelo mostrou-se o mais enxuto dentro de um nível de relevância no âmbito biológico, onde através de um esforço muscular diafragmático foi possível calcular fluxos, volumes e pressões pulmonares, além de poder simular características importantes de algumas doenças, como, por exemplo, a heterogeneidade respiratória devido às mudanças das propriedades do sistema (resistências e complacências) causadas pelas patologias.

Um equipamento inspirado em uma bomba de infusão foi considerado para simular os sinais de referência do modelo desenvolvido. Uma das vantagens da planta física escolhida é o fato de ser projetada baseada nos pequenos fluxos, volumes e pressões referentes à respiração neonatal. Consequentemente é mais precisa quando 
comparada aos simuladores no mercado. Além disso, sua simplicidade construtiva tende a torná-lo financeiramente acessível à comunidade acadêmica e médica.

De maneira geral, os resultados das simulações foram satisfatórios. $\mathrm{Na}$ perspectiva biológica, o modelo conseguiu emular de forma fidedigna os cenários e condições previstos. Na ventilação espontânea, a planta não possui sistema de controle, pois devido à lei de conservação de massa foi possível relacionar diretamente o fluxo de ar do modelo com a velocidade do pistão. Por outro lado, o modo controlado por pressão há um sistema de controle capaz de reproduzir a pressão pulmonar do modelo respiratório na pressão dentro da seringa.

Os erros referentes ao sistema de controle não ultrapassam os $5 \%$ e a velocidade angular máxima para o caso mais crítico é de aproximadamente -130 RPM. Além disso, o deslocamento do pistão não ultrapassa os $60 \mathrm{~mm}$ o que é algo factível para seringas usuais. 


\section{PROPOSTAS DE MELHORIA}

Abaixo estão listados alguns pontos de melhoria para trabalhos futuros:

- Inclusão do modo de ventilação controlado/assistido via fluxo controlado no simulador;

- Implementação de atuadores melhores para as simulações, como por exemplo, atuadores de bobinas móveis;

- Inclusão de cenários distintos de simulação como manobras para identificação da pressão pulmonar;

- Construção de um protótipo. 


\section{REFERÊNCIAS}

Aebersold, M. (2016). The History of Simulation and its impact on the future . AACN Advanced Critical Care , 56-61.

American Lung Association. (02 de September de 2019). Lung Health \& Diseases. Fonte: American Lung Association: https://www.lung.org/lung-health-anddiseases/lung-disease-lookup/bronchopulmonary-dysplasia/

Arrighi, L., Cifuentes, J., Fonseca, D., Méndez, L., Prieto, F., \& Ramírez, J. J. (s.d.). Development of a Neonatal Interactive Simulator by Using an RFID Modulefor Healthcare Professionals Training. Intech , pp. Available from: http://www.intechopen.com/books/deploying-rfid-challenges-solutions-andopenissues/development-of-a-neonatal-interactive-simulator-by-using-an-rfid-module-forhealthcareprofessionals.

Associação de Medicina Intensiva Brasileira. (2013). Diretrizes Brasileiras de ventilação mecânica.

Baldoli, I., Cuttano, A., Scaramuzzo, R. T., Tognarelli, S., Ciantelli, M., Cecchi, F., et al. (2015). A novel Simulator for mechanical ventilation in newborns: MEchatronic REspiratpry System SImulator for Neonatal Applications. journal of Engineering in Medicine , 581-591.

Carvalho, W. B. (1998). Ventilação pulmonar mecânica em pediatria. Jornal de pediatria .

Carvalho, W. B., Bonassa, J., Carvalho, C. R., Amaral, J. L., Beppu, O. S., \& Auler, J. O. (1997). Atualização em ventilação pulmonar mecânica. São Paulo: Atheneu.

Charles C. Ebbets and Ebbets Photo Graphics LLC 
Cuttano, A., Boldrini, A., Arianna, M., Laschi, C., Sigali, E., \& Cecchi, F. (2013). MEchatronic REspiratory System SImulator for neonatal Applications (MERESSINA) project: a novel bioengineering goal. Medical Devices: Evidence and Research , 115121.

Cuttano, A., Scaramuzzo, R., Gentile, M., Moscuzza, F., Ciantelli, M., Sigali, E., et al. (2012). High-fdelity simulation in Neonatology and the Italian Experiene. $J$ Pediatr Neonat Individual Med , pp. 67-72.

Diong, B., Nazeran, H., Nava, P., \& Goldman, M. (2007). Modeling Human Respiratory Impedance. IEEE Engineering in Medicine and Biology Magazine .

Donkers, K., Truscott, J., Garrubba, C., \& DeLong, D. (2016). High-Fidelity Simulation Use in Preparation of Physician Assistant Students for Neonatal and Obstetric Care. Journal of Physician Assistant Education , 68-72.

Edler, A. A., Chen, M., Honkanen, A., Hackel, A., \& Golianu, B. (2010). Affordable Simulation for Small-Scale Training and Assessment. Society for Simulation in Healthcare, pp. 112-115.

Fairchild, K., Mohr, M., Paget-Brown, A., Tabacaru, C., Lake, D., Delos, J., et al. (2016). Clinical associations of immature breathing in preterm infants: part 1 - central apnea. Pediatric Research .

Franklin, G. F., Powell, J. D., \& Emami-naeini, A. (2002). Feedback Control of Dynamic Systems. Prentice Hall.

Friedland, B. (2012). Control System Design: An Introduction to the Space-State Methods. Mineola: Dover Pulblications. 
Garingo, A., Friedlich, P., Tesoriero, L., Patil, S., Jackson, P., \& Seri, I. (2012). The use of mobile robotic telemedicine technology in the neonatal intensive care unit. Journal of Perinatology , pp. 55-63.

Ghafarian, P., Jamaati, H., \& Mohammadreza, S. H. (2016). A Review on Human Respiratory Modeling. Tanaffos , 61-69.

Gimeno, A., Lehtonen, L., Parra-Llorca, A., \& Vento, M. (2017). Early neonatal death: A challenge worldwide. Seminars in Fetal \& Neonatal Medicine , 153-160.

Gozzi, R. (25 de Junho de 2019). Aula 141 - Pleuras, Derrame Pleural e Pneumotórax. Fonte: Anatomia Fácil: http://anatomiafacil.com.br/

Hall, J. E. (2017). Guyton \& Hall Tratado de Fisiologia Médica. Elsevier.

Hodson, H. (14 de Abril de 2020). Hot-wire Anemometers. Fonte: Whittle Laboratory of the university of Cambridge: http://www-g.eng.cam.ac.uk/whittle/currentresearch/hph/hot-wire/hot-wire.html

IngMar Medical . (09 de September de 2019). ASL 5000 Breathing Simulator. Fonte: IngMar Medical Respiratory Simulation Specialists: https://www.ingmarmed.com/product/asl-5000-breathing-simulator/

Insoft, R. M., \& Todres, I. D. (2018). Growth and Development. In: C. J. Coté, J. Lerman, \& B. J. Anderson, A Practice for Anesthesia for Infants and Children. Elsevier.

IST - Innovative Sensor Technology. (14 de Abril de 2020). Thermal Mass Flow Sensor. Fonte: IST - Innovative Sensor Technology: http://www.ist-agjapan.com/brand3/pdf/FS5.pdf 
Kaye, J. M. (1997). Traumap: The design of a 3D virtual environment for modeling cardiopulmonary interactions. A Dissertation in Computer and Information Science - University of Pennsylvania .

Kliegman, R. M., ST Geme III, J. W., Blum, N. J., Shah, S. S., Tasker, R. C., Wilson, K. M., et al. (2019). Nelson Textbook of Pediatrics. Elsevier.

Komatsu, D. (2007). Estudo controlado randomizado entre o uso da pressão positiva intermitente e pressão positiva contínua em vias aéreas em recém-nascidos pré-termo após a etubação traquel. São Paulo.

Kulakowski, T. B., Gardner, F. J., \& Shearer, L. (2007). Dynamic Modeling and Control od Engineering System .

Lansky, S., Friche, A. A., Silva, A. A., Campos, D., Bitterncourt, S. D., Carvalho, M. L., et al. (2014). Birth in Brazil survey: neonatal mortality profile, and maternal child care. Caderno de Saude Pública, S192-S207.

Lehtonen, L., Gimeno, A., Parra-Llorca, A., \& Vento, M. (2017). Early neonatal death: A challenge worldwide. Seminars in Fetal \& Neonatal Medicine , pp. 153-160.

Lonardoni, J. A., Iwata, L. P., \& Fleury, A. d. (2003). Simple Mathematical Models for the Simulation of the Human Respiratory. International Congress of Mechanical Engineering - COBEM. São Paulo.

Marieb, E., Wilheim, P., \& Mallat, J. (2014). Anatomia Humana.

Merrit, E. H. (1991). Hydraulic Control Systems. John Wiley \& Sons. 
Michigan Instruments. (03 de September de 2019). Infant Lung Simulators Adult/Infant Model. $\quad$ Fonte: Michigan Instruments: https://www.michiganinstruments.com/lung-simulators/infant-test-lung-simulators/

Muntean, I., Ionescu, C., \& Nascu, I. (2009). Models for the respiratory system using morphology-based analogy. Fiste internatinal conference on Complexity and Intelligence of the Artificial and Natural Complex System. Medical Aplications of the complex systems. Biomedical Computing. IEEE Computer Science.

Murphy, A. A., \& Halamek, L. P. (2005). Educational Perspectives: Simulationbased Training in Neonatal Resuscitation. journal of the American Academy of Pediatrics, p. e489.

Ochs, M., \& O'brodovich, H. (2019). The Structural and Physiologic Basis os Respiratory Disease. In: R. Wilmott, A. Bush, R. Deterding, \& F. Ratjen, Kendig's Disorders of the Respiratory Tract in Children (pp. 63-100.e2). Elsevier.

Otis, A. B., McKerrow, C. B., Bartlett, R. A., Mead, J., Mcilroy, M., Selverstone, N. J., et al. (1956). Mechanical factor in distribution of pulmonary ventilation. Journal of Applied Physiology , 427-443.

Pagatini, G. (2017). Sistema Especilista Protóriopo para Diagnóstico de Falhas em Equipamentos de Infusão. Dissertação do Programa de Pós-graduação em Engenharia Mecânica da UFSC . Florianópolis, SC, Brasil: UFSC.

Price, M. (2007). MIT OpenCourseWase. Acesso em 28 de Agosto de 2020, disponível em Understanding Impedances: http://ocw.mit.edu

Pritchard, P. J. (2011). Fox and McDonald's Introduction to Fluid Mechanics. John Wiley \& Sons, inc. 
Sarmento, G. J. (2007). Princípios e práticas de ventilação mecânica em pediatria e neonatologia.

Schmidt, M., Foitzik, B., Hochmuth, O., \& Schmalisch. (2003). Computer simulation of the measured respiratory impedance in newborn infants and the effect of the measurement equipament. Medical Engineering \& Physics , 220-228.

Stanford Children's Health. (02 de 09 de 2019). Respiratory Disorders in the Newborn. Fonte: Stanford Children's Heath: https://www.stanfordchildrens.org/en/topic/default?id=pneumothorax-in-children-90P02397\&sid $=$

Stankiewicz, B., Palko, K. J., Darowski, M., Zielisnki, K., \& Kozarski, M. (2017). A new infant hybrid respiratory simulator: preliminary evaluation based on clinical data. International Federation for Medical and Biological Engineering 2017.

Tortora, G. J., \& Derrickson, B. (2017). Corpo Humano: Fundamentos de Anatomia e Fisiologia. Artmed.

TSI Incorporated. (14 de Abril de 2020). OEM Mass Flow Sensor 840205. Fonte: TSI understanding accelerated: https://www.tsi.com/products/flow-meters,-flowsensors,-and-flow-analyzers/flow-sensors/oem-mass-flow-sensor-840205/

Unicef. (2014). Committing to Child Survival: A Promise Renewed.

UNICEF. (2019). Levels and Trends in Child Mortality.

UNICEF. (Março de 2018). Neonatal Mortality Data. Fonte: UNICEF: https://data.unicef.org/data/number-neonatal-deaths/ 
United Nations, Department of Economic and Social Affairs, Population Division. (2017). World Population Prospects: The 2017 Revision.

Weiner, G. M. (2016). Textbook of Neonatal Resuscitation. Elk Grove Village: American Academy of Pediatrics. 


\section{Apêndice A - Patologias Relacionadas ao Sistema Respiratório Neonatal}

\section{A Síndrome do desconforto respiratório}

A síndrome do desconforto respiratório do Recém-nascido (SDR), também conhecido como doença da membrana Hiliana, é uma condição corriqueira em bebês pré-maturo. A SDR faz com que o RN necessite de oxigênio adicional e auxílio na respiração. Em geral, a causa do SDR deve-se ao fato de não haver surfactante suficiente nos pulmões. Surfactante são substâncias a base de proteína e gorduras que ajudam o pulmão a inflar e prevenindo os alvéolos de colapsar. Ao se danificaram, células mortas se acumulam nas vias aéreas afetando assim a respiração, o RN tem que fazer mais força muscular para respirar.

Os principais sintomas são: coloração azulada da pele, narinas dilatadas, respiração rápida e superficial, apresentação de ruídos e grunhidos ao respirar. Por outro lado, o Diagnóstico pode ser feito de algumas formas: identificação visual de mudança de cor de pele do R.N, raio-x no tórax, realização de testes de sangue para verificar níveis de oxigenação e saturação no sangue. (Stanford Children's Health, 2019)

\section{Displasia Broncopulmonar}

É uma forma de doença crônica dos pulmões, que em geral afeta prematuros e infantos. A condição resulta dos danos causados pela utilização de ventiladores mecânicos e oxigênio, gerando uma infecção no paciente. Ou seja, é uma doença que pode ser contraída ao se tratar de outra condição anterior.

Os principais sintomas são: Dificuldade de respiração, Respiração rápida e superficial, dependência de oxigênio, chiado no peito e tosse. (American Lung Association, 2019) 


\section{Apêndice B - Modelo de simulação Simulink}

O simulador foi desenvolvido em diagrama de bloco a partir do software Matlab/Simulink. Na Figura 8.1 apresenta-se o modelo principal de simulação onde destacam-se 3 blocos principais:

- Modelo de referência do sistema respiratório: calcula-se e fornece como sinais de referência as variáveis de volume, fluxo e pressões pulmonares;

- Controlador: nesse bloco são calculados os ganhos associados a estratégia de controle utilizada, além de determinar a variável de entrada $u(t)$ para a planta de simulação;

- Planta: através do sinal de entrada u(t) determina as o fluxo de saída da seringa de acordo com a equação de conservação de massa, como na Equação (30)

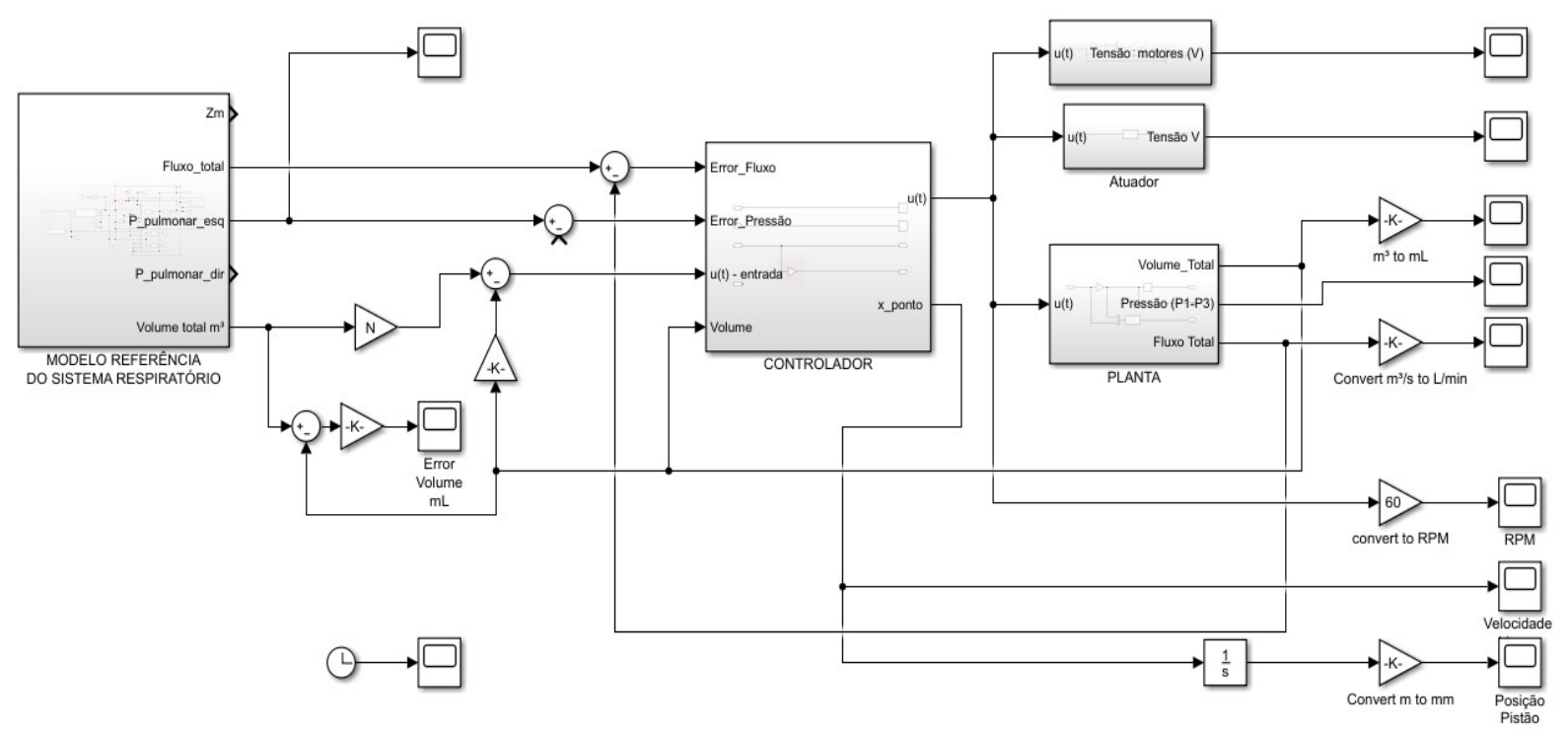

Figura 8.1 - Modelo de simulação em diagrama de blocos. (Autor) 